University of San Diego

Digital USD

1995

\title{
The Identification of Behavioral Indicators of a Superintendent's Leadership Success: A Delphi Study
}

Douglas George Player EdD

University of San Diego

Follow this and additional works at: https://digital.sandiego.edu/dissertations

Part of the Leadership Studies Commons

\section{Digital USD Citation}

Player, Douglas George EdD, "The Identification of Behavioral Indicators of a Superintendent's Leadership Success: A Delphi Study" (1995). Dissertations. 619.

https://digital.sandiego.edu/dissertations/619

This Dissertation: Open Access is brought to you for free and open access by the Theses and Dissertations at Digital USD. It has been accepted for inclusion in Dissertations by an authorized administrator of Digital USD. For more information, please contact digital@sandiego.edu. 


\title{
THE IDENTIFICATION OF
}

\section{BEHAVIORAL INDICATORS OF A SUPERINTENDENT'S \\ LEADERSHIP SUCCESS: A DELPHI STUDY}

\author{
by \\ Douglas George Player
}

A dissertation submitted in partial fulfillment

of the requirements for the degree of

Doctor of Education

University of San Diego

1995

\author{
Dissertation Committee \\ Raymond F. Latta, Ph.D., Director \\ Edward F. DeRoche, Ph.D. \\ Sam Lim, Ed.D.
}




\section{Abstract of the Dissertation}

\section{The Identification of Behavioral Indicators of a Superintendent's Leadership Success -- A Delphi Study}

Player, Douglas G. University of San Diego, 1995, 239 pp.

Director: Raymond F. Latta, Ph.D.

In British Columbia, as well as other Canadian provinces, an annual report is produced by every school district. The report informs the citizens using a variety of indicators that demonstrate the level of success of the district. These reports do not include specific indicators on the level of success of the superintendent or other administrators in the district. This study sought to identify and describe behaviors that could serve as indicators of a superintendent's leadership success. It also sought to ensure that the indicators were aligned with the leadership behaviors applicable to a Total Quality Management model.

The research methodology used a Delphi process that required three iterations. Questionnaires were sent to three groups of panelists: (a) chief executive officers in business and industry in British Columbia; (b) superintendents of schools throughout Canada; and (c) writers in North America. Thirty-one behaviors were identified,described and prioritized. The top seven behaviors were, in order of priority: (1) develops, shares and focuses on a vision for the organization that leads to the future; (2) focuses on the primary activity of the organization, that of learning; (3) maintains ethical standards and integrity; (4) builds, maintains and fosters relationships 
within and without the organization; (5) ensures that leadership is participatory in nature and/or encourages decisive decision making at the action level; (6) communicates continuously and effectively; and (7) creates and nurtures a learning community culture. The findings were compared and triangulated with Deming's 14 points of quality and with prior research on leadership behavior. A statistical analysis using the Kendall W was applied and produced a coefficient of concordance that showed no significance at the .05 level. Therefore, the null hypothesis that the two populations had no common rankings was rejected.

A comparison of the top seven behaviors revealed an alignment with the principles of quality. Specific discrepancies in rankings by the two panelist groups were examined. A draft model of a behaviorally anchored rating scale model was produced. Suggestions for both further study and upon which superintendent growth and development programs could be developed or imported from industry were made. 
(C) Copyright held by Douglas George Player 


\section{Dedication}

This study is dedicated to my parents, Elliot and Anne Player, who fostered within me a love of learning and a desire to continuously grow. They deserved to see this accomplishment.

"The one who comes to question himself has cared for mankind."

-- Kenneth Patchen 


\section{Acknowledgments}

This study could not have been completed without the support and assistance of many people. I would like to gratefully acknowledge the following:

Dr. Raymond Latta of San Diego State University, my doctoral committee chair and friend, for conceiving this program and for his generous support and gentle nudges that enabled me to undertake and complete this challenge.

Dr. Ed DeRoche, Dean of Education at University of San Diego and one of my committee members, for his exceptional support of this experimental program and his "servant" leadership style in his support of the cohort group.

Dr. Sam Lim, Assistant Deputy Minister, B.C. Ministry of Education and one of my committee members, for taking the time from an unrelenting schedule to honor me with his supportive presence on my committee.

My colleague Deborah, who helped me understand the spiritual nature of leadership and as a result has launched me on a never ending search, for her special and unfailing support and friendship.

The past Board of School Trustees of School District \#45 (West Vancouver) for their understanding of my need to pursue this program and support through difficult times that followed. 
The present Board of School Trustees of School District \#45 (West Vancouver) for their acceptance of the continuing process of completing this study.

The panelists in this study, both CEOs and superintendents, for their participation and insights.

My office staff in the school district, in particular my executive assistant Beth Denman, who were always at the other end of E-mail or the fax to assist both my district duties and my university challenges.

Bobbi-Lee Taylor who, as my scribe, prepared the following pages to ensure their veracity, for her assistance in data co!lection and her support throughout the process.

The staff of both USD and SDSU, in particular Debbie Wright and Mary Scherr, for being there and supporting the implementation of such an innovative program.

Donna Palmer for always asking the right questions about my progress in the program and for caring enough to ask.

My family, especially my wife Doreen, who have not seen much of me for four years, for allowing me to pursue this very personal journey that enabled me to have the honor of graduating in the same year as my son Warren and my daughter Katy. 


\section{Table of Contents}

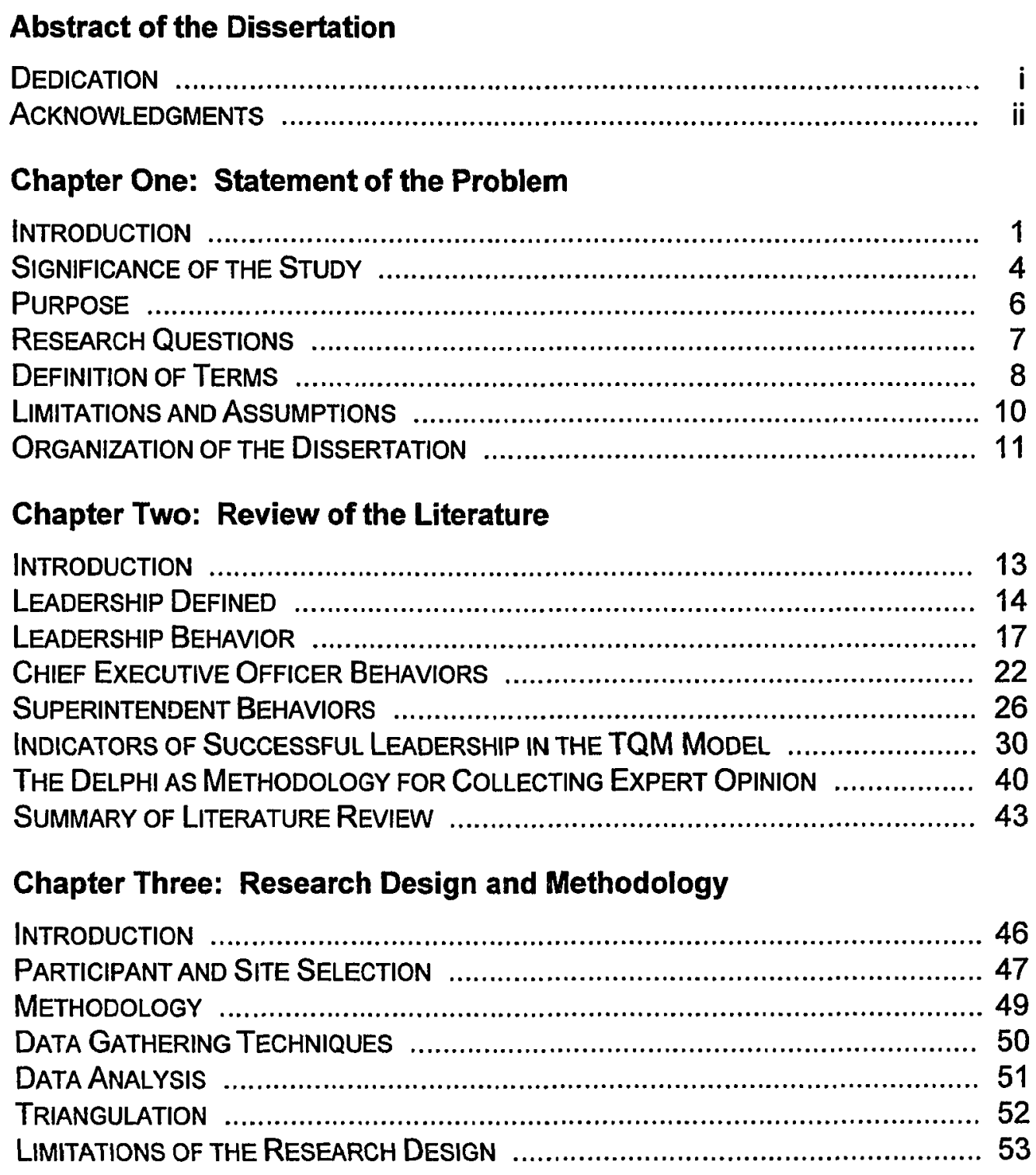

Chapter Four: Findings of the Study

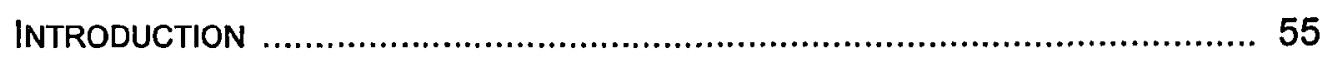

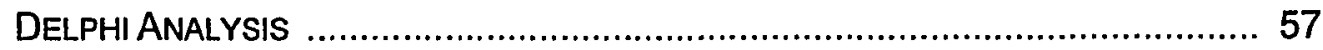

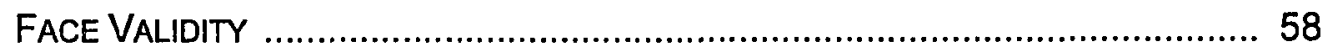

DEMOGRAPHIC ANALYSIS ................................................................. 58

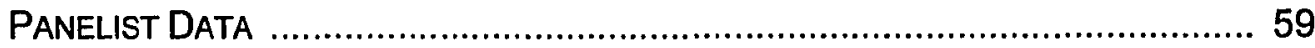

iv 


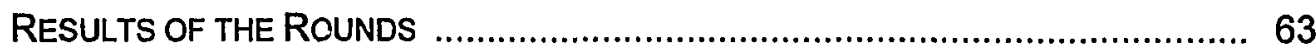

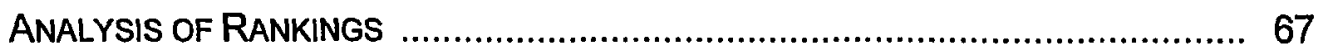

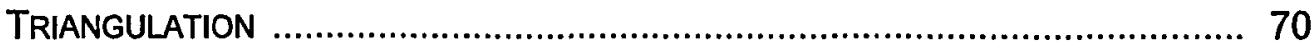

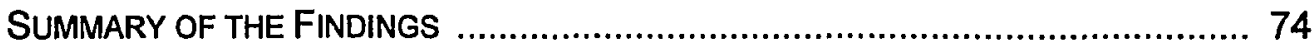

Chapter Five: Summary, Conclusions, and Recommendations

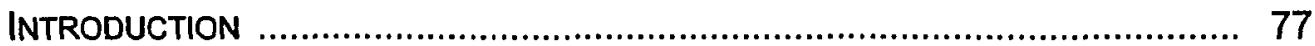

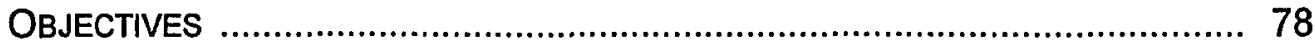

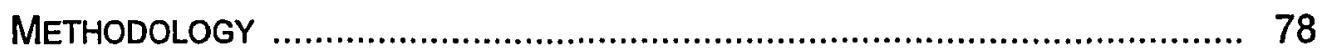

DISCUSSION OF FINDINGS ............................................................ 80

DISCUSSION OF DISCREPANCIES IN RANKINGS F......................................... 86

COROLLARY RESEARCH QUESTIONS .................................................. 90

STRENGTHS OF THE STUDY ……......................................................... 91

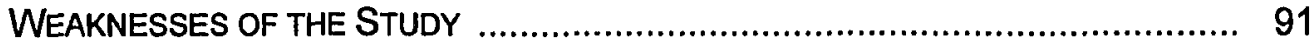

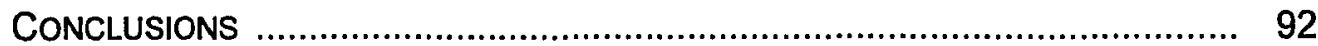

RECOMMENDATIONS FOR FURTHER STUDY ............................................. 95

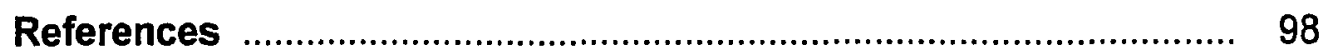

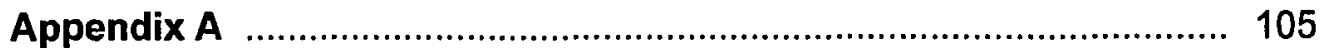

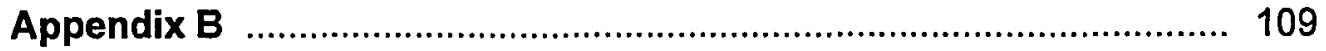

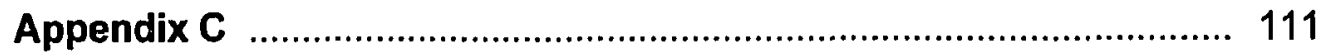

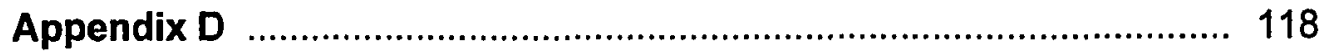

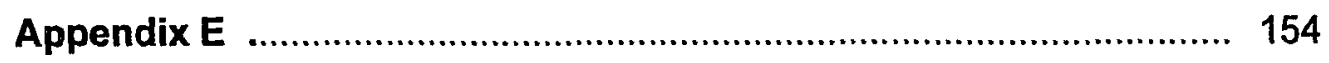

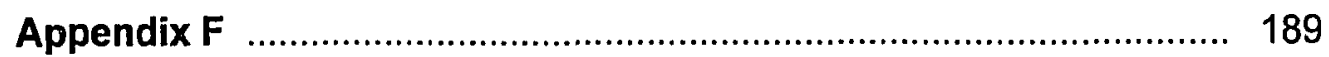

Appendix G .

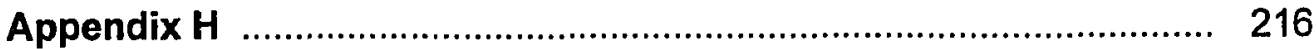

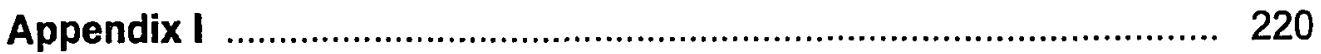

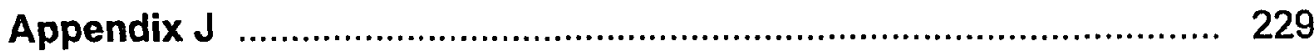

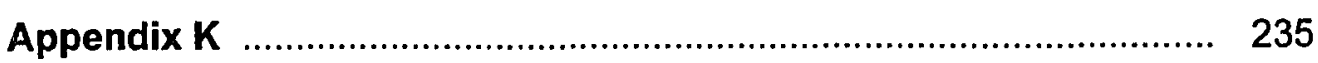


Figures and Tables

Figure 1. Comparative age and gender of study participants ................ 59

Figure 2. Comparative years of service of study participants ................ 60

Figure 3. Comparative size of organizations of survey participants ....... 61

Figure 4. Geographic [Canada] location of superintendents participating in study ....................................................... 62

Figure 5. TQM program activity of study participants ........................... 63

Figure 6. Top seven choices of behavioral indicators of

a superintendent's leadership success as chosen by superintendents and CEOs

Figure 7. Triangulation of participant's top seven behavioral indicators

Table 1. Triangulation of the top seven behavioral indicators with group selections and Deming's 14 points 


\section{Appendices}

Appendix A School District Annual Report Order ............................... 105

Appendix B Education Pilot Criteria Framework .............................. 109

Appendix C Initial Survey Instrument ………............................... 111

Appendix D Participant Responses to Round One ............................ 118

Appendix E Round One Transition Text Document .......................... 154

Appendix F Synthesized Behavior and Description Document ........... 189

Appendix G Round Three Survey Instrument ................................ 207

Appendix H Triangulation of Top Seven Behavioral Indicators with Literature Review and Deming's 14 Points ............. 216

Appendix I Statistical Report on Participant Responses ..................... 220

Appendix J Behaviorally Anchored Rating Scale Model ..................... 229

Appendix K Timeline of Study Activities ……................................... 235 


\section{Chapter One: Statement of the Problem}

Total Quality Management (TQM) has had a major influence on the development of quality indicators in business. The TQM movement arose out of a concern that businesses were not producing the quality of product demanded by the consumer or providing the service to meet the consumer's needs and demands. TQM is beginning to have an impact on education for similar reasons. Parents, businesses, and the public at large are demanding that students who graduate be better equipped to meet the demands of the information age. The consumer is demanding a better quality product from the public school system (Streshley \& Newcomer 1994). As a result, governments have responded in a variety of ways, one of which is to provide the public with more and better information on the quality of the schools. In British Columbia and, more recently, in Alberta an annual district report is now required by law (British Columbia School Act, 1992).

The British Columbia district annual report is mandated to provide information to the public that indicates, under the goals of the province, citizens are receiving value for their tax dollar. The current reports, due to a lack of a specified structure, vary in their scope and details. As a result, the government has initiated a program that will bring greater standardization to the reports (See Appendix A). One area that has not been included in the district annual report is an assessment of the success of the leadership of the superintendent. The 
government is seeking ways to provide such data. This study was intended to contribute to the process providing citizens with information about the performance of the senior school district administrator.

California's Proposition 98 mandated annual school report cards, but to date, like the British Columbia experience, only traditional measures such as test scores are being used as indicators. In a system seeking continuous quality improvement, traditional indicators do not go far enough. Total Quality, through such indices as the Baldridge criteria, offers alternatives to the traditional indicators (Hart \& Bogan, 1992).

Kouzes and Pozner (1993, p. 220) pointed out that "we have awakened to the silent terror of declining resources and social fortunes accompanied by a loss of confidence in our leaders, in our institutions and even in ourselves." At the same time, we know that credibility is critical to the working relationship a superintendent has with his/her constituents. Kanter's research (1977) made it clear that a leader's credibility is more important than many other factors. The data gathering and reporting aspects of TQM, that include "softer" qualitative surveys of consumer opinions, provide one example of a means of reporting to the public the success of the superintendent.

We know that the client focus within the TQM model reflects the commitment most educational restructuring initiatives have made to create a role for parents as partners in their children's education (Murphy, 1991; Newman 1993). The school system's need for TQM is demonstrated by the number of illiterates being turned out annually who somehow escape every effort to 
educate them even though the pupil-teacher ratio is the lowest ever (Johnston, 1993, p. 13). Johnston (1993) went on to suggest that "the installation of TQM stands to contribute more to the school system at less cost than any other process possible" (p. 13). Similarly, we are told that total quality organizations and transformational leadership, while concepts developed in non-educational settings, are of increasing interest to those attempting to restructure schools (Leithwood \& Steinbach, 1993; Sergiovanni, 1990; Bonstingl, 1992). It was the leadership of the district that this researcher was interested in studying. Identifying behavioral indicators of a superintendent's leadership success would enable assessing and reporting on these behaviors, thus assisting in improving the quality of the district.

This study sought to create a list of behaviors that could serve as indicators of a superintendent's success [or lack of it] as a leader, thus enabling a school board to assess and report that success to the public. The intent of producing the list in a priorized order was to provide boards with data that could be used to improve the practice of measuring a superintendent's leadership success. The list would provide concrete behaviors that could be examined through consumer surveys. The data gathered from such surveys could then be used to report to the public as well as to design a professional growth plan for the superintendent. The practice of listening to the consumer is consistent with those undertaken in a TQM environment. Hayes (1992) pointed out that the measurement of customers' attitudes is becoming an important element in the quality movement in organizations. He also pointed out that "soft" measures that focus on perceptions and attitudes, rather than more concrete objective data, are used to determine the success of the various aspects of the organization. A list 
of priorized behavioral indicators allows a school board to both measure the success of leadership at the district level and target these behaviors which, when improved, will strengthen leadership the most.

\section{Significance of the Study}

The state or province has the right and responsibility to ensure that the districts are functioning at acceptable levels -- fiscally, administratively, and educationally -- while the districts are responsible for ensuring that the schools are functioning well (Cooley \& George, 1992). The annual report in British Columbia has addressed, in part, the educational and fiscal reporting but little has been done to address the assessment of the level of administrative success. Cooley and George (1992) noted that efforts to improve education would be greatly facilitated if a broad set of indicators were available that provided useful information about the system and how the various components interact and change over time. Of critical importance is the need to use appropriate indicators. All too often educational reform is influenced by disinformation (Berliner, 1992).

This research has sought to identify indicators of the superintendent's leadership success that can be assessed by the public. Such indicators could serve as a means of providing the superintendent with evaluative feedback. They might also be utilized to report to the school board, district personnel, and to the public through a district level annual report. As Darling-Hammond (1992) suggested, leadership indicators would be an additional illuminator of educational activities. Identifying leadership behavior indicators would also 
enable the benchmarking of successful superintendents, a practice that is used effectively in quality organizations in the world of business (Spendolini, 1992).

The significance of this study was to establish key leadership behaviors that could be used by the British Columbia Ministry of Education to launch a benchmarking project involving superintendents. This could be developed in cooperation with the Technology Alliance of British Columbia's current "Project Benchmark". This project is attempting to develop curricular benchmarks as a basis for reporting to the public the applicability of curriculum to industry.

As in industry, the productivity of any school depends mostly on the skill of those who directly manage the workers or interact with the customers. In the case of schools, this group is the teachers. Yet according to Deming (1986), teachers' success depends almost completely on how well they in turn are managed and supported by the administrators above them. If this is correct, the school-based administrators have a strong impact upon the classroom. Thus, the examination of the leadership behaviors of the superintendent becomes very important to the success of the overall enterprise as the superintendent manages and sets both the tone and direction with the principals. By identifying indicators and receiving direct customer input on those indicators, the organization could gain current readings on customer satisfaction level. If we are to work to continuously improve the entire school system, then we must require the extensive collection of data so that we can both determine which of the systems or sub-systems need attention, and address the credibility gap that currently exists with respect to leadership at the district level. (Blankenstein, 1992; Kouzes \& Posner, 1993). 
The significance of this study is that all top seven behaviors that were identified have been linked with Deming's 14 Points (1986) on quality. By determining the extent to which a superintendent's behaviors match these priorities, it follows that the quality of the district's leadership could be measured.

An anticipated outcome of this study was the creation of a behavioral anchored rating scale that could form the basis for assessing and reporting a superintendent's success as a leader to the public. The scale could also act as the foundation for establishing a superintendent's leadership growth and development plan. TQM emphasizes the continuous growth and development of all members of the organization including the leader. Thus, gathering data upon which to base the leadership growth and development plan of the superintendent was seen as a valuable benefit of establishing behavioral indicators.

\section{Purpose}

The purpose of this study was to develop a list of priorized behaviors to serve as indicators of a superintendent's success as a leader in a school system seeking continuous quality improvement. This was accomplished by conducting a Delphi (Linstone \& Turoff, 1975) study using three groups of experts. The first group consisted of individuals in academic fields involved in the research and study of leadership and recognized writers who had written in the field of leadership in education and business. Business leaders from British Columbia, in particular CEOs, constituted a second group. The third group consisted of selected superintendents within Canada. A nested sub-group of superintendents and chief executive officers was to be used to determine if a difference existed 
between systems that were involved in a total quality program and those that are not involved in a total quality program.

\section{Research Questions}

1. What superintendent behaviors constitute successful leadership?

2. What is the perceived order of importance, by each group, of the identified behaviors as the behaviors relate to leadership success?

3. Do perceived differences and ranking of the behaviors exist among or within each group?

\section{Corollary research questions.}

4. How can knowledge about leadership success be reported to educational stakeholders via the British Columbia annual report system?

5. Can behavioral indicators provide a foundation upon which to build a leadership growth and development plan for the superintendent? 


\section{Definition of Terms}

$360^{\circ}$ (degree) Feedback: A method of gathering opinion on an individual's performance by surveying direct reports, peers, supervisors, and customers.

Baldridge: A national quality award designed to reward organizations that practice the principles of Total Quality Management.

Behavior. A function of the person and the situation in interaction with one another.

Benchmarking: A process of identifying and emulating other organizations that are best at performing the tasks that need to be improved.

Behavioral Anchored Rating Scale: A rating scale of three or more points on which the behavior of interest is specifically described for each point on the scale.

Behavioral Indicator. An observable measure of action undertaken by a superintendent to provide leadership.

Continuous Quality Improvement: A value of business and service organizations that suggests an openness to, and behavior in support of, changes intended to make a service or product better meet the customer's expectations. 
Customer. The customer is defined as the recipient of the educational services of the superintendent. For the purposes of this study, the customers included individuals from within the following groups: trustees, teachers, support staff, parents, members of the business community, residents who do not have children, and students (past and present). In addition, Ministry of Education officials and business partners outside the community would also be considered customers.

Indicator. A numerical measure of some important aspect of the educational system.

Leadership: The influence relationship that brings about positive intended change in an organization by transforming followers into leaders while bringing out the best in both.

Quality Indicator. A measure that, if tracked, is used to gather evidence of continuous improvement in a system.

Success: The ability to consistently meet or exceed customer expectations.

Total Quality Management: A structured system for meeting and exceeding customer needs by creating organization wide participation in the planning and implementation of continuous quality improvement processes. 


\section{Limitations and Assumptions}

The limitations of this study are threefold. First, the population sample relates to only one country in the case of superintendents and to one province in the case of CEOs. This makes the potential for use of the data as a base for reporting in the B.C. school district annual reports more applicable but may limit the ability to generalize beyond the provincial or national boundaries.

Second, the choice of the Delphi technique poses its own limitations. While this technique provides the advantage of anonymity of response that helps to overcome the psychological barriers of face-to-face panel discussions, the validity of the results could be influenced by the potential marginal capabilities of the experts. However, in view of the fact that these experts have risen to the level of leadership that they currently occupy, this limitation is seen as marginal. More important was the limited sample size that falls at the bottom of the acceptable limits suggested by the research on the Delphi.

Third, a limit on this study is the lack of research on superintendent behaviors with which the results of the study could be compared. This restricts the ability to validate the results through former research.

A number of assumptions underlie the basis for this project. First, the researcher assumed that behaviors that relate to a leader's success could be identified. Another assumption was made that the position or vocation of the panelists gives them the necessary expertise to deal with this subject and,

therefore, be considered experts in their position. Further, it is assumed that the 
CEOs and superintendents will have more than a reading knowledge of both quality and leadership effectiveness. However, very few school districts are immersed in the quality journey. Finally, the assumption was made that the superintendent's behaviors refer to a superintendent who was the chief executive officer of his/her organization as opposed to one who operated in a district with a dual leadership model in which the secretary treasurer and superintendent had equal authority.

\section{Organization of the Dissertation}

This dissertation reports on the researcher's attempt to identify behavioral indicators of successful superintendents. Upon identification, the indicators could be used as the base for developing a behavioral anchored rating scale that may enable reporting the quality of a district's leadership in an annual report.

The dissertation has been organized into five chapters. Chapter One contains an overview of the problem, significance and purpose of the study, research questions, definition of key terms, and concludes with a discussion of the limitations and assumptions pertinent to the study. Chapter Two provides a comprehensive review of the literature, examined prior to beginning the study, on the area of leadership behaviors. This chapter also provides a brief review of the literature surrounding the Quality Movement, as it applies directly to the issue of leadership in an organization that has undertaken a formal Total Quality program. Chapter Three provides a synopsis of the research design and methodology which, in this case, used a Delphi approach. Chapter Four deals extensively with the findings of the study. The results of each round of the 
Delphi are detailed, as are the demographic data of the panelists and their organizations. A thorough discussion of the findings is undertaken and the findings are summarized. The final chapter, Chapter Five, contains the findings, conclusions, and recommendations of the study. 


\section{Chapter Two: Review of the Literature}

This chapter provides a comprehensive review of the literature, examined prior to beginning the study, on the area of leadership behaviors. It also provides a brief review of the literature surrounding the Quality Movement, as it applies directly to the issue of leadership in an organization that has undertaken a formal Total Quality program. This review of the literature addresses six major areas: (a) the definition of leadership as it applies to this research; (b) a review of the research as it applies to a senior leader's behavior; (c) a specific look at studies of the superintendent's behavior; (d) a look at the CEO's behavior; (e) a consideration of indicators identified as linked to leadership in the Quality Movement; and $(f)$ the Delphi as a methodology.

The organization of this review is designed to provide a leadership definition first as it forms the basis for any indicator of success that may be found. It was expected in the study that the panelists would consider their advice in view of the researcher's definition. It would not be possible to develop a clear definition of leadership without a thorough review of the current literature.

Similarly, the review of the literature was undertaken to examine any previously identified leadership behaviors. This served two useful purposes. First, the researcher would know what behaviors had been identified as key indicators of a superintendent's success. Second, the review would assist in identifying leadership components that serve as the founding principles of the 
Total Quality Movement. Identifying linkages between the behaviors identified by the panelists and those identified by the TQM model would enable the researcher to confirm that the behaviors were acceptable indicators of a superintendent's leadership success in a TQM environment.

The examination of quality and quality indicators in the literature review was undertaken to ensure that the behavioral indicators identified would remain true to the behaviors that the Quality Movement has deemed to be most directly linked to assessing continuous quality improvement in an organization. It would also serve to verify the importance that leadership plays in improving quality in an organization.

Finally, this review concludes with an examination of the literature related to the Delphi as a methodology for collecting expert opinion. This methodology was chosen for this study as it provides an efficient manner of gathering the opinions of CEOs and superintendents on behavior indicators.

\section{Leadership Defined}

Leadership has proven to be very difficult to define. Bennis and Nanus (1985) reported that they had located over 350 definitions of leadership in the literature. Rost (1991), in developing his definition, analyzed 221 definitions in materials written from 1900 to 1990 . However, Rost did note a significant change in the emphasis in definitions as the decades progressed. The first three decades saw an emphasis on control and centralization of authority. In the two decades following, leadership definitions tended to take on a group approach 
that led to Gibb (1969) defining leadership in terms of a noncoercive influence relationship. This approach has had an obvious impact on Rost as he used the same parameters in his own definition. Rost believed that the relationship had to reflect mutual purposes and, as such, coercion could not be applied. A definition that eliminates any coercion also removes the application of certain behaviors that were a part of the "command and control" model of leadership. In the case of a superintendent subtle power use, such as promises of promotion or threat of demotion, would be considered unacceptable.

The decade of the 1960s saw Fielder (1967) and others use such terms as directing and coordinating. This was also the period when individuals engaged in MBA programs were imbued with the idea of leadership being defined in terms of the behaviors of planning, organizing, directing, and controlling. These terms alone identified behaviors that were used to establish measures of leadership success. Thus, an individual who could organize was often seen as a leader. In the school system, this often led to the appointment of those who were seen to be excellent organizers in athletics. Many athletic coaches, for example, were promoted to the ranks of administration. Some proved to be leaders while others remained only strong managers.

However, in 1978 James MacGregor Burns' Pulitzer prize winning book Leadership brought a new direction to leadership study with his emphasis on the transformational nature of the leader's role. He spoke of the mutuality of the leadership process between leaders and followers with each helping the other grow and become more effective. Burns viewed the role of the leader as one of developing leadership in followers. This change in emphasis altered the 
behaviors expected of a leader. Planning and organizing became tasks of the middle manager rather than that of the leader. Directing and controlling behaviors were not seen to contribute to the growth and development of followers and were, therefore, considered liabilities.

Bennis and Nanus (1985) in their work also saw leadership as transformational in that they believed the leader's most important task was to transform his/her followers into leaders who acted as change agents committed to action. Building upon this transformational yet behavioral approach, Kouzes and Posner (1987) developed their definition of leadership based upon Maslow's hierarchy of needs and posited that leadership involved a process of achieving one's personal best, thereby bringing out the best in both the leaders and their followers. They went on to suggest that there were specific practices and commitments undertaken by leaders who achieve extraordinary results within their organization. In 1990, Rost gave his interim definition that stated that leadership was "an influence relationship among leaders and followers who intend real changes that reflect their mutual purposes" (p. 102). He has since (1993) changed the term "followers" to "collaborators" (p. 99). Thus, the trend in leadership definitions is to move away from the control theories of the past to the collaborative influence relationships emphasizing the growth of followers. Maxwell (1993) perhaps best summarized this trend by stating that "leadership is influence" (p. 1).

The theoretical change suggests that a controlling leader's behaviors would be different from those of an influencing leader's behavior. If a superintendent is to be successful in terms of current leadership practice, there 
may be behaviors that can be identified that may foster the kind of leadership that the more current definitions describe. This study has provided its own definition of leadership drawn from the recent scholars. For the purposes of this study, leadership was defined as: "the influence relationship that brings about positive intended change in an organization by transforming followers into leaders while bringing out the best in both". Combined with the definition of success given earlier, which is based upon the TQM systemic approach to leadership, this study sought to identify those superintendent behaviors that were most likely to satisfy the definition of leadership utilized in this study as well as the definition of success.

\section{Leadership Behavior}

Burns (1978) noted that leadership is one of the most observed and least understood phenomena on earth. Clark and Clark (1990) stated that there were not a large number of comprehensive, rigorous studies of leadership. Truskie (1990) noted that while there have been thousands of studies conducted in the general area of leadership, few have focused on leadership at the top. Bridges' (1982) research suggested that there is a total lack of studies that describe the behaviors and skills of groups of superintendents who are exemplary in various types of districts. The literature is limited on the topic of a leader's behavior at the superintendent's level because, as Boyatzis (1982) noted, until recently, most leaders studied were at the lowest levels of organizations. Recently more attention has been given to senior leaders and executives (Kotter, 1982; Levinson \& Rosenthal, 1984; Pincus, 1994). Even 
these studies were often narrowly focused. Pincus (1994), for example, concentrated only on a leader's communication behavior.

Early studies of leaders focused on their traits. The fault with the trait theory approach was an absence of consideration of the situation faced by the leader, including the followers to be led, and of any concern with the quality of the leader's performance. Hence, the development of lists of desired qualities of leaders has given way to an approach that deals with leadership, events, and behaviors in an attempt to understand the roles of various participants in such events (Clark \& Clark, 1990). Sales' (1989) in-depth examination of leadership noted that managerial work is behaviorally demanding. "It is much more than reflecting. It requires the ability to shift from one style and set of movements to another in a matter of moments" (p. 17). He goes on to point out that European studies found that it was unusual for CEOs to work at any one thing for any longer than one half hour. In pointing to relationships as the key to leadership, Sales suggests that leaders are peripatetic with their working life being a never ending series of contacts with others.

The study of behaviors is hampered by the problematic situation that the behaviors of leaders are not easily described nor readily categorized (Clark \& Clark 1990). The most significant early work on leadership functions was the research done by Shartle and his colleagues at Ohio State University on dimensions of leader behavior among naval officers (Shartle \& Stogdill, 1948; Fleishman, 1973). These studies produced the Leadership Behavior Description Questionnaire which measures the main factors of leader consideration and initiating structure. 
Equally significant was the study at Harvard by Bales (1958) who identified two critical dimensions of behavior: behavior centered on task accomplishment; and behavior that was directed toward interpersonal relations, which Bales labeled "socio-emotional relationship". The work completed at both Ohio State and Harvard was done in the same era as the popularization of the MBA programs that operated on a different leadership definition from those that are used in the 1990s. Therefore, the behaviors associated with these studies lack a relational context.

One series of organizational studies summarized in Kahn and Katz (1960) indicates more effective leaders: (a) behave so as to make clear the differentiation of their role from that of employees by refraining from performing the same functions as the rank and file worker; (b) spend substantial time in supervisory functions -- but not closely supervising employee behavior minute by minute; and (c) orient their behavior predominantly toward employee concerns rather than behaving in a more institutional fashion. This study's findings suggested a supervisory function that is hierarchically based and substantially different from the collaborative models of leadership that are currently favored.

Hersey and Blanchard (1969) and House (1971) suggested that effectiveness depended on engaging in different combinations of task and relationship behavior in different situations. House and Baetz (1979) supported this so called situational leadership approach. This approach still guides much of the leadership behavior training given to leaders in organizations. However, Sashkin and Burke (1978) found that situational approaches seem to work well, for clear reasons, or even better, but for very unclear reasons. These 
approaches would work well when the situation seemed to require clear direction from the leader and there was a return to the "command and control" model. On the other hand, when the situation called for a more ambiguous response, the model seemed to work better. In essence, the follower was more empowered in the latter situation.

Leadership behavior was seen by Sashkin and Burke (1990) as purposefully conceived and directed by leaders capable [having the requisite personal characteristics] of dealing with specific organizational conditions and needs. They also claimed that visionary leaders empower followers through their [the leader's] actions both on an organizational level and on an individual interpersonal level by means of behaviors they employ. This approach to leadership behavior exemplifies the current development of the transformational movement in leadership.

Dean and Mary Tjosvold (1991) believed that leadership was creating positive relationships and cited studies that demonstrated that collaborative, participatory behavior in leaders inspired commitment from followers. Moreover, they suggested that what successful leaders have in common were interpersonal abilities and sensibilities.

Eggers and Leahy's (1994) recent study of 346 entrepreneurial leaders identified 34 leadership skills, of which the top seven were: financial management, communication, motivation of others, vision, self motivation, planning/goal setting, and marketing. It is worth noting that they found that the ability to express ideas was only a portion of the required communication skills. 
Of equal importance was the ability to listen openly and carefully to others. Perhaps this showed the individuals that their ideas were valued.

Jaques (1989) also found that effective leaders use power to give ownership to empower others, who then use power and influence to enact the leader's vision of the organization.

Sashkin and Burke (1990) believed that a comprehensive understanding of organizational leadership must incorporate three elements: (a) the leader's personal characteristics; (b) the leader's effect on organizational functioning and culture; and (c) the leader's behavior. It is the third element, behavior, that this study addressed. In doing so, this study attempted to determine if there was consensus among three groups represented on the panel with respect to the priorized behaviors that constitute successful leadership by a superintendent. The need for research on specific behaviors was confirmed by Yukl (1989) who stated that "further progress in the behavior research requires a shift in focus to more specific aspects of behavior" (p. 273).

The literature suggests that transformational leadership is a process of mutual actualization between a leader and followers. Through this process of mutual actualization, leadership enhances the performance of both leader and followers. An examination of the literature regarding behaviors of CEOs was undertaken to determine behaviors that school superintendents who are CEOs might employ to achieve that mutual actualization. 


\section{Chief Executive Officer Behaviors}

The superintendent is seen as the CEO of a school district. A review of research related to the behaviors of successful CEOs in business and industry revealed some interesting findings and implications.

George Steiner (1983), in a study of 47 executives (25 of who were CEOs from the largest corporations in the United States), identified 14 essential skills and qualities required of the 'new' Chief Executive Officer (CEO). The eight essential skills that could manifest as behaviors were: (a) being a leader, in the sense of being an enabler; (b) envisioning the future and leading followers toward that vision; (c) balancing, in the decision making process, both traditional economic considerations and non-economic interests of internal and external interests; (d) assuming personal responsibility for advocacy and activism on behalf of the organization by being the spokesperson; (e) formulating his thinking on a wide range of issues of the day and communicating it effectively; $(f)$ swimming in political waters; (g) planning for constant change; and (h) maintaining poise at all times. School systems on this continent are undergoing constant change, both fiscally and philosophically, and the expectation is that superintendents will maintain their poise at all times.

Bennis and Nanus (1985) studied the lives of 90 CEOs, most of whom led Fortune 500 companies. They were looking for qualities that were common to these leaders. The researchers noted that most of the CEOs were men and discovered that the only thing that the majority of these leaders had in common was that they were still married to their first spouse. Even this becomes a 
challenge in the superintendency as the commitment to school, community, and professional events often leads to an imbalance between home and professional life.

Kouzes and Posner (1987) studied the lives of 500 middle-level and senior-level managers and determined that there were a series of practices and commitments that leaders undertake to achieve peak performance. Their list included, what they referred to as, the five best practices known as: (a) challenging the process; (b) inspiring a shared vision; (c) enabling others to act; (d) modeling the way; and (e) encouraging the heart (p. 8). These practices have furthered the transformational leadership movement. However, the actual behaviors that CEOs or superintendents might undertake to accomplish these practices were not clearly identified by this study.

These two researchers have more recently concentrated on the credibility issue confronting senior leaders and have developed a number of recommendations on the ways through which a leader can develop and maintain credibility. Their work in this area reinforces the need to develop transformational leadership attributes in the CEO. However, while they speak of some behaviors such as communicating, they too fail to provide a clear description of how leadership behavior manifests itself. If indicators of successful superintendent leadership are to be developed, then the observer [the customer] must have a clear picture and description of the behavior.

David Kurtz's (1989) study of over 200 CEOs found a common behavior that is consistent with Theory $Y$ or the use of participatory decision making. He 
also noted that CEOs tended to be well organized, humorous, and creative although he did not describe the behaviors that identified these characteristics.

Jaques (1989) found that leaders at the top of an organization must have a long-range vision and accompanying goals. He found that executives must think and function over periods of at least a decade or two. This finding has significant implications for a school district setting in that superintendents operate in a political venue in which the politician's term is only three years. Thus, if a long span of vision is demonstrated as an important behavior, what are the implications for the success of a superintendent who may be trying to survive the politics of a short-term Board?

This whole survival agenda is commented on extensively in a recent study by Jeffries (1994). She makes the point by quoting Willard Waller who, writing in Sociology of Teaching in 1932, describes a situation that still exists. Waller says that for the superintendent:

Opportunities for becoming unpopular, to the point, almost, of infamy, are numerous, but opportunities for gaining friends are few. At the end of the first year, the superintendent has made some enemies but the majority of the community ... is still satisfied with the manner in which he is conducting the school [district]. He has made some bitter enemies, as, unavoidably he must ... The superintendent has now acquired certain enemies on the school board and they serve the community as further radiant points of antagonism toward him. But the important fact, and the inexorable tragedy of the superintendent's life, is that in the second year, 
he usually makes a few more enemies but rarely has an opportunity to restore the balance by making friends of those who have previously been inimical to him. If he does win at the end of the second year, he stands a greater chance of losing in the third year, for his position is continuously weakened. He makes more enemies, and only lukewarm friends. (Quoted in Jeffries, 1994, pp. 77-78)

The extent to which such a survival agenda might affect the panelists in this study remains to be seen.

In examining behaviors of profit achieving CEOs, Frank Toney (1994) found four areas to be critical. First, these CEOs built efficient organizational structures wherein strategy was goal focused. Second, they communicated with their subordinates in such a way that the vision was clearly defined. They were inspirational in their communication and built teams within the structures while interacting informally with individuals within the organization. They also communicated by being a positive role model. Third, the CEOs identified were constantly scanning the environment and optimizing their channels of information. Finally, this study found that the profitable CEOs critically analyzed alternatives, particularly in relation to cash flow and product costing. The latter skill is becoming more critical to superintendents who are seeing a diminishing of public funding and, in many cases, becoming entrepreneurial in their approach to district leadership. This is evidenced in British Columbia by superintendents of 44 districts who are now recruiting foreign students to supplement school district budgets by millions of dollars. 
In a study of 18 visionary companies, where the average age of the company was 92 years and which were identified from an original survey sample of 700 CEOs, Collins and Porras (1994) found that the key actions of CEOs were similar to "the yin and the yang". CEOs needed to preserve the core of the organization while at the same time stimulating progress but, here again, no specific behaviors were suggested to accomplish these seemingly opposite actions. Even though no behaviors were suggested, the study applies well to a school system that is so steeped in such tradition that the required progress and meaningful reform are often hard for the superintendent to accomplish.

\section{Superintendent Behaviors}

Blumberg and Blumberg (1985) spoke to the behaviors of superintendents who were successful in terms of the survival agenda when they explained:

The politics of their survival has been less concerned with surviving per se and more with behaving in ways that permit them to have a continuing productive impact upon the system, thus ensuring their survival and power. That is, they become a commodity that is valued because it is potent and active, and not because it is impotent and inactive. (p. 50)

Behaving in a productive manner is useful today only if the productivity contributes to the quality of the system and the quality of the education that students in the system receive. Thus, while the survival agenda is likely to be ever present, studies seeking to identify, not only survival behaviors, but also behaviors that act as indicators of quality in leadership, are much needed. One 
such study was conducted by Thomas (1994), a British Columbia superintendent. In his review of the research on leadership, he concluded that there were 20 learned qualities which leaders develop to increase their effectiveness in leadership situations. He believed that the degree to which the characteristics are integrated and applied determined the degree to which they become indicators of leadership effectiveness. His list included some items that could be classified as behaviors, such as: leaders communicate; leaders plan their future; and leaders problem find. While these items indicated behavior, they did not provide a description of how the behavior manifested itself when undertaken by a superintendent. It is this description of the manifestation of the behavior that would allow the behavior to be identified and used as an indicator of a superintendent's leadership success.

The research of Kirby et al (1992) on extraordinary leaders in education confirmed Sashkin's findings that these individuals are visionary leaders who "express their visions through effective communication, are consistent in their actions to support their visions, show respect for others and value their input, and act to create risks that others can support and achieve" (p. 309). This study also found that leaders encouraged followers to challenge their old ways.

Kirby is not alone in her assessment of vision as a critical factor in successful leadership. Schlechty (1990) spoke of it as the first essential in leading an educational organization. Senge (1990) saw vision as an imperative to the successful learning organization. He stated that vision "is a force in people's hearts, a force of impressive powers" (p. 206). The behavior of 
visioning is somewhat abstract to many and needs to be clearly described if it is to be used as an indicator.

Lee (1991), in her review of the literature, identified five key behaviors of effective leaders in education. These were: (a) formulating a shared vision; (b) defining and setting goals; (c) empowerment; (d) building and maintaining a positive climate; and (e) communicating effectively. This thorough review adds to the potency of visioning as a key behavioral indicator of a superintendent's leadership success.

Saskatchewan Director of Education Eale Newton (1991), in his paper 'Voices, Vision and Vitality: International Indicators of Effective Superintendents' Leadership', notes that effective superintendents "have ongoing cycles of planning, acting, observing and reflecting" (p. 8). He also suggested that superintendents have time to read and think and engage in lifelong learning. His research findings identified the following behaviors as critical to a superintendent's success:

1. Voices: Effective superintendents listen to all partners in education. They have both systematic and informal procedures for doing so.

2. Vision: Effective superintendents have personal visions that they articulate and share in the process of working towards a system vision. 
3. Related to voices and vision, effective superintendents can link "bottom up" or local initiatives with "top down" or external expectations by seeing both as part of a bigger picture.

4. Much of the above is integrated by effective superintendents through some form of strategic planning.

5. In effective school jurisdictions there is emphasis on the system. High expectations in terms of priorities, monitoring, and evaluations are balanced with comprehensive professional development programs and personal encouragement. Such systems are, therefore, simultaneously loose-tight with sufficient linkage to coordinate efforts.

6. There is not only tolerance for complexity but a vitality in dealing with it, as effective school systems move toward becoming learning organizations.

7. Effective administrators show the way by being action oriented, by having the human relations skills to involve all stakeholders, and by working toward a shared articulated vision and by being politically astute. (p. 1314)

These seven indicators are aligned with those used in the private sector to assess continuous quality improvement. Given this alignment, such indicators might be useful for triangulating the findings of the study proposed. 
In an exploratory study that examined 290 exemplary superintendents identified by the National School Board Association and 125 identified by the American Association of School Administrators, Glass (1992) found that the outstanding superintendents sought more citizen participation and emphasized strategic planning. They also were more interested in sharing and creating a partnership with Board members. Finally, Glass found that exemplary superintendents better fit the general literature definition of "chief executive." Thus, another link is made between the world of education and that of business and industry.

His study noted that exemplary superintendents were found primarily in urban areas with only one small group identified who served in rural areas. Moreover, Glass found that the average age of an exemplary superintendent was 53 years and that the average length of tenure was over eight years. Glass spoke of the desperate need for a set of professional standards for the superintendency. He felt that there should be performance criteria clearly defined against which a superintendent's performance could be measured as well as a knowledge base that could be tested. Studies, such as the one proposed herein, that seek to identify indicators of a superintendent's leadership effectiveness need to be undertaken. Glass' work provides a foundation for such studies.

\section{Indicators of Successful Leadership in the TQM Model}

One of the purposes of this study was not only to establish behavioral indicators of a superintendent's leadership success, but also to attempt to 
determine if the identified indicators were associated with the TQM model. It was necessary to: (a) research and examine the principles of leadership that were established by the founder of the Quality Movement; and (b) examine the views of practicing leaders who were seen to be at the forefront of quality.

Edwards Deming is commonly accepted as the founder of the Quality Movement. His seminal work in 1986 established 14 points that are seen as the foundation of quality. He also identified ten leadership attributes that he felt transformational leaders must exhibit if leadership was to be considered transformational, with the vision and quest being quality. Of the 14 points, nine were seen to have direct application as indicators of quality in the successful leadership by superintendents. These included:

- Point 1 (Create a constancy of purpose for improvement of product and service) This related directly to the visioning behavior that is required in a quality educational environment and is confirmed by the majority of studies of both CEOs and superintendents.

- Point 5 (Improve constantly and forever the system of production and service) In education, the leader who seeks incremental but continuous improvement is identified as a more successful leader than the leader who jumps on every bandwagon that goes by. However, this practice can only occur if the vision is clearly expressed and communicated throughout the system. Thus, it is easy to see how these points are not only linked to quality but also linked to one another. 
- Point 6 (Institute training and retraining) When discussing this point, Deming suggested that the greatest waste in systems is the failure to use the abilities of people. Thus, a useful indicator would be how well employees felt their abilities are used and how well the system develops the innate abilities of its employees. Retraining and training in curricula, technology, and methodology are important to the continuous improvement of a school system.

- $\quad$ Point 7 (Adopt and institute leadership) Deming was clear that the job of management is not supervision but leadership. In order to exercise that leadership, the leader must know the work that they supervise.

Superintendents supervise principals and teachers, so they need to know the practices of leadership and teaching, and to be able to demonstrate their knowledge relative to both. Moreover, the superintendent needs to understand that the primary focus of the organization is learning and how it occurs.

- $\quad$ Point 8 (Drive out fear) People are afraid of the knowledge explosion for fear it will make them look incompetent; this new knowledge is fundamental to improve the quality of the school system. As an indicator, this point touches on the way in which a superintendent of a school system would communicate with its employees and the supportive culture that needs to be built around acquiring new knowledge and practices.

- $\quad$ Point 9 (Break down barriers between staff areas) The school system is known for its bureaucratization through excessive central office staffing. It 
has also created barriers in the schools through the use of departments and divisions. This point suggests that the organization must be flatter and more integrated and, as an indicator of quality, would lead to change within the system.

- Point 12 (Remove barriers that rob people of pride of workmanship) This indicator seeks to know if the employees are given the opportunity to work with pride. In the school system, this requires integrity on the part of the leader in dealing with personnel. It also means that the teacher, who faces so many children every day, needs to know how well he or she is performing. It is the superintendent's responsibility to have systems in place that enable this to happen.

- $\quad$ Point 13 (Initiate a program of education and training) This point is differentiated from Point 6, which Deming believed referred to management and new employees. Point 13 refers to the need for every individual in the system to be learning. Thus, it is important that an indicator in a quality system address the question of the presence of a learning community culture and, of course, it is the superintendent who must role model this behavior.

- Point 14 (Take action to accomplish the transformation) This point requires the superintendent to ensure that a quality program is implemented and to communicate the principles continuously within and without the school system. 
These nine points of Deming are essential principles that are drawn from the Quality Movement. They confirm that indicators of behavior taken from TQM in the private sector can be applied to the superintendent. As was the case with Glass' findings, these nine points may be useful in triangulating the findings of the study proposed and reported on in this dissertation.

The Baldridge criteria also gave a list of quality indicators that were transferable to the area of education. The Baldridge Award was developed to foster the involvement of industry in the Quality Movement. It is only in the last year that this prestigious award has been open to educational systems. The Education Pilot Criteria framework clearly identifies leadership as the "Driver" of the system of dynamic relationships (See Appendix B). The framework notes that senior leadership sets directions; creates shared values, goals, and systems; and guides the pursuit of performance improvement in the system. Aligned with this framework, the indices for the Baldridge leadership area offer viable alternatives to the traditional indicators used in school systems. Hart and Bogan (1992) list the following nine indicators for the Baldridge leadership area:

1. Missionary: To reach the objective of this criterion, the superintendent must be visibly "walking the talk", leading the quality initiatives, and carrying the quality message throughout the school system.

2. Stretch goals: This indicator requires that the leadership ensure that the goals established are not easily attainable but rather set the standard high. For example, Hart and Bogan (1992) report that Milliken has established goals of ten-fold improvement in only four years. School 
systems could apply this practice to such areas as reducing the dropout rate.

3. Strong cycle-time driver: This criterion requires that there be a quick turn around time on any cycle. In school systems, student assignments turn around or inquiry response time are examples.

4. Clear, easily remembered values: School systems that have established a strategic plan with accompanying values need to insure knowledge of, and adherence to, these values.

5. Flat organization: This criterion requires that there be minimal layers in the system. In the school system, the bureaucracy of central offices must give way to an emphasis on the classroom in schools. This criterion is directly related to Deming's ninth point.

6. Non-denominational: The non-denominational criterion speaks to the need of a school system to adopt an eclectic approach to quality, where a school system develops its unique approach to quality improvement while abiding by fundamental principles.

7. Learning from anyone: This criterion encourages teamwork within the system and the continual searching of other systems for "best practices". This is seen as a leader's responsibility in developing a learning community. 
8. Contact with customers: In a school system, this criterion would require that the superintendent not be office bound, but be in the schools listening to the internal customers, and in the community communicating with the external customers.

9. Managers as coaches: This final criterion requires that the superintendent be able to demonstrate the values and excellence expected of teachers and administrators within the system. The leader must be seen as a capable advisor. This criterion is directly linked to Deming's seventh point.

The Baldridge criteria provide a perspective in searching for indicators of leadership that is essential in an organization that is focused on the TQM model. One of the purposes of seeking to develop behavioral indicators for superintendents in this study was to ensure that the indicators were applicable to a system that was moving towards a TQM process.

Business and industry have established a few leaders in the practices of TQM. One such recognized leader was David Kearns who, through the use of quality tools, took the Xerox Corporation from the brink of extinction to a world leader in its industry.

Kearns (1992) gave a CEO's perspective of quality leadership in his book Prophets of the Dark in which he told the story of Xerox's quality transformation. Kearns identified the six vital components of quality leadership as follows: 
- A focus on quality as defined by the customer.

The education system has not paid enough attention to the voice of the student and parent. Students, as a direct customer, need to have a greater say in that which is delivered to them (Palmer, 1995). Quality leadership means that a superintendent must behave in a manner that exhibits active listening, particularly to students and parents. The ninth Baldridge criterion speaks to this point.

- Learning how to monitor, control, and constantly improve the system.

As in Deming's Point 5, Kearns is suggesting that quality occurs only when the leader is monitoring progress towards specified goals. Then, based on the results of this monitoring, the superintendent looks for systemic approaches to ensure continuous improvement. Too often in education, a systemic approach is ignored in favor of tinkering with a small facet of the organization.

- Making decisions based on data and not guesswork.

Education is extremely vulnerable in this area. Everyone has been through the system and has their own "gut feeling" about what is right or wrong. A quality leader will insist on a data-rich environment so that the facts can be displayed for both internal and external customers. Even now, when through the use of technology data is more readily captured 
and available, it is ignored or shelved rather than using the quality tools to analyze the information to improve the system.

- $\quad$ Restructured relationships between management and workers.

This focuses on both flattening the organization and breaking down barriers between staff and management (Deming's Point 9). Quality leaders understand the new relational aspect of leadership and rely on networking, rather than hierarchy, to facilitate decision making. As Phil Quigley of Pacific Bell stated: "I don't think of leadership as a position. I don't think of leadership as a skill. I think of leadership as a relationship." (Kouzes \& Posner, 1993, p. 1)

- Focus on employees working together as "all one team".

Teaming goes hand-in-hand with quality and, certainly, many teachers model this in education. However, education continues to be an isolated activity because of the nature of the individual classroom. The quality leader models team-building at the top and, through the communication of a vision for the organization, develops a unity within it.

- Building strengths from crisis and opportunity from problems.

Education is often in crisis as a result of such things as fiscal restraint or changes in government policy. Superintendents often react in a negative manner rather than adopting a quality approach of using the crisis as an 
opportunity to bring the team together in a proactive developmental approach. Kearns' approach to quality altered the paradigm and he used Xerox's financial woes to develop a new era of organization.

These components are key to leadership in the continuous quality organization that was the focus of this study, but they do not describe the behaviors that are required of the CEO to develop the components. Recently, Xerox has developed a 'Leading in the 90s' workshop that focuses on such areas as improvement of communication skills and introduction of interactive skills that do appear to be developing specific behaviors that enhance continuous quality improvement. Were this skill proven to be critical to a superintendent's leadership effectiveness, programs such as that developed by Xerox could be imported directly to education.

Another current leader who was seen to practice quality in the field was General H. Norman Schwartzkopf (1992) who led the successful Desert Storm campaign in the Middle East. He listed 11 principles of quality leadership, which include: (a) have clear goals; (b) give yourself a clear agenda; (c) let people know where they stand; (d) what's broken, fix now; (e) no repainting the flagpole; (f) set high standards; (g) lay the concept out, but let your people execute it; (h) people come to work to succeed; (i) never lie -- ever; (j) when in charge, take command; and $(k)$ do what's right. These 11 points from a recognized leader offer potential behavioral indicators of leadership success and certainly proved to be successful in leading a multi-national armed force to decisive victory. While the military model was a "command and control" model, Schwartzkopf has made some obvious adjustments. For example, he believes that you let the people 
closest to the action determine how to execute the concept. He, like Deming, also believes in honesty and letting people know where they stand. Thus, there is some transferability to education of the appropriate principles that emphasize relational leadership.

Haycock (1994), a researcher who has practiced in the field in British Columbia, identified a specific behavior that he believed superintendents should undertake more often to achieve quality in the school district. He suggested that the behavior manifests itself when superintendents ask more often the question: "How do you know?" (p. 87). This is a simple yet specific behavior, the essence of what this study sought to identify. Perhaps, generically worded, it would state that the successful superintendent asks effective questions.

\section{The Delphi as Methodology for Collecting Expert Opinion}

The Delphi technique, a procedure developed by the Rand Corporation in 1953, sought to obtain consensus among experts regarding urgent defense problems without having to bring the experts together for face-to-face discussions. The word "Delphi" was derived from Greek mythology. Delphi was the sanctuary of Apollo and the most sacred of Greek oracles. It was from Delphi that Apollo's predictions were made known to the Greeks. Throughout the centuries, the term Delphi has been identified with predictions of the future (Uhl, 1983).

The Delphi process has been accepted as a useful method of eliciting and refining group judgments and opinions. The rationale for the procedures lies 
in the old adage that "two heads are better than one" when the issue is one where exact knowledge is not available (Dalkey, 1969). The methodology has three features: (a) anonymous response where opinions of the panelists are obtained through a formal questionnaire; (b) iteration and controlled feedback where interaction occurs through a process in several iterations with thoughtfully controlled feedback between the three rounds proposed for this study; and (c) statistical group response where group opinion is found in an appropriate aggregate of individual opinions in the final round.

Helmer (1964) summed up the procedure as successive questioning of individual experts, without face-to-face confrontation, interspersed with controlled feedback of the group's opinions and reasons, offered in support of such opinions.

The technique can be used in any context where it is appropriate to seek consensus on a particular subject. Moreover, it is a method that can, and has been used, to collect opinions of individual experts and combine the opinions into judgments that have operational utility to the policy maker (Helmer, 1967). The ultimate outcome of this study was intended to have an impact on governmental policy makers who determine the required format of the district annual reports as well as to develop potential quality indicators of a superintendent's leadership success.

An advantage of the Delphi technique, in its simplest form, is that it eliminates committee activity. By doing so, it reduces the influence of certain psychological factors such as specious persuasion; the unwillingness to abandon 
publicly expressed opinions; and the "band wagon" effect of majority opinion (Helmer, 1966). Dalkey (1969) pointed out that in a study of ten experiments involving 14 groups, more often than not, face-to-face discussions tended to make group estimates less accurate whereas, more often than not, the anonymous controlled feedback procedure made group estimates more accurate.

The Delphi technique, through its controlled feedback, forces all respondents to think through their judgments carefully, vis-à-vis all other respondents, and allows the researcher to focus on the best rationale for the group judgments. Helmer (1964) confirmed that to compare two groups of rankings, a statistical testing to see if any patterning existed, could be used. The Kendall W seemed to provide the most suitable statistical procedure for examining the data and establishing a coefficient of concordance.

Jones (1975) noted that a concern often raised about the credibility of Delphi results is that when experts are asked to evaluate areas in which they are presently working, they are often overly favorable to areas of personal interest. However, he reported that no such bias occurred in the four Delphis he studied; and it appeared that particular groups of experts used were able to rise above any desire to protect personal interests. Thus, such a bias was not perceived to be a factor in this study even though the superintendents are obviously working in the field being examined.

In the 1970s, the Delphi method became recognized for its applicability to social research. The Delphi can be used for any purpose for which a committee 
can be used and is intended to overcome the disadvantages of groups while capitalizing on the advantages (Martino, 1983).

Uhl (1983) pointed out that the Delphi technique can be effective in educational planning. He identified four phases for its use that included: the analysis phase, the mission and goals phase; the objectives and action phase; and the resource-use, needs-analysis, and expenditure-strategies phase.

Given that the problem of identifying successful leadership behaviors of the superintendent is an analysis of an educational problem and that this study seeks to determine those behaviors, it followed that the Delphi method was an appropriate method to identify the behaviors. Thomas (1981) pointed out that the Delphi was a very thoughtful, quiet conversation where everyone gets to listen.

\section{Summary of Literature Review}

This literature review has revealed that the definition of leadership has changed over time from a view of leadership as "command and control" to a view of leadership as an influence relationship. This influence relationship does not subscribe to behaviors that were previously associated with effective leadership such as planning, organizing, directing, and controlling. Thus, what the literature revealed was limited in terms of the behaviors that demonstrated successful leadership when leadership is defined as influence. 
The literature on CEO behavior suggested that certain behaviors did appear more often than others in the studies. Visioning, communicating, and participatory decision making appeared most often. This indicated that while no composite list was available, there were enough behaviors to possibly triangulate this study.

The review of superintendent behaviors also did not present a composite list of behaviors. However, some behaviors that appeared repeatedly included visioning, communicating, enabling, and seeking citizen participation. The review also suggested a strong need for studies that identified performance criteria for superintendents in the form of specific behavioral indicators.

The review of leadership criteria from the Total Quality model produced specific criteria based upon the principles established by the founder of the Quality Movement. It was apparent that these criteria could be applied to education. It was further noted that practicing leaders in business and industry had developed programs to train leaders in business in specific leadership behaviors. Xerox Corporation's 'Leading in the 90s' was such an example.

The literature review confirmed that the Delphi technique was an acceptable methodology for seeking experts' opinions and consensus when the participants were geographically separated. The methodology offered the opportunity to refine group judgments and techniques through controlled feedback while avoiding the biasing that can occur in face-to-face meetings. 
The literature reviewed has provided a strong foundation for the study proposed herein and its methodology. Preliminary findings related to the CEO and superintendent behaviors point the researcher in the right direction. The need for a study of this kind was clear. The Delphi technique appeared to be a well-grounded methodology for this type of study. Sufficient direction was given to motivate the researcher to further pursue his course of action.

Chapter Three describes the research design and methodology used in this study. It will discuss the selection of participants and the data gathering procedures, along with the intended data analysis. The use of triangulation will also be addressed. 


\section{Chapter Three: Research Design and Methodology}

Chapter Three provides a synopsis of the research design and methodology which, in this case, used a Delphi approach. The purpose of this study was to identify a list of priorized behaviors to serve as indicators of a superintendent's success as a leader in a system seeking continuous quality improvement. An anticipated outcome of the study was the creation of a behavioral anchored rating scale that could form the basis for reporting a superintendent's leadership success as viewed by the public. The scale was also expected to provide the foundation for establishing a superintendent's leadership growth and development plan.

The project was intended primarily to identify what superintendent behaviors demonstrate successful leadership. Second, the study was intended to ascertain the order of importance of the seven top behaviors as perceived by each group of experts, and then to determine if consensus could be reached among the three expert groups on both the identified behaviors and their ranking of importance. A third purpose of the study was to determine if the behaviors identified and the priorities determined could provide the basis for establishing growth and development plans for superintendents. Finally, the study sought to examine how knowledge about the behaviors identified could strengthen a district annual report as required within the B.C. annual report system. 


\section{Participant and Site Selection}

Bunning (1979) reported that there were no established guidelines for sample size when using the Delphi. He suggested that 15 to 20 well-selected experts provided a broad enough range of expertise and gave the researcher a reasonable data base with which to work. Delbecq, Vand de Ven, and Gustavson (1975) noted that their experience demonstrated that few new ideas are generated within a homogeneous group once the size exceeded 20 to 30 well-chosen participants.

Choice of panelists is important in the use of the Delphi technique. Harman and Press (1975) suggested that a good panel of experts should have diversity, depth, and breadth so the selection did pay attention to these needs. They also pointed out that if the panelists are not strongly motivated to cooperate fully to the extent of providing introspective responses that are carefully considered, the survey may not be reliable. While some studies use motivational techniques such as honoraria or real time interaction, the subject matter of this research was expected to be sufficiently motivational for the participants.

While two groups are sufficient for a comparative Delphi study, the subjects for this study were made up of three expert groups. The researcher chose to attempt to use three expert groups, knowing that the dropout rate potential in a Delphi study could be high. Should the panel of writers be difficult to hold in numbers, triangulation with the research findings was available as a feasible substitute. In the case of superintendents, experts were chosen from the ranks of superintendents within British Columbia and across Canada who 
were committed to their own professional growth as a leader. Provinces with participating experts included Quebec, Ontario, and Newfoundland. The experts in British Columbia were located throughout the province to ensure that a range in district size and locale were represented in the sample.

In the case of CEOs, the experts were chief executive officers of corporations of a variety of sizes and representing various industries. The experts represented some of the largest resource companies in British Columbia as well as small firms in the service sector.

In the case of writers, potential experts were chosen from writers who had been published in the areas of both leadership and quality. These individuals reflected a sample from throughout Canada and the United States.

A sample population of 30 experts was identified in each group with a minimum goal of 15 experts per group expected to agree to serve on that group's panel. The total for the sample, which was referred to as "the panel", was expected to be a minimum of 45 members.

As the panelists were asked to provide information that could be politically sensitive to the position they hold, strict confidentiality of the participants and their responses was maintained. All participants were informed of the nature of the project and were required to sign a consent form indicating that their participation was totally voluntary. Panelists were permitted to ask questions about the research during the study and to withdraw from the research at any time. 
The panelists were expected to benefit from a study that necessitated their own clarification of the leadership behaviors that were examined. The researcher will also provide each panelist with a complementary summary of the results of the project within two to three months after the completion of the project. These results will be forwarded to the British Columbia Ministry of Education for their consideration in the ongoing revision of the parameters for district annual reports.

\section{Methodology}

This study called for a methodology that would enable participants to provide information from a variety of diverse locations in the country. It also required that ability to establish consensus among these participants in a manner that did not have them meeting face-to-face. Another characteristic of the methodology was the need for a future focus as the study was intended to look at behaviors that could be used in future annual reports. Finally, the methodology needed to be able to submit a ranking order to statistical analysis so that a determination could be made as to whether or not the null hypothesis would be accepted or rejected. The Delphi offered a methodology that satisfied these needs. It was a methodology that allows for consensus to develop among individuals who are not face-to-face. The methodology was developed by Rand specifically to look at future possibilities while the ranking methodologies were treatable by the Kendall W. Therefore, this was the methodology chosen for this study. (For further information on the Delphi, please refer to the literature review in Chapter Two.) 


\section{Data Gathering Techniques}

The Delphi sequence was carried out by initiating the gathering of information through the provision of an example of a leadership behavior (See Appendix C). For each behavior identified the respondent was asked to describe the behavior in no more than 25 words. The questionnaires on subsequent rounds provided information to the respondents about the degree of consensus and differences with regard to their information as provided on the previous round (See Appendices D, F, and G). The questionnaires served as a medium for group interaction of the expert panel in the process of generating the key behaviors that demonstrate successful leadership by the superintendent. The researcher responsible for collecting panel responses and preparing the successive rounds of questionnaires was identified as the moderator. Preliminary activities that took place included the pre-testing of the first questionnaire and identifying the three panels of experts. The purpose of the study and an explanation of the method were provided to participants and the researcher sought the informed consent of the participants by way of a form approved by the Human Subjects Committee (See Appendix C).

Each round required somewhat different activities on the part of the panelists and the moderator. The first round, begun in November 1994, sought the opinions of the expert panelists on which leadership behaviors of the superintendent were most likely to demonstrate successful leadership. The experts were also asked to provide a brief comment describing what the behavior was or how the behavior would manifest itself in the superintendent's actions. 
The second round, begun in February 1995, provided feedback to the panelists about how the panel as a whole responded to the first questionnaire. This information provided the basis for the second questionnaire in which the panelists were asked to review the leadership behaviors identified in the first round and to comment on their appropriateness. Each panelist was also sent a copy of his/her own responses to the first questionnaire so appropriate comparisons could be made and were not lost over time. An analysis of the written descriptions of what the behaviors look like was provided and further comment on each was sought from the panelists in the second round. Due to the low response of the writers, they were dropped and the study proceeded with only two panels: those of superintendents and CEOs.

In the third round, panelists were asked to review the behaviors identified in the second round. They were asked to rank the top seven behaviors in order of importance to a superintendent's successful leadership. Bunning (1979) indicated that three to four rounds are usually needed to bring the study to a conclusion. Hence, three rounds for this study were felt to be sufficient.

\section{Data Analysis}

The data generated in the study was analyzed according to the procedures of a classical Delphi study. The information from the first questionnaire was synthesized into one list to form the questionnaire for the second round. This included a synthesized descriptor of each behavior (See Appendices $D, E$, and F). 
Demographic data identified superintendents and CEOs who were currently involved in a district or company that had adopted and was implementing a plan of continuous quality improvement. From this data, a nested subgroup of five superintendents and five CEOs was intended to be determined. However, the limited number of responses indicating that the organization was involved in a formal quality improvement program eliminated the possibility of establishing such a nested subgroup.

The second round questionnaire included an opportunity to add any item that did not appear in the synthesis of the first round. An analysis of Round Two was undertaken to establish behaviors suggested along with a description for the third round. The third round questionnaire contained five items written in by participants that did not appear on the second round questionnaire sent to panelists.

Panelists were asked to rank the seven top behaviors in order of importance in Round Three (See Appendix G). The rankings were statistically analyzed using Kendall $W$ and yielded a coefficient of concordance. The null hypothesis was that the two populations had no common rankings for behaviors.

\section{Triangulation}

The data gathered from the panelist groups in Round Three was triangulated with the findings of the research [literature] review undertaken for this study. The data was also linked to Deming's 14 points (1986) to confirm that the behaviors were comparable to those identified by leading experts in the field 
of quality (See Appendix H). This procedure added to the strength of this study. The final analysis of data occurred at this time.

\section{Limitations of the Research Design}

Certain limitations have been noted by authors that may apply to the use of the Delphi technique. Delbecq et al (1975) listed three critical conditions that were required to complete a successful Delphi: adequate time; participant skill in written communication; and motivation. These conditions require that the panelists be willing to commit to participation in a long-term project several months in duration. As the panelists were in positions that can be particularly demanding of one's time, a higher mortality rate than in one survey study was expected. While written skill was not seen as a likely deficiency in the expert panel, in actuality it may have been a limitation for some who had trouble containing their descriptions to 25 words or less.

Uhl (1983) noted that when using the Delphi technique for social research it is not possible to check the plausibility of expert responses. Given this limitation and that a random sample was not being used, the results cannot be generalized for all districts but could be helpful in providing a foundation to create parameters for reporting the superintendent's leadership success in behavioral terms to the customers. The parameters could be useful in developing any report adaptations for the circumstances found in particular districts. 
Bunning (1979) also listed limitations regarding the expertise of the panelists when using a Delphi study. Those which applied to this study include: important possibilities that are overlooked; the heavy expenditure of time in completing the questionnaires; and unquestioned beliefs and values that limit the ability to foresee basic changes and goals.

A number of assumptions underlay the basis for this project. The researcher assumed that behaviors that relate to a leader's success could be identified. The assumption was made that the 30 panelists who agreed to participate gave thoughtful consideration to the subject matter. Another assumption was made that the position or vocation of the panelists gave them the necessary expertise to deal with this subject.

The findings of the study are displayed, statistically and graphically, in Chapter Four. 


\section{Chapter Four: Findings of the Study}

The purpose of this study was to develop a list of priorized behaviors to serve as indicators of a superintendent's success as a leader in a school system seeking continuous quality improvement. Chapter Four deals extensively with the findings of the study. The results of each round of the Delphi are detailed, as are the demographic data of the panelists and their organizations. The findings in this chapter are presented in the following order. First, the Delphi analysis is presented to show how consensus on the behaviors was developed. Face validity is discussed next and then the results of each round are reported. A thorough demographic analysis of the panelists and their organizations is provided in Figures 1-5. An analysis of the study's findings is presented by way of a discussion of congruence of some behaviors and discrepancies among others. Finally, comment is made on triangulation of the results and a chapter summary is provided.

The findings of this study were based upon the counsel of an expert panel of 30 , consisting of 15 superintendents and 15 CEOs. These leaders participated in all three rounds of a Delphi study that culminated in the identification of 31 behaviors seen as essential to successful leadership by a superintendent of schools. The top seven behaviors have been identified in priority order and triangulated with the research [literature] review and Deming's 14 points (1986). 
Of the first 30 superintendents selected from the B.C. public school listing and from the Canadian Association of School Administrators' leadership academy and executive listing, 18 participated in Round Two and 15 in Round Three for a final return rate of $50 \%$.

Of the 25 CEOs selected from the Board of Trade listing and the West Vancouver School District's partnership list, 16 CEOs participated in Round Two and 15 in Round Three for a final return rate of $60 \%$.

Of the 20 writers selected from the list of recently published leadership books, one writer participated in Round One. Thereafter, the writers' panel was dropped in favor of the triangulation with research and Deming's 14 points (1986).

The demographic characteristics of the panel and the consensus results of the three rounds of Delphi methodology are described in this chapter. The expertise of the panel is impressive with some of the longest serving superintendents in B.C. and CEOs from some of the largest resource corporations in the province responding. The latter sections of the chapter present the findings of each of the three rounds of the Delphi. Since the research process is an emergent one, the final round feedback from the panelists records the result. 
Delphi Analysis

The Delphi analysis involved three iterative rounds. Round One required that the participants identify five to seven behaviors and give descriptions of each behavior in 25 words or less. In the first round, the moderator received three telephone calls where two panelists sought clarification of the process and two others commented on how difficult they found the request to clearly define the behavior. Three of the panelists who called indicated that they had spent between two to four hours responding to the first survey indicating that they had given the exercise serious consideration.

The first round of responses was synthesized and Round Two began with a questionnaire that listed 24 behaviors for consideration and possible revision. Panelists were asked to add any additional behaviors omitted from the information gathered on the first round that are essential to successful leadership by a superintendent of schools. Seven new behaviors were added and a number of revisions were made to the original 24 (See Appendix G).

In the final round, the panelists were asked to rank the top seven behaviors. The rankings were determined by recording the total number of times an item was scored in the top seven behaviors and the total number of points ascribed to each rank. The points were assigned as per the following scale: first (1) place ranking $=7$ points; second $(2)=6$ points; third $(3)=5$ points; fourth (4) $=4$ points; fifth $(5)=3$ points; sixth $(6)=2$ points; and seventh $(7)=1$ point. $A$ mean was calculated for each behavior based upon the points assigned divided 
by the number of times selected by panelists. Finally, rank based on the total number of points was assigned for each group and for the total panel response.

The rank indicated the consensus of the panel. In the case of CEOs, 24 behaviors were chosen for ranking; in the case of superintendents, 22 behaviors; and for the total response, 26 behaviors were selected.

\section{Face Validity}

The face validity of the instrument was confirmed by the acceptance of the three members of the dissertation committee. The Ministry of Education in B.C. accepted the goal of the writer and had input into the direction of the study with the intent of using the findings to develop a system of reporting on the leadership success of the superintendents. The results of the study have demonstrated congruence with leadership theory and the Quality Movement. Finally, the information gathered will be used by organizations such as the Canadian Association of School Administrators to develop professional development programs for superintendents.

\section{Demographic Analysis}

The demographic data was obtained during Round One of the Delphi process. During that time the panelists were asked to complete a questionnaire that sought both personal and institutional data (see Appendix C). The criteria for the selection of the panelists were that they had to be superintendent (or equivalent) of a public school district, which in the case of Quebec and Ontario 
meant Director General and Director respectively. The CEOs were required to bear the title of chief executive officer.

\section{Panelist Data}

The age and gender of the panelists are indicated by Figure 1. The majority of panelists (60\%) were males in the $51-60$ age range with eight CEOs and eight superintendents falling into this category. Only one CEO and two superintendents were female and in both cases they were under 50 years of age.

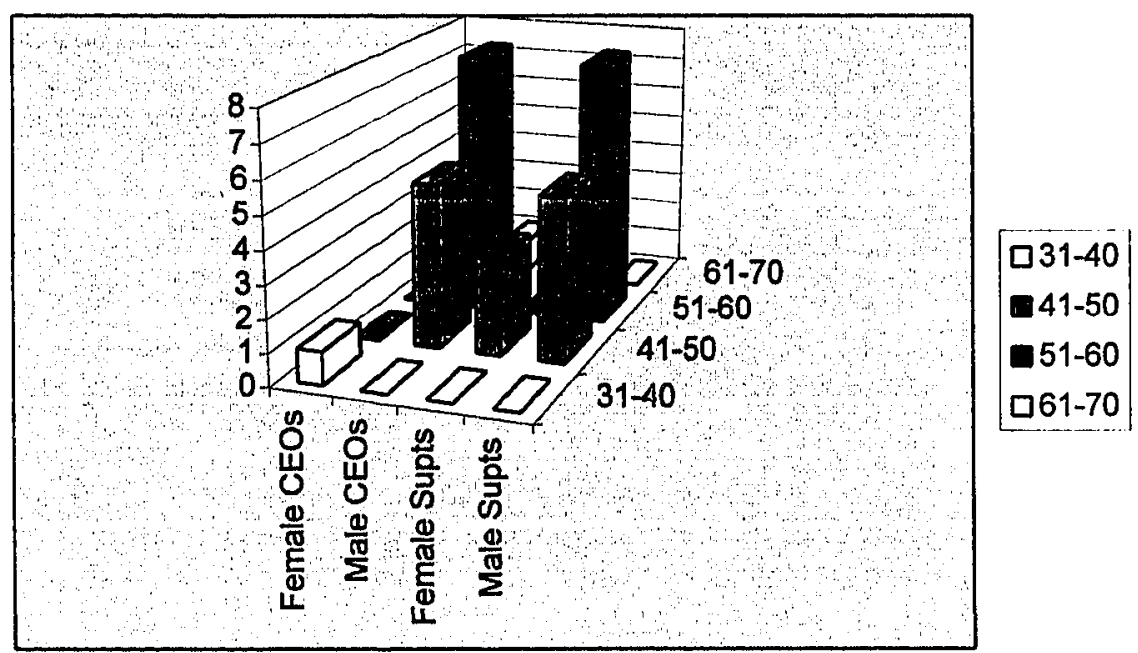

Figure 1. Comparable age and gender of study participants 
The number of years in present positions is indicated in Figure 2. From the data, it is apparent that the CEOs have been in their positions longer than superintendents; and CEOs have a longer range of service (1 to 30 years) than do superintendents ( 1 to 11 years).

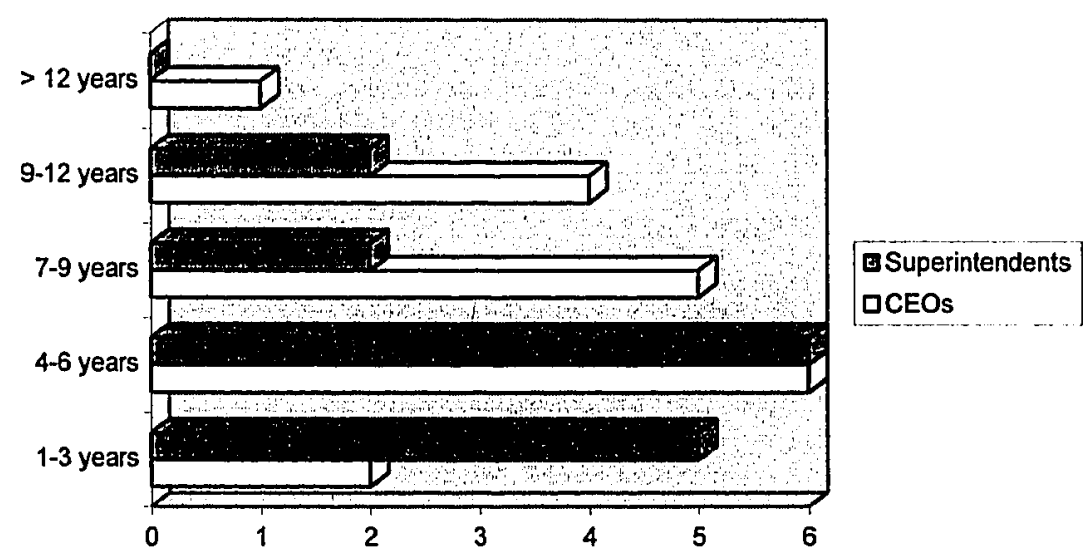

Figure 2. Comparative years of service of study participants

The superintendent's responsibility, when measured in number of employees supervised, tends to be greater than that of the CEOs. Figure 3 indicates that the CEOs are leading primarily small businesses whereas the superintendents have larger organizations based on the number of employees. However, the panelists in each category do cover a range of organization from small ( $<500$ employees) to very large $(>3,500$ employees). 


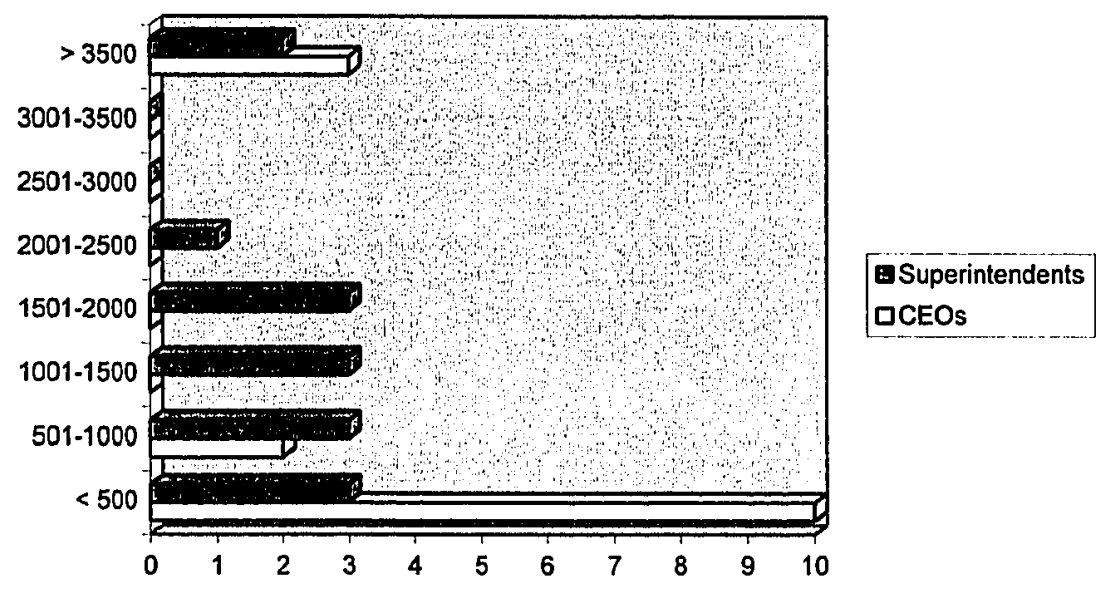

Figure 3. Comparative size of organizations of survey participants

The desire to have the superintendents be representative of a cross section of the province has been accomplished as shown in Figure 4. Representation has been garnered from each distinct geographical area in the province as well as from the Maritimes, Quebec and Ontario. No responses were received from selected panelists in the Prairie provinces.

While all the CEOs are based in the lower mainland region of B.C., their enterprises operate both throughout B.C. and the world. The businesses represent resource sectors such as mining, forestry, and energy as well as service sectors such as telecommunications, health, and marketing. 


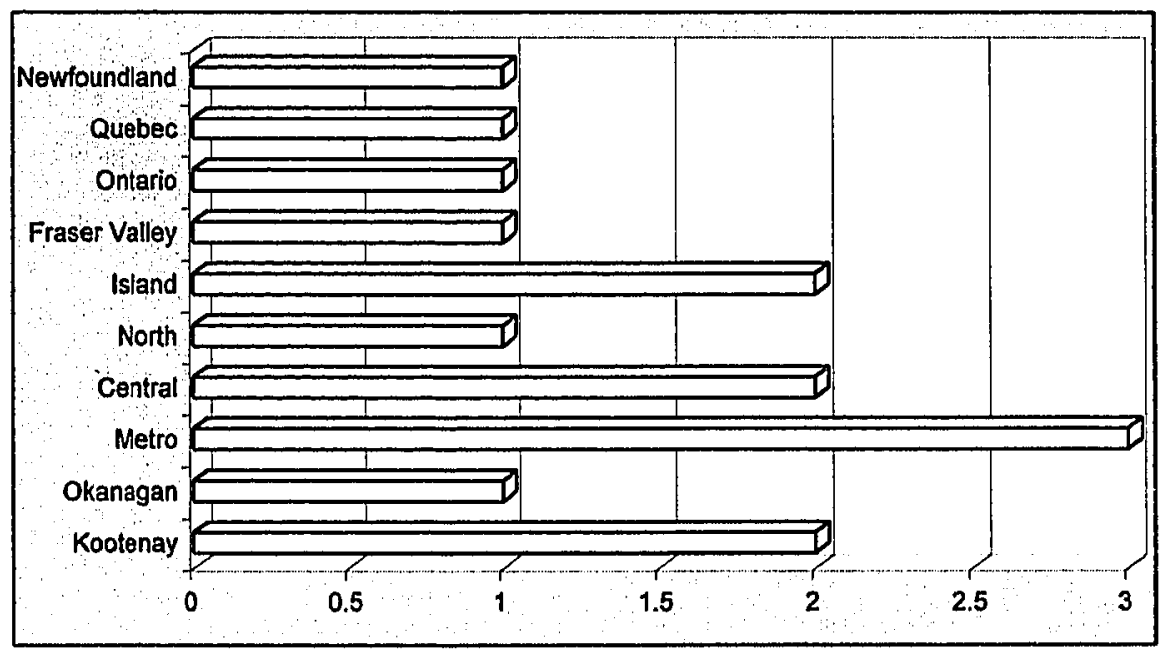

Figure 4. Geographic location of superintendents participating in study

While the intention of the study was to establish sub-nest groups of each category of organization with a formal Total Quality program in operation, only three CEOs and no Superintendents reported having implemented formal Total Quality programs (See Figure 5). 


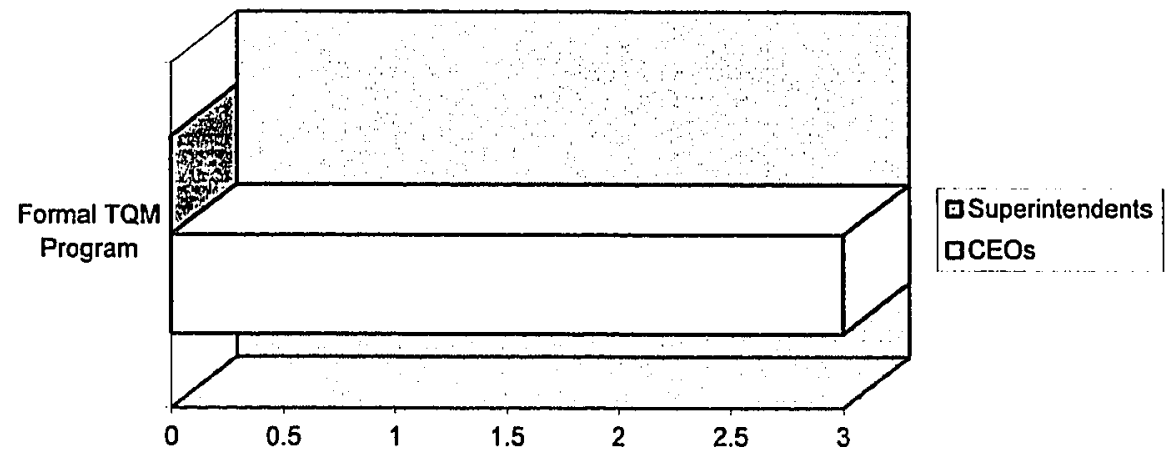

Figure 5. TQM program activity of study participants

\section{Results of the Rounds}

The results of Round One were collected and key words from the 24 submissions were identified as possible behavioral indicators. For each indicator, the text and similar wordings were then grouped for analysis and synthesis. The analysis categorized similar concepts for the naming of the behavior. For example, the following descriptors were drawn from the first round and grouped to identify one indicator: (a) walking around; (b) visible; (c) visibility; (d) visible presence; and (e) leads by example. Then, descriptors drawn from the panelists' submissions outlining the indicators were identified. In this example, the following descriptors were listed: (a) required no descriptor; (b) interaction with people; (c) observed throughout the district and community; (d) to be seen and leads by example; and (e) a positive model of desired attitudes. 
The researcher then developed the behavioral indicator and the description of that behavior to formulate the questionnaire for Round Two. In the case of this example, the indicator was exhibits a visible presence by employing Management By Walking Around (MBWA) and the description of the indicator was "spends time in the field interacting with personnel at all levels of the organization and within the community".

Thus, the researcher employed the actual words that were submitted by the panelists allowing only for changes to ensure correct grammar and syntax in the synthesis. Appendix E shows the actual boldfacing of key words that established the basis for the indicator and description. Appendix $F$ shows the listings for each indicator and description that was garnered from Round One.

In total, 26 behaviors and descriptors were determined to be unique and were synthesized for inclusion in the survey instrument for Round Two.

Round Two brought responses from 18 superintendents and 16 CEOs. Revisions were relatively minor although important enough to have impact. For example, as a result of a suggestion for revision, the indicator example used earlier was adjusted for Round Three to read: "exhibits a visible presence by employing Management By Walking Around (MBWA) electronically and physically" [author's emphasis]. This added a new dimension to the indicator that was more in keeping with the Information Age and the requirements of B.C. superintendents to stay "tuned in" to the Internet via the Community Learning Network access provided by the Ministry of Education. 
Round Two also saw the addition of five behaviors to the original list of 26 . The additions were submitted in four returns. Two of the additions were submitted by superintendents and three were submitted by CEOs. The list of 31 behaviors was then compiled and returned to the panelists for the third round. (See Appendix G)

In Round Three, the panelists were asked to rate the top seven behaviors that would lead to a superintendent's success. They were asked to rank these top seven in order of importance using (1) to represent the most important behavior and (7) to represent the least important behavior. There were responses from 15 superintendents and 15 CEOs. The results of this round are included in Appendix 1.

The top seven behavioral indicators as chosen by superintendents (in order of priority) were:

1. focuses on the primary activity of the organization -- learning.

2. develops, shares, and focuses on a vision of the organization that leads to the future.

3. maintains ethical standards and integrity.

4. builds, maintains, and fosters relationships within and without the organization.

5. ensures that leadership is participatory in nature and/or encourages decisive decision making by teams at the "action level".

6. builds trust.

7. creates and nurtures a Learning Community culture. 
The seven behavioral indicators chosen by the CEOs (in order of priority) were:

1. develops, shares, and focuses on a vision for the organization that leads to the future.

2. communicates continuously and effectively.

3. builds, maintains, and fosters relationships within and without the organization.

4. maintains ethical standards and integrity.

5. creates and nurtures a Learning Community culture.

6. identifies, selects, and keeps strong staff in appropriate placements.

7. focuses on the primary activity of the organization -- learning.

The seven behavioral indicators chosen when the results of the two populations are combined were:

1. develops, shares, and focuses on a vision of the organization that leads to the future.

2. focuses on the primary activity of the organization -- learning.

3. maintains ethical standards and integrity.

4. builds, maintains, and fosters relationships within and without the organization.

5. ensures leadership is participatory in nature and/or encourages decisive decision making by teams at the "action level".

6. communicates continuously and effectively.

7. creates and nurtures a Learning Community culture. 


\section{Analysis of Rankings}

The one statistical analysis that was applied to analyze the results of these selections was the Kendall $W$ which is a test of significance where there is a ranking of items. The null hypothesis stated that the two populations had no common rankings for the behaviors. The statistical analysis revealed that the probability is .106 assuming a chi-square distribution with one degree of freedom. The Kendall coefficient of concordance equals .084 . Therefore, the null hypothesis was rejected at the .05 level of significance.

The analysis revealed a trend towards agreement that indicates the two populations are approaching a common ranking or a common theme. Thus, this analysis supported the view that there is some commonality in the rankings but some differences also exist.

The examination of each behavioral indicator's ranking reveals particular nuances in the results. While "vision" is ranked first by CEOs and second by superintendents, the number of times this was selected (12) is equally high by each group. Hence, this indicates that vision is seen as a key behavioral indicator by both populations. Moreover, when one notes that the superintendent's first choice is "focusing on ... learning", an indicator which relates directly to the purpose of a school district, one can hypothesize that there is concurrence on the first priority for the behavior that will lead to a superintendent's success. 
However, quite a different perspective can be gleaned from the second ranking by the CEOs. They rank "communication" very high with a full two thirds of the CEOs ranking this indicator in the top seven. The superintendents, on the other hand, ranked this behavioral indicator as 11 th and only one third of the superintendents ranked this indicator in the top seven. This issue will be examined in the recommendations in the next chapter.

Worthy of note is that both populations chose to rank the indicator relating to "fostering relationships" similarly. This is directly related to the definition of leadership used for this study which states that "leadership is an influence relationship". Ranking this behavioral indicator with equity indicates that the leaders who acted as panelists appear to operate on a post Burns (1978) mode of transformational leadership with emphasis on the relational nature of leadership.

Similarly, both populations ranked "creating a learning community culture" in the top seven, with a similar number of panelists from each population choosing this indicator. This is an indicator that relates to the continuous learning aspect -- an important component of the Total Quality Movement.

Emphasis is also placed upon the participatory nature of decision making when in a Total Quality environment. While CEOs ranked this eighth and superintendents fifth, this indicator ranked fifth for the combined groups. While these leaders indicated that only three operated in an organization that had a formal Total Quality program, the indicators they have chosen most frequently tend to be directly related to the criteria used in the Baldridge awards. An 
examination of the seven indicators chosen by the combined populations reveals that each of the indicators is directly related to the Total Quality movement as identified in Deming's 14 points (1986).

Another behavioral indicator that received three times the number of selections by CEOs over superintendents, and yet did not make the top seven, was the indicator of "recognizing and rewarding excellence". This behavior is directly related to the Total Quality movement and yet only two superintendents chose this indicator in their rankings.

Similarly, the behavioral indicator ranked sixth by the CEOs, with double the number of selections compared to the superintendents and with a large rank discrepancy, deserves some examination. The indicator "identifies, selects, and keeps strong staff in appropriate placements" is only ranked 17 th by the superintendents and yet the effective operation of a school district requires strong, qualified, and motivated staff. An issue that may have affected this discrepancy is the dominant position of clauses in the union contracts in many districts in B.C. that reduce the ability of the leaders to identify and select staff from the market.

Figure 6 provides a graphic of how the top seven behaviors chosen by the participants relate to Deming's 14 points. For example, "builds trust", which was chosen as one of the top seven seven behaviors by the superintendents, relates directly to Deming's eighth point (drive out fear) and ninth point (break down barriers). 


\section{Triangulation}

To confirm the results and strengthen this study, the top seven behaviors of the combined group were triangulated with both the research contained in the literature review and Deming's 14 points (1986). He identified these 14 points as principles of transformation of Western management and they became cornerstones of the Quality Movement. The results of this triangulation can be seen in Appendix $\mathrm{H}$ as well as graphically in Figure 7. Confirmation of the identified behaviors was found in 20 of the studies in the research [literature] review and linkages were found with nine of Deming's 14 points.

Table 1 provides the triangulation in chart form. This chart triangulates behavior and the relevant points from Deming's list of 14. The chart also provides the rankings given each behavior by the superintendent and also by the CEOs. 


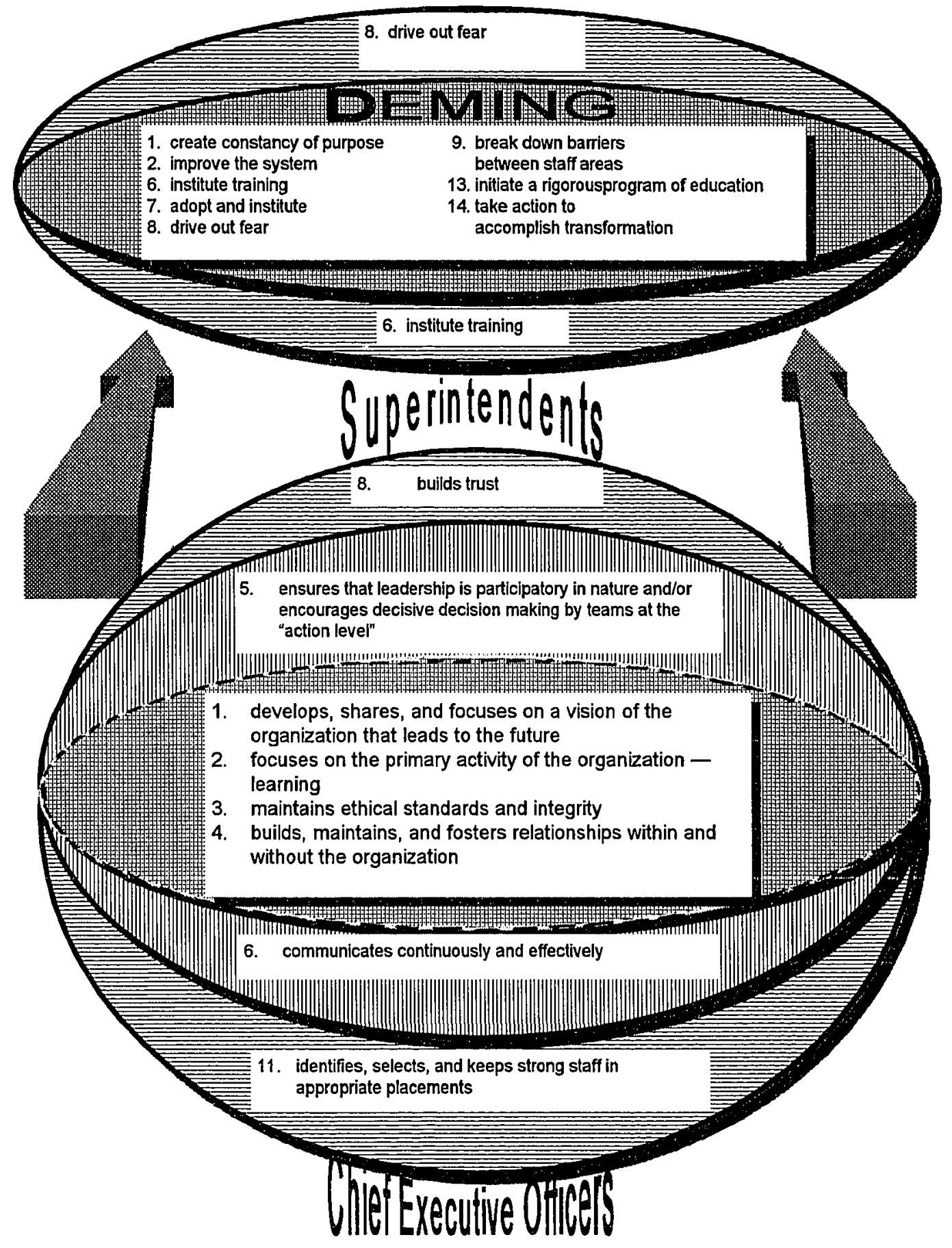

Figure 6. Top seven choices of behaviorai indicators of a superintendent's leadership success as chosen by superintendents and CEOs 
Superintendents' Top Seven

7. Creates a learning community

6. Builds trust

wa:

5. Ensures leadership is participatory

4. Builds and fosters relationships

ain

3. Maintains ethical standards and intregrity

min

2. Vision

Enan

1. Focus on learning

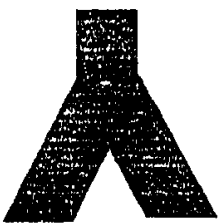

1. Vision 1. Constancy of purpose

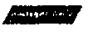

2. Communicates continuously

2. Improve the system

3. Builds and fosters relationships

6. Institute training

sams

4. Maintains ethical standards and integrity

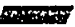

5. Creates a learning community

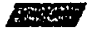

6. Selects and keeps strong staff ...

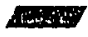

7. Focuses ... on learning

CEOs' Top Seven
7. Adopt and institute leadership

8. Drive out fear

9. Break down barriers between staff areas

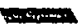

13. Initiate a rigorous program of education

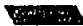

14. Take action to accomplish the transformation

Deming's 14 Points

Figure 7. Triangulation of participant's top seven behavioral indicators 
Table 1

Triangulation of the Top Seven Behavioral Indicators with Group Selections and Deming's 14 Points

\begin{tabular}{|c|c|c|c|}
\hline Behavior & $\begin{array}{l}\text { CEO } \\
\text { Rank } \\
\end{array}$ & $\begin{array}{l}\text { Supt } \\
\text { Rank } \\
\end{array}$ & $\begin{array}{l}\text { Deming's } \\
14 \text { Points }\end{array}$ \\
\hline $\begin{array}{l}\text { Develops, shares, and } \\
\text { focuses on a vision of } \\
\text { the organization that } \\
\text { leads to the future }\end{array}$ & 1 & 2 & $\begin{array}{l}\text { Point 1: Create a constancy of } \\
\text { purpose for improvement of } \\
\text { product and service. }\end{array}$ \\
\hline $\begin{array}{l}\text { Focuses on the primary } \\
\text { activity of the } \\
\text { organization -- learning }\end{array}$ & 7 & 1 & $\begin{array}{l}\text { Point 7: Adopt and institute } \\
\text { leadership }\end{array}$ \\
\hline $\begin{array}{l}\text { Maintains ethical } \\
\text { standards and integrity }\end{array}$ & 4 & 3 & $\begin{array}{l}\text { Point 12: Removes barriers } \\
\text { that rob people of pride in } \\
\text { workmanship }\end{array}$ \\
\hline $\begin{array}{l}\text { Builds, maintains, and } \\
\text { fosters relationships } \\
\text { within and without } \\
\text { organization }\end{array}$ & 3 & 4 & $\begin{array}{l}\text { Point 9: Breakdown barriers } \\
\text { between staff areas } \\
\text { Point 5: Improve constantly } \\
\text { and forever the system of } \\
\text { production and service. }\end{array}$ \\
\hline
\end{tabular}


Behavior

CEO Supt

Deming's

Rank

Rank

14 Points

Ensures that leadership

Point 9: Breakdown barriers

is participatory in nature

8

5 between staff areas

and/or encourages

decisive decision making

by teams at the "action

level"

Communicates

Point 8: Drive out fear

continuously and

2

11

effectively

Point 14: Take action to accomplish transformation

Creates and nurtures a

Point 6: Institute training and

learning community 5

7 retraining

culture

Point 13: Initiate a rigorous

program of education and

training

\section{Summary of the Findings}

The three rounds of the Delphi process developed a total of 31 behavioral indicators that were seen to be essential to successful leadership by a 
superintendent of schools. The rankings that were finally given to these indicators resulted in 24 choices by CEOs, 22 choices by superintendents and 26 choices overall.

Analysis using the Kendall coefficient of concordance revealed no significant difference at the .05 level of significance but it did reveal a trend toward common rankings. A closer examination of the behavioral indicators chosen demonstrates that each of the top seven chosen by the combined group relates directly to a Total Quality program as identified by Deming (1986).

Some differences existed in the rankings by the two populations which deserve comment that will be given in Chapter Five. It was also evident that the choice of the indicators did support the definition of leadership given in this study which defined leadership, in part, as "an influence relationship".

The findings suggest that there are common behaviors seen by both CEOs and superintendents as keys to successful leadership. This finding suggests that similar behaviors of leaders in education and in business are required to achieve success. Thus, the dichotomy that is often made between education and business does not appear to be as distinct at the top level of leadership.

These findings lend credence to the potential for importing some professional development programs from business to education. The results suggest that programs that develop the seven top ranked behaviors may be 
applicable to each group suggesting professional development may even be carried out jointly.

The triangulation of the findings suggests that these behaviors are important in the context of a Total Quality program. Thus, leaders in either education or business, who are pursuing TQM should address the need to act in a manner that emphasizes the identified behaviors.

Chapter Five will present the conclusions drawn from these findings. It will also recommend areas for further study. 


\section{Chapter Five: Summary, Conclusions, and Recommendations}

Chapter Five contains the summary, conclusions, and recommendations of the study. In many Canadian provinces an annual report is produced by every school district. This document reports to the public a variety of indicators that demonstrate the success being achieved by the district. None of the reports contain any specific indicators of the level of success of the superintendent. This study sought to create a list of behaviors that could serve as indicators of a superintendent's success as a leader in a quality environment, thus enabling some assessment and reporting of that success to the public.

The purpose of this study was to develop a list of priorized behaviors to serve as indicators of a superintendent's success as a leader in a school system seeking continuous quality improvement. This was accomplished by conducting a Delphi (Linstone \& Turoff, 1975) study using three groups of experts. The first group consisted of individuals in academic fields involved in the research and study of leadership and recognized writers who had written in the field of leadership in education and business. Business leaders from British Columbia, in particular CEOs, constituted a second group. The third group consisted of selected superintendents within Canada. A nested sub-group of superintendents and chief executive officers was to be used to determine if a difference existed between systems that were involved in a total quality program and those that are not involved in a total quality program. 


\section{Objectives}

The objectives of this research were stated in the form of three research questions. Two corollary research questions determined the remaining objectives. These questions were as follows:

1. What superintendent behaviors constitute successful leadership?

2. What is the perceived order of importance, by each group, of the identified behaviors as the behaviors relate to leadership success?

3. Do perceived differences and ranking of the behaviors exist among or within each group?

The corollary research questions were:

1. How can knowledge about leadership success be reported to educational stakeholders via the British Columbia annual report system?

2. Can behavioral indicators provide a foundation upon which to build a leadership growth and development plan for the superintendent?

\section{Methodology}

This study called for a methodology that would enable participants to provide information from a variety of diverse locations in the country. It also 
required that ability to establish consensus among these participants in a manner that did not have them meeting face-to-face. Another characteristic of the methodology was the need for a future focus as the study was intended to look at behaviors that could be used in future annual reports. Finally, the methodology needed to be able to submit a ranking order to statistical analysis so that a determination could be made as to whether or not the null hypothesis would be accepted or rejected. The Delphi offered a methodology that satisfied these needs. It was a methodology that allows for consensus to develop among individuals who are not face-to-face. The methodology was developed by Rand specifically to look at future possibilities while the ranking methodologies were treatable by the Kendall $\mathrm{W}$. Therefore, this was the methodology chosen for this study. (For further information on the Delphi, please refer to the literature review in Chapter Two.)

Using a Delphi process, 31 behavioral indicators of a superintendent's leadership success were identified and described. This chapter discusses, in depth, the seven top behaviors identified in the combined panelists' rankings. Each behavior is examined as it applies to quality leadership in an educational setting pursuing a TQM environment. Secondly, this chapter also focuses on the issues that surfaced from the rankings of some of the other 31 behaviors. The applicability of these behaviors to the corollary research questions is discussed in the form of suggestions. Finally, the strengths and weaknesses of this study are addressed along with conclusions and recommendations for further study. 


\section{Discussion of Findings}

A discussion of the top seven behaviors can be misleading. While these seven behaviors have been chosen as the top seven through statistical calculation, it is important to understand that in a quality environment, the behaviors are interdependent and should be treated as such. Isolation of a single behavior, while purposeful for discussion, is not a sensible way to measure success. Rather the behaviors must be seen as a totality whose combined effect leads to quality leadership and the measurement of the same.

The behavior that received the top ranking in this studying was "develops, shares, and focuses on a vision for the organization that leads to the future". This behavior forms the cornerstone of the Quality Movement as it relates to both Deming's first point, and is also the behavior referred to most often in the review of the literature. The superintendent's responsibility is to see that such a vision is in place and to keep that vision in the forefront. This can be done by ensuring that all decisions by the Board and staff align with the vision.

How a vision is created in the system is also important. While it is up to the superintendent to establish a vision, the process through which it is created can vary. In a quality organization, "visioning" is a collaborative process and should involve the fifth ranked behavior that is "participatory decision making". The overwhelming selection of "visioning" as the most important behavior suggests that superintendents involved in this study were oriented to quality practices even though no one superintendent indicated that there was a formal quality program operating in their district. 
The behavior ranked second by the combined group relates directly to the first behavior. It was "focuses on the primary activity of the organization -learning". Learning is the primary reason for school systems existing. One would expect, therefore, that any vision statement would relate to this area. The description of the behavior is worthy of note. The description is "managing attention by directing the focus of employees to what is best for student learning". The behavior depends upon communicating and relating, which are two other top ranked behaviors. The notion of relationship supports the definition of leadership used in this study which was: "the influence relationship that brings about positive intended change in an organization by transforming followers into leaders while bringing out the best in both". Relationships are also the foundation of the new paradigm of transformational leadership (Yukl, 1989).

This behavioral description raises the issue of how a superintendent manages or directs the attention of employees to focus on that which is best for students, viewed as learners. This behavior is also an area in which there is potential for developing specific strategies for a superintendent's growth and development. Deming is quite clear that, in order to be quality leaders, superintendents must know the work that they supervise to ensure that they never lose touch with the learners throughout their districts. Only by being present in the classrooms can the superintendent understand the needs of teachers and, through appropriate goal setting, focus the resources of the district upon the classroom needs.

The third behavior, that of "maintaining ethical standards and integrity", gives the superintendent long-term credibility in relationships. Of note here is the 
need, not only for the leader to model integrity in professional relationships, but also to teach and to hold the team of administrators accountable for ethical standards in decision making. A basic course in ethics should be required of leaders in the field, perhaps as part of an ongoing credentialing program for superintendents.

A servant leadership model should be considered as a means to maintain this behavior. Superintendents need to be sure that any decision made is, on balance, serving the needs of those most affected by the decision. The decision must always fall within the legal bounds of both the laws of the land and Board policy. Superintendents, seeking to maintain integrity, must be sure that any decision taken is one of which they can be proud.

The behavior ranked fourth indicates that superintendents who served as panelists in the study have shifted to a new model of leadership that has relationships as its foundation. "Building, maintaining, and fostering relationships within and without the organization" is essential in a quality environment. The Japanese used this Deming principle, and moved very quickly into the economic forefront by establishing relationships with suppliers that did not rely solely on the competitive low bid. School systems need to learn from this. Governments need to change legislation that requires accepting only low bids.

School systems also need to develop relationships with business partners so that the needs of students are being met through more profound knowledge of what awaits them beyond their years of formal schooling. The superintendent 
has a major responsibility in cultivating and facilitating the relationships between the school system and the external world.

The importance of this behavior cannot be under-estimated within the system. Relationships need to be developed between personnel in secondary schools and feeder schools, as well as within the schools themselves. The isolation that can occur within the school setting must be broken down, and only through modelling of this behavior by the superintendent will the whole system begin to pay greater attention to the relational nature of leadership.

The fifth behavior was "ensures that leadership is participatory in nature and/or encourages decisive decision making at the "action level". This behavior requires that leadership be participatory and that teams be empowered to make decisions closest to the action. This is a key quality principle espoused by Deming that also received support from the literature review. However, the demographics, specifically the ages of superintendents, indicate that these leaders were raised in a culture that operated on hierarchical principles. This means that the practice of participatory decision making may not be in their repertoire of skills. This suggests another area in which there should be programs designed to support the professional growth and development of superintendents.

Decision making should be examined from a systems point of view with the intent of instituting more participatory leadership practices within school districts. A specific suggestion would be to include the union leaders as part of 
the executive decision making process, while at the same time, ensuring that staff are involved in a collaborative manner in site based decision making.

"Communicates continuously and effectively" was ranked sixth by the combined group. This behavior, however, had the largest discrepancy between the two panels. A discrepancy such as this, raises cause for concern, because this behavior is delineated in two of Deming's principles and is seen as an essential characteristic of a quality organization. However, only one third of the superintendents even ranked this behavior. Just as in real estate, the adage is "location, location, location"; the quality leadership paradigm in a school system requires the adage "communication, communication, communication". In the past, superintendents have often kept data, such as budgets and achievement results, as a means of increasing their power. In an era of leadership through relationships, the information is needed for honest communication. In a quality organization, information is free flowing and all data is treated as friendly data. If negative information is forthcoming, then it is used as an opportunity for continuous improvement. Collaboration requires that those involved have the full picture in order to make decisions that are in the best interest of the system.

The low rating of this behavior by superintendents suggests an immediate need for directing the attention of the superintendents to this critical behavior. Freedom of information legislation, that is being passed in every province in Canada, will require that a superintendent become a master communicator as there will no longer be an opportunity to prevent the free flow of data to all citizens and employees. 
The fact that CEOs seem to have a better understanding of the importance of this behavior suggests that this is an area where successful programs and practices exist in the private sector. Perhaps some of these successful programs and practices can be imported from business to the educational environment. Xerox's 'Leading in the $90 \mathrm{~s}$ ", for example, offers an industry training program that focuses on communication. Communication, therefore, is a behavior that requires attention not only as an indicator but also as a need for professional growth and development.

The final behavior in the top seven was "creates and nurtures a learning community culture". No doubt the current impact of authors, such as Senge (1990) and Sergiovanni (1992), have had an impact on the choice of this behavior. In spite of its current popularity, in a school system, however, this behavior should have been an expected practice. Learning is what schools are all about. The schools or districts are communities within themselves. For the purpose of this study it is important to note, that two of the fundamental principles of quality suggested by Deming also emphasize the "learning community culture".

The fact that more CEOs than superintendents ranked this behavior indicates that business and industry are more acutely aware of the rapid changes taking place in the world and recognize that lifelong learning leads not only to quality; but also to survival. School systems have been much slower to change. Superintendents may be paying lip service to the concept, and not fully understand that each and every employee must be a continuous learner if the system is to reach its full potential. Superintendents need to model this 
behavior; the description captured its essence well. It stated that the superintendent needs to actively "foster a learning community by demonstrating a personal unquenchable thirst for knowledge while providing and supporting opportunities for growth".

The top seven behaviors chosen and discussed above, are linked directly to the Quality Movement and provide a list of behaviors that, when taken together, constitute successful leadership on the part of superintendents. The first two research questions of the study sought to identify and rank behavioral indicators of a superintendent's success. This was done. The third research question asked if there were perceived differences within or between the groups. The small sample did not allow an analysis within the panelist groups. There were, however, some issues raised by the differences in the rankings between groups. The difference in the ranking of communication as a behavior has been dealt with, but other discrepancies outside of the top seven also existed.

\section{Discussion of Discrepancies in Rankings}

In examining the data, discrepancies were found and analyzed. Five of the discrepancies merit further discussion.

The first discrepancy was found in the 11th ranked behavior of "identifies and keeps strong staff in appropriate placements". This behavior was ranked sixth by CEOs indicating that a very high priority for business and industry. On the other hand, superintendents ranked this behavior 17 th, which raises the issue of whether this activity received the priority that it should have received 
from the superintendents. A possible explanation lies in the state of teacher employment contracts in British Columbia and other provinces that have clauses dictating hiring procedures. This is an area that should be considered in the current provincial negotiation process. As this is seen as a very important behavior in business and industry, the responsibility for staff selection and placement should not be abrogated by senior staff. There needs to be the leeway, in any provincial contract, for superintendents to meet the needs of children through the appropriate placement of staff based upon each teacher's unique skills and abilities.

A second discrepancy in the ranking of behaviors was the indicator that stated that a successful superintendent "demonstrates/cultivates superintendents-board relationships by facilitating effective, informed board decision making". Ranked ninth by the superintendents, this behavior is a high priority and one which personal experience suggests requires between 40 and $60 \%$ of a superintendent's working time. The expertise and demands of lay boards vary, but the politics of this form of governance often place the superintendent in a survival mode. This can cause the focus of the superintendent to be directed to matters of politics, rather than education. While every organization suffers from its own internal politics, the ranking discrepancy here indicates that a superintendent's role results in their taking a different approach in working with their school board than a CEO would take in working with a corporate board. The question in a quality environment is whether the time and attention given by superintendents to this activity results in any improvement to the system. 
It would be doubtful that the needs of children are better served if a superintendent's attention is directed too often to the political aspects of the job. This discrepancy suggests that every school board should examine the demands placed by its trustees on the superintendent to determine if they meet Deming's quality principles of maintaining a constancy of purpose and driving out fear. Often the demands placed on a superintendent by a board result from a lack of clear understanding of each other's role. The time requirements for cultivating this relationship could be reduced by a clear understanding of roles. The superintendent should concentrate relationship building on the chair of the board. Additionally, semi-annual private meetings between the entire board and the superintendent, where open and honest feedback was shared on each other's perceptions of performance, could assist in driving out any fear that hampered the quality performance of both the superintendent and board members.

A third discrepancy in the rankings was seen in the different rankings given to "recognizing and rewarding excellence". In this area, superintendents must become more aware of the impact that they can have on the personnel in the organization. Teachers enjoy receiving praise for their work and need to be recognized. Often, the unions object to both the rewards and the manner by which praise is given. They are opposed to monetary rewards that smack of merit pay but many other alternatives exist. For example, superintendents might take time at the end of every week to write personal notes to teachers whom they have observed doing good work. They should take the time to read teacher reports and send a note complementing the teacher on particular aspects of the report. These practices not only serve to build staff moral, which is a quality 
indicator, but also serve as valuable data gathering exercise for the superintendent where one models the quality behavior of developing a data rich environment. The fact that only two superintendents ranked this behavior in the top seven suggests that this is another area in which superintendents could use some training and/or look to the private sector and do some benchmarking.

A fourth discrepancy in the rankings was the behavior "continues to enhance personal knowledge related to the development/delivery of relevant learning systems". No superintendents chose to rank this behavior. While this may be a sign of the frustration with the limited time available for superintendents to stay on top of the new thinking, in a field where the future of society lies in the hands of the students, superintendents have an obligation to stay abreast of the rapidly changing world and, in Deming's words, acquire profound knowledge.

The fifth discrepancy to be addressed arises from the fact that two superintendents selected behavior of "organizing and preparing well"; no CEOs chose this behavior. This may indicate that the superintendents who chose this behavior remain in a paradigm where leadership was management. These behaviors are not high-level leadership behaviors. Their ranking may indicate that there are still individuals who give more attention than advisable to the managerial tasks of the superintendency. It is also noteworthy that other lower level managerial tasks, such as "maintains budget control", "technically competent", and "ensures that physical facilities and equipment are adequate" were not chosen by any of the panelists. This gives hope that the new paradigm of leadership, wherein management tasks are subservient to relational issues, is taking hold in both business and education. 


\section{Corollary Research Questions}

The corollary research questions of this study are best addressed through a 'suggestion' format. There are two specific suggestions that can be made which best summarize and respond to the corollary research questions of this study. The first suggestion is that the behaviors identified in this study be used to develop a behavioral anchored rating scale. This scale could be used in a $360^{\circ}$ feedback format to gather data for reporting the superintendent's leadership success to the public via a district annual report. The identification of behaviors, that both CEOs and superintendents see as important indicators of a superintendent's leadership success, provides the background for a collaborative effort on the part of the British Columbia Ministry of Education personnel and superintendents to create a feedback instrument. This instrument would serve the dual purpose of providing evaluative feedback and reporting data about the superintendent's leadership success. Such a practice would be consistent with the TQM philosophy of having a data rich environment. The $360^{\circ}$ feedback instruments have proven valuable in business organizations, such as American Telegraph and Telephone, and have been piloted in School District \#45 (West Vancouver). The British Columbia Ministry of Education should, at a minimum, produce an instrument, focussing on the top seven behaviors, that seeks feedback on the leadership behaviors identified in this study. Boards should then be required to report on the quality of the superintendent's leadership in the district annual report.

A second suggestion is that the British Columbia Ministry of Education, the British Columbia School Superintendents' Association, and the Canadian 
Association of School Administrators collaborate to develop professional development programs based upon the top behaviors identified. The programs should be directed at enhancing those leadership behaviors that align with the Quality Movement. Partnerships with business and industry, whose training programs have already been benchmarked, should be explored. This would avoid any "reinventing [of] the wheel" and develop stronger ties between leaders in business and education.

By implementing the two suggestions above, both corollary research questions of this study received an affirmative response.

\section{Strengths of the Study}

The strengths of this study are threefold. First, there was a high retention rate of the two panelist groups. The retention rate of over $50 \%$ from each group ensured that the responses were based upon a solid population base over time. A second strength was the consistency in the rankings between the panelist groups. The ranking of behaviors, such as "visioning" by both groups in the same numbers, enabled the researcher to put greater weight on this finding. Finally, it was possible to triangulate the results of this study with the research in the literature reviewed and the principles of quality.

\section{Weaknesses of the Study}

As with most studies, this one had some weaknesses. First, there was both a limited sample size and a limited geographical area. Therefore, the 
findings of the study may be restricted to the province of British Columbia. The sample size suggests that a replication of this study with a larger sample would be useful to confirm or reject the findings of this study. Another weakness was the demographics of the panelists who were predominantly men aged 51-60.

\section{Conclusions}

A number of conclusions can be drawn from this study. The first conclusion is that it is possible to identify and describe behaviors that can be used as indicators of a superintendent's leadership success. While some panelists in this study spoke of how difficult the initial survey was to complete, the iterations demonstrated that the panelists did reach consensus on behaviors that were key indicators of a superintendent's leadership success.

A second conclusion that can be drawn from this study is that "visioning", as a behavior, is seen as the most important leadership behaviors. This behavior received the highest ranking by both panels, was reported in the most studies in the literature review, and was the first principle espoused by Deming. The support from all of these sources on a consistent basis indicates that this behavior is a necessity if quality leadership is to be modeled.

A third conclusion is that there is a paradigm shift occurring in leadership. The "command and control" managerial approach of the Industrial Age is giving way to a relational, participatory approach of the Information Age. The evidence for this conclusion lies in the choices made by both superintendents and CEOs in their ranking of the behaviors. Many managerial and task oriented behaviors 
received no ranking while those behaviors associated with empowerment and relationships tended to fall in the top seven behaviors. This study suggests that the leadership transformation is well underway and is being embraced by superintendents.

A fourth conclusion that can be drawn from this study is that there are specific leadership behaviors that require further development and attention by superintendents. "Communication" is a behavior that seemed to receive too low a ranking from superintendents. Moreover, there appear to be some professional development programs that could be imported from industry and, with minor modification, used to in-service superintendents. This would be an area that would be a valuable use of some of the more than $\$ 30$ million that the British Columbia Ministry of Education spends on professional growth and development programs.

A fifth conclusion is that there needs to be greater attention placed on the Quality Movement, particularly in the educational realm. Not one superintendent reported being involved in a formal TQM model. This suggests that either they have not had the exposure to the benefits of this model, or that they are choosing to ignore the movement as an approach that is endemic only to business and industry. The British Columbia Ministry of Education needs to examine how it might foster a quality movement in education The potential benefits that have been proven in industry hold promise for education. This may provide opportunities for educators to develop partnerships with industry for the mutual benefit of all employees. 
Another conclusion is that school boards need to examine the amount of time that superintendents devote to the political realm. The superintendents in this study viewed developing and maintaining a relationship with the board as a very important behavior. This is likely true in current practice but, if the time devoted to this area detracts from the superintendent's real purpose of building a quality educational environment, then there needs to be a re-evaluation of priorities. A question of the how often the survival mode is required of superintendents is relevant to this examination. This may be an area in where it would be fruitful for the British Columbia Ministry of Education to investigate. This study also revealed that CEOs have greater longevity in their role than superintendents, but what is not clear is the effect this has on the organization.

There is no questioning the fact, that more studies in this area need to be undertaken. The literature reviewed indicated that there was a dearth of studies identifying specific behaviors that could be used as indicators of leadership success. Mitchell tells us that it is: "... amazing that any thoughtful person is still interested in educational administration, particularly the superintendency... The position destroys those who are not well prepared, and many who were thought to be fully competent" (Mitchell, 1981, p. 40). Identifying behaviors that indicate a superintendent's leadership success and then developing specific training programs around those behaviors may prevent the tragedy of Mitchell's observation while, at the same time, improving the quality of the system. It is only through more research that these behaviors can be confirmed.

Finally, this study has enabled the development of a draft model of a behavioral anchored rating scale (See Appendix J). This scale suggests that the 
findings can be incorporated into a Quality measurement tool that enables one to gather data on the superintendent's success as a leader in the school system. Developing behavioral indicators of a superintendent's success was the purpose of this research. Refinement and development of this draft model would enable a leadership category to be included with the other indicators (Appendix $A$ ) in the British Columbia annual reporting system.

Moreover, this rating scale could provide the appropriate data upon which a superintendent could delineate a professional growth and development model. This provides the data to respond to the fifth research question by providing a foundation for a superintendent's leadership, growth, and development plan.

\section{Recommendations for Further Study}

The significance of this study was to establish key leadership behaviors that could be used by the British Columbia Ministry of Education to launch a benchmarking project involving superintendents. A number of areas for further study have arisen out of this research. They include:

1. A replication of this study, using a larger sample to confirm the findings, is recommended. Such a study should widen the geographical area as well as the age and gender group that is sampled;

2. A comparative study that examines school systems implementing a formal Total Quality program against those that are not is recommended. More 
concrete information on the success of the TQM model will be available as more school systems adopt the model.

3. An experimental study that examines the effect of continuous and effective communication within a school district is required. Superintendents need to have better knowledge of how, why and when to communicate with district personnel.

4. A Delphi study is recommended to examine the reasons that superintendents have given the issue of "identifying, selecting, and keeping strong staff" a relatively low ranking. If this is a result of unionization, then the effects of a more collaborative approach to the union needs to be examined.

5. A survey that examines the practices and successes of "recognizing and rewarding excellence" in school districts is needed. Superintendents need to develop a repertoire of techniques for showing their appreciation of the efforts of employees.

6. A qualitative examination of the time commitment given to cultivating board/superintendent relationships and its effectiveness to the overall quality of the school system is recommended. There needs to be a clear understanding of the effect of such time on the improvement of service in a district so that the board and superintendent may allocate time in the most efficient manner possible. 
7. A study that determines if these behaviors are applicable to other levels of administration in the school system is recommended. This would enable a determination of professional growth programs, based on these behaviors, applied to both the superintendent and school based administrators.

8. A study that benchmarks current professional growth programs in industry with a view to establishing their applicability to education would be useful. This would eliminate some of the costs of duplicating programs designed only for the education sector. 


\section{References}

Bales, R. F. (1950). Interaction process analysis. Reading, MA: Addison-Wesley.

Bass, B. M. (1985). Leadership performance beyond expectations. New York: Free Press.

Bennis, W. G., \& Nanus, B. (1985). Leaders. New York: Harper and Row.

Berliner, D. C. (1992, February). Educational reform in an era of disinformation. Paper presented at the meetings of the American Association of Career and Technical Educators, San Antonio, TX.

Blake, R. R., \& Mouton, J. S. (1964). The managerial grid. Houston, TX: Gulf.

Blumberg, A., \& Blumberg, P. (1985). The school superintendent: Living with conflict. New York: Teachers' College Press.

Bonstingl, J. J. (1992). Schools of quality. Alexandria, VA: Association for Supervision and Curriculum Development.

Boyatzis, R. E. (1982). The competent manager. New York: Wiley - Interscience.

Bridges, E. M. (1982). Research on the school administrator: the state of the art, 1967-1980. Educational administration quarterly, 18(3), 12-33.

Bunning, R. L. (1979). The Delphi technique: A projection tool for serious inquiry. In The 1979 annual handbook for group facilitators, La Jolla: University Associates.

Burke, W. W. (1988). Leadership report (Rev. Ed.). Pelham, NY: W. Warner Burke and Associates.

Burns, J. M. (1978). Leadership. New York: Harper and Row.

Clarke, K. E., \& Clarke, M. B. (Eds.). (1990). Measures of leadership. Greensboro, TX: Leadership Library of America. 
Collins, J.C., \& Porras, J. I. (1994). Built to last: successful habits of visionary companies. New York: Harper Collins.

Cooley, W. A., \& George, C. A. (1992). Educational indicators for Pennsylvania. Policy paper \#14. Philadelphia, PA: State of Pennsylvania.

Dalkey, N. C. (1969). The Delphi method: An experimental study of group opinion. Santa Monica, CA: Rand Corporation.

Dalkey, N., Brown, B., \& Cochrane, S. (1970). The Delphi method IV: Effect of percentile feedback and feed-in of relevant facts. Santa Monica, CA: Rand Corporation.

Darling-Hammond, L. (1992, September). Educational indicators and enlightened policy. Educational Policy, 6(3), 234-265.

Delbecq, A. L., Vand de Ven, A. H., \& Gustavson, D. H. (1975). Group techniques for program planning: a guide to nominal and group Delphi processes. Glenview, IL: Scott Foresman.

Deming, W. E. (1986). Qut of the crisis. Cambridge, MA: MIT.

Eggers, J. H., \& Leahy, K. T. (1994) Entrepreneurial leadership in the U.S. Issues and Observations, 14(1). Greensboro, TX: Center for Creative Leadership.

Fielder, F. E., \& Garcia, J. E. (1987). New approaches to effective leadership. New York: John Wiley and Sons.

Fielder, F. E. (1967). A theory of leadership effectiveness. New York: McGrawHill.

Fielder, F. E., \& House, R. J. (1988). Leadership theory: a report of progress. In C. L. Cooper \& I. Robertson (Eds.), Intenational review of industrial and organizational psychology (pp. 73-92). London: Wiley.

Fleishman, E. A. (1973). Twenty years of consideration and structure. In E. A. Fleishman, \& J. G. Hunt (Eds.). Current developments in the study of leadership (pp. 1-37). Carbondale, IL: Southern Illinois University Press.

Gibb, C. A. (1969). Leadership. In G. Lindzey, \& E. Aronson (Eds.), Handbook of social psychology Vol. 2. (2nd Ed., pp. 202-282). Reading, MA.: AddisonWesley. 
Glass, T. E. (1992, February). Exemplary superintendents: What makes them different? Paper delivered at the annual general meeting of American Association of School Administrators, San Diego, CA.

Glasser, W. (1992). The quality school (2nd Ed.). New York: Harper Collins.

Government of British Columbia (1992). The school act. Victoria, B.C.: Queens Printer.

Harman, A. J., \& Press, S. J. (1975). Collecting and analyzing expert group judgement data. Santa Monica, CA: Rand Corporation.

Hart, C. W. L., \& Bogan, C. E. (1992). The Baldridge. New York: McGraw Hill.

Haycock, K. (1994). Principle: Institute a vigorous program of education and retraining. In S. Bareham (Ed.). What public education can learn from total quality managers: a monograph series by B. C. school administrators and educators. Vancouver, B.C.: British Columbia School Superintendents' Association.

Hayes, B. E. (1992). Measuring customer satisfaction. Milwaukee, WI: American Society for Quality Control.

Helmer, O. (1964, September) Convergence of expert consensus through feedback. Paper presented at the 10th annual meeting of the Western section of Oceanic Resources and Scientific Association, Honolulu, HI.

Helmer, O. (1966, December). The use of the Delphi technique in problems of educational innovation. Paper prepared for publication in The American Behavioral Scientist, Santa Monica, CA.

Helmer, O. (1967, November). Systematic use of expert opinions. Paper produced for presentation at the Air Force Association of Graduates board meeting, Santa Monica, CA.

Hersey, P., \& Blanchard, K. H. (1969). Life cycle theory of leadership. Training and Development Journal, 23(5), 26-34.

Horine, J., \& Bass, B. (1993). Transformational leadership: the cornerstone of quality. C. L.S. Report, 92(3), 1-31.

House, R. J. (1971). A path-goal theory of leader effectiveness. Administrative Science Quarterly, 16, 321-328. 
House, R. J., \& Baetz, M. L. (1990). Leadership: Some empirical generalizations and new research. In K. E. Clarke \& M. B. Clarke (Eds.), Measures of leadership (pp. 301). Greensboro, TX: Leadership Library of America.

Jaques, E. (1989). Requisite organization. Arlington, VA: Cason Hall.

Jeffries, J. (1994). The leadership of a superintendent: Putting the California school reform movement to work. San Diego, CA: University of San Diego.

Johnson, R. S. (1993). TQM: Leadership for the quality transformation. Milwaukee, WI: American Society for Quality Control.

Jones, C. G. (1975). A Delphi evaluation of agreement between organizations. In H. A. Linstone \& M. Turoff (Eds.). The Delphi method: Techniques and applications. Reading, MA: Addison-Wesley.

Kanter, R. M. (1977). Men and women of the corporation. New York: Basic Books.

Kearns, D. T., \& Nadler, D. A. (1992). Prophets in the dark. New York: Harper Collins.

Kirby, P. C., King, M. I., \& Paradise, L. V. (1992). Extraordinary leaders in education: Understanding transformational leadership. Journal of educational research, 85(5) (pp. 303-311).

Kotter, J. P. (1982). The general managers. New York: The Free Press.

Kouzes, J. M., \& Posner, B. Z. (1993). Credibility. San Francisco, CA: JosseyBass.

Kouzes, J. M., \& Posner, B. Z. (1987). The leadership challenge. San Francisco: Jossey-Bass.

Kurtz, D. L., Boone,L. E., \& Fleenor, C. P. (1989). CEO: Who gets to the top in America. East Lansing, MI: Michigan State University Press.

Lehnen, R. G. (1993, April). Developing education policy for Indiana. Paper prepared for American Education Research Association, Indianapolis, IN: Indiana University Press.

Lee, A. (1991, April). The perceived characteristics and behaviors of effective leaders in education. An unpublished research proposal presented to University of British Columbia, Vancouver, British Columbia. 
Leithwood, K., \& Steinbach, R. (1993). Total quality leadership. Journal of Personnel Evaluation in Education, 7(4), 8-12.

Levinson, H., \& Rosenthal, S. (1984). CEO: Corporate leadership in action. New York: Basic Books.

Martin, M., \& Kowalski, M. (1992). Managing quality education. St. Paul, MN: 3M.

Martino, J. (1983). Technological forecasting for decision making (2nd Ed.). New York: North-Holland.

Maxwell, J. C. (1993). Developing the leader within you. Nashville, TN: Thomas Nelson.

Mintzberg, H. (1973). The nature of managerial work. New York: Harper and Row.

Mitchell, E. (1981). Educational leadership: Confronting crisis with style. In K. Cirincione-Coles (Ed.), The future of education: Policy issues and challenges (pp. 35-42). Beverley Hills, CA: Sage Publications.

Murphy, J. (1991). Restructuring schools: Capturing and assessing the phenomena. New York: Teachers College Press.

Newmann, F. (1993). Beyond common sense in educational restructuring. Educational Researcher, 22(2), 4-13.

Newton, E. (1991, September). Voices, visions, and vitality: International indicators of effective superintendents' leadership. Paper presented at the national conference of Canadian Association of School Administrators, Calgary, Alberta.

Palmer, D. M. (1995). The unheard voice. Victoria, B. C.: Queen's Printer

Pincus, J. D., \& De Bonais J. N. (1994). Top dog. San Francisco, CA: McGrawHill.

Porter, L. W., Lawler, F. E. III, \& Hackman, J. R. (1975). Behavior in organizations. New York: McGraw-Hill.

Rost, J. C. (1991). Leadership for the twenty-first century. New York: Praeger.

Rost, J. C. (1993). Leadership development in the new millennium. Journal of Leadership Studies, 1(1), 92-110. 
Sales, L. R. (1989). Leadership: Managing in real organizations. New York: McGraw-Hill.

Sashkin, M., \& Burke, W. W. (1990). Understanding and assessing organizational leadership. In K. E. Clarke \& M. B. Clarke (Eds.), Measures of leadership (pp. 297-326). Greensboro: Leadership Library of America.

Schlechty, P. C. (1990). Schools for the 21st century: Leadership imperatives for educational reform. San Francisco, CA: Jossey-Bass.

Schwartzkopf, H. N., \& Petre, P. (1992). It doesn't take a hero. New York: Linda Grey-Bantam Books.

Senge, P. M. (1990). The fifth discipline. New York: Doubleday.

Sergiovanni, T. (1992). Moral leadership: Getting to the heart of school improvement. San Francisco, CA: Jossey-Bass.

Sergiovanni, T. J. (1990). Value-added leadership: How to get extraordinary performance in schools. Orlando, FL: Harcourt Brace Jovanovich.

Shartle, C. L., \& Stogdill, R. M. (1953). Studies in naval leadership: methods. results, and applications (Tech. Rep.). Columbus, $\mathrm{OH}$ : Ohio State University.

Steiner, G. A. (1983). The new CEO. New York: Macmillan.

Streshley, W. A., \& Newcomer, L. (1994). Managing change with accountability: A challenge for educators. NASSP Bulletin, $\underline{78(560), 62-68 .}$

Spendolini, M. J. (1992). The Benchmarking Book. New York: AMACOM.

Thomas, L. (1994). Principle: Institute leadership. In S. Bareham (Ed.), What public education can learn from total quality managers: A monograph series by B. C. school administrators and educators. Vancouver, B.C.: British Columbia School Superintendents' Association.

Thomas, L. (1981, February). What Is Delphi? Personnel and Guidance Journal, 497, 15-18.

Tjosvold, D. \& Tjosvold, M. M. (1991). Leading the team organization. New York: Lexington Books.

Toney, F. (1994). CEOs: Actions and traits that result in profitable companies. Journal of leadership studies, 1(4), (pp. 69-81). 
Truskie, S. D. (1990). The president/CEO study. Pittsburgh. PA: Management Science and Development.

Uhl, N. P. (1983). Using the Delphi technique in institutional planning. In N. P. Uhl (Ed.), New directions for institutional research (pp. 81-83). San Francisco, CA: Jossey-Bass.

Yukl, G. A. (1989). Leadership in organizations (2nd Ed.). Englewood Cliffs, N.J.: Prentice-Hall. 


\section{Appendix A \\ School District Annual Report Order}

\section{SCHOOL DISTRICT ANNUAL REPORT ORDER}

Authority: School Act, section 98

Ministerial Order 156/94 (M156/94) ....................Effective June 13, 1994

Order of the Minister of Education

\section{Key indicators of student and school performance}

1. A board must ensure that the annual report prepared in accordance with section 98 of the School Act includes

(a) a statement of the board's mission, vision or purpose for its school district,

(b) a statement of the board's goals or objectives to realize the mission, vision or purpose, and

(c) information relating to the key indicators listed in column 1 of Schedule 1, and incorporating the data described in column 2 of that Schedule. 


\section{SCHOOL DISTRICT ANNUAL REPORT ORDER \\ SCHEDULE 1}

Key Indicators of Student and School Performance

\begin{tabular}{|c|c|}
\hline KEY INDICATORS & $\begin{array}{l}\text { DATA FOR KEY INDICATORS } \\
\text { a Specified information provided to } \\
\text { Districts in Information Profiles is } \\
\text { required to be reported. } \\
\text { - Information which should be used if } \\
\text { available. }\end{array}$ \\
\hline COLUMN 1 & COLUMN2 \\
\hline $\begin{array}{l}\text { READING/WRITING } \\
\text { ACHIEVEMENT } \\
\text { Student achievement in } \\
\text { reading, writing and } \\
\text { communication skills. }\end{array}$ & $\begin{array}{l}\text { Q Provincial Examination results: } \\
\text { - school and district results (for last } \\
5 \text { years) } \\
\text { - percent of students who have } \\
\text { achieved A, B, C } \\
\text { - percent of students who } \\
\text { participated in provincial exams } \\
\text { - number of students who } \\
\text { participated in provincial exams } \\
\text { - Assessments (other than Gr. 12) } \\
\text { - Provincial Learning Assessment } \\
\text { Program results as provided by } \\
\text { the Ministry } \\
\text { - Local information }\end{array}$ \\
\hline $\begin{array}{l}\text { MATHEMATICS } \\
\text { ACHIEVEMENT } \\
\text { Student achievement in } \\
\text { mathematics. }\end{array}$ & $\begin{array}{l}\text { Drovincial Examination results: } \\
\text { - school and district results (for last } \\
5 \text { years) } \\
\text { - percent of students who have } \\
\text { achieved A, B, C } \\
\text { - percent of students who } \\
\text { participated in provincial exams } \\
\text { - number of students who } \\
\text { participated in provincial exams } \\
\text { - Assessments (other than Gr. 12) } \\
\text { - Provincial Leaming Assessment } \\
\text { Program results as provided by } \\
\text { the Ministry } \\
\text { - Local information }\end{array}$ \\
\hline $\begin{array}{l}\text { STUDENT ACHIEVEMENT IN } \\
\text { OTHER DISCIPLINES } \\
\text { Student achievement in the four } \\
\text { strand areas of } \\
\text { Science/Mathematics, Humanities, } \\
\text { Fine Arts, and Practical Arts. }\end{array}$ & $\begin{array}{l}\text { - Provincial Examination results: } \\
\text { - school and district results (for last } 5 \text { years) } \\
\text { - percent of students who have achieved A, } \\
\text { B, C } \\
\text { - percent of students who participated in } \\
\text { provincial exams } \\
\text { - number of students who participated in } \\
\text { provincial exams } \\
\text { - Assessments (other than Gr. 12) } \\
\text { - Provincial Leaming Assessment Program } \\
\text { results as provided by the Ministry } \\
\text { - Local information }\end{array}$ \\
\hline
\end{tabular}


SCHOOL DISTRICT ANNUAL REPORT ORDER SCHEDULE 1 - Continued

\begin{tabular}{|c|c|}
\hline $\begin{array}{l}\text { SCIENTIEICIECHNOLOGICAI } \\
\text { LITERACY } \\
\text { Student achievement in areas of } \\
\text { scientific applications, } \\
\text { understanding and use of } \\
\text { technology, and access to and } \\
\text { manipulation of information. The } \\
\text { data should draw from the four } \\
\text { strand areas of } \\
\text { Science/Mathematics, Humanities, } \\
\text { Fine Arts, Practical Arts and other } \\
\text { applications. }\end{array}$ & $\begin{array}{l}\text { Q Computer science and technology course } \\
\text { enrolments (for last } 5 \text { years) } \\
\text { - Technology usage in other curriculum areas } \\
\text { - Local information }\end{array}$ \\
\hline $\begin{array}{l}\text { SCHOQLCOMPLITON RATE } \\
\text { Students who achieve graduation or } \\
\text { its equivalent. Provincial measure } \\
\text { consists of the number of students } \\
\text { who graduate as a percentage of } \\
\text { those who entered Grade } 8 \text { five } \\
\text { years earlier. }\end{array}$ & $\begin{array}{l}\text { Percent of eligible Grade } 12 \text { 's who graduate } \\
\square \text { Percent of Grade } 8 \text { 's who graduate } \\
\text { - Local information }\end{array}$ \\
\hline $\begin{array}{l}\text { STUDENT TRANSUIONS } \\
\text { Students who enter the workforce } \\
\text { directly or enter } \\
\text { post-secondary studies. }\end{array}$ & $\begin{array}{l}\text { Percent eligible for university } \\
\text { Q Percent going to post-secondary education } \\
\text { - Local information }\end{array}$ \\
\hline $\begin{array}{l}\text { CLIENT SATISEACTION } \\
\text { Measures indicating community } \\
\text { satisfaction with the effectiveness } \\
\text { of the programs in the district. } \\
\text { Measures could be direct, or } \\
\text { inferential, such as financial } \\
\text { support or participation rates in } \\
\text { various activities, or survey results. }\end{array}$ & $\begin{array}{l}\text { - Results of district client surveys } \\
\text { - School accreditation surveys } \\
\text { - Local information }\end{array}$ \\
\hline $\begin{array}{l}\text { STUDENT PREPAREDNESSEOR } \\
\text { EMPLOXMENT } \\
\text { Measures of success in preparing } \\
\text { students for employment. Measures } \\
\text { could be direct, such as employment } \\
\text { rates, or inferential, such as survey } \\
\text { questionnaires, or financial support } \\
\text { or participation rates in various } \\
\text { activities bv emplovers. }\end{array}$ & $\begin{array}{l}\text { a Career program enrolments } \\
\text { - Provincial employer survey } \\
\text { - Local information } \\
\text {. }\end{array}$ \\
\hline
\end{tabular}




\section{SCHOOL DISTRICT ANNUAL REPORT ORDER SCHEDULE 1 - Continued}

\begin{tabular}{|l|l|}
\hline $\begin{array}{l}\text { SCHOQL QUALIY } \\
\text { Measures that indicate the quality } \\
\text { of programs in the district. }\end{array}$ & $\begin{array}{l}\text { Q Class size (elementary- secondary } \\
\text { student/educator ratio [SER]) } \\
\text { - Current status of school growth plans } \\
\text { Measures could include results of } \\
\text { school accreditation, school annual } \\
\text { reports, district-level evaluations. } \\
\text { school) } \\
\text { - Student Surveys } \\
\text { - Parent surveys } \\
\text { - Local information }\end{array}$ \\
\hline $\begin{array}{l}\text { FINANCES } \\
\begin{array}{l}\text { Measures that describe spending in } \\
\text { the district in relation to district } \\
\text { and provincial goals. }\end{array}\end{array}$ & $\begin{array}{l}\text { Q Budgeted cost per pupil } \\
\text { Q Learning resources, operating capital and } \\
\text { total expenditures } \\
\text { - Local information }\end{array}$ \\
\hline
\end{tabular}




\section{Appendix B}

\section{Education Pilot Criteria Framework}

The core values and concepts are embodied in seven categories, as follows:

\subsection{Leadership \\ 2.0 Information and Analysis \\ 3.0 Strategic and Operational Planning \\ 4.0 Human Resource \\ Development and Management}

5.0 Educational and Business Process Management

6.0 School Performance Results

7.0 Student Focus and Student and Stakeholder Satisfaction

The framework connecting and integrating the Categories is

illustrated.

\section{Source -}

American Society for Quality Control

P.O. Box 3005

Milwaukee, WI

53201-3005
The framework has four basic elements:

\section{Driver}

Senior leadership sets directions, creates shared values, goals, and systems, and guides the pursuit of student and school performance improvement.

\section{System}

The system comproses the set of well-defined and well-designed processes for improving the school's performance.

\section{Measures of Progress}

Measures of progress provide a results-oriented basis for channeling actions to delivering ever-improving student and school performance.

\section{Goal}

The basic aims of the system are the delivery of ever-improving educational services, leading to success and satisfaction. 


\section{EDUCATION PILOT CRITERIA FRAMEWORK Dynamic Relationships}

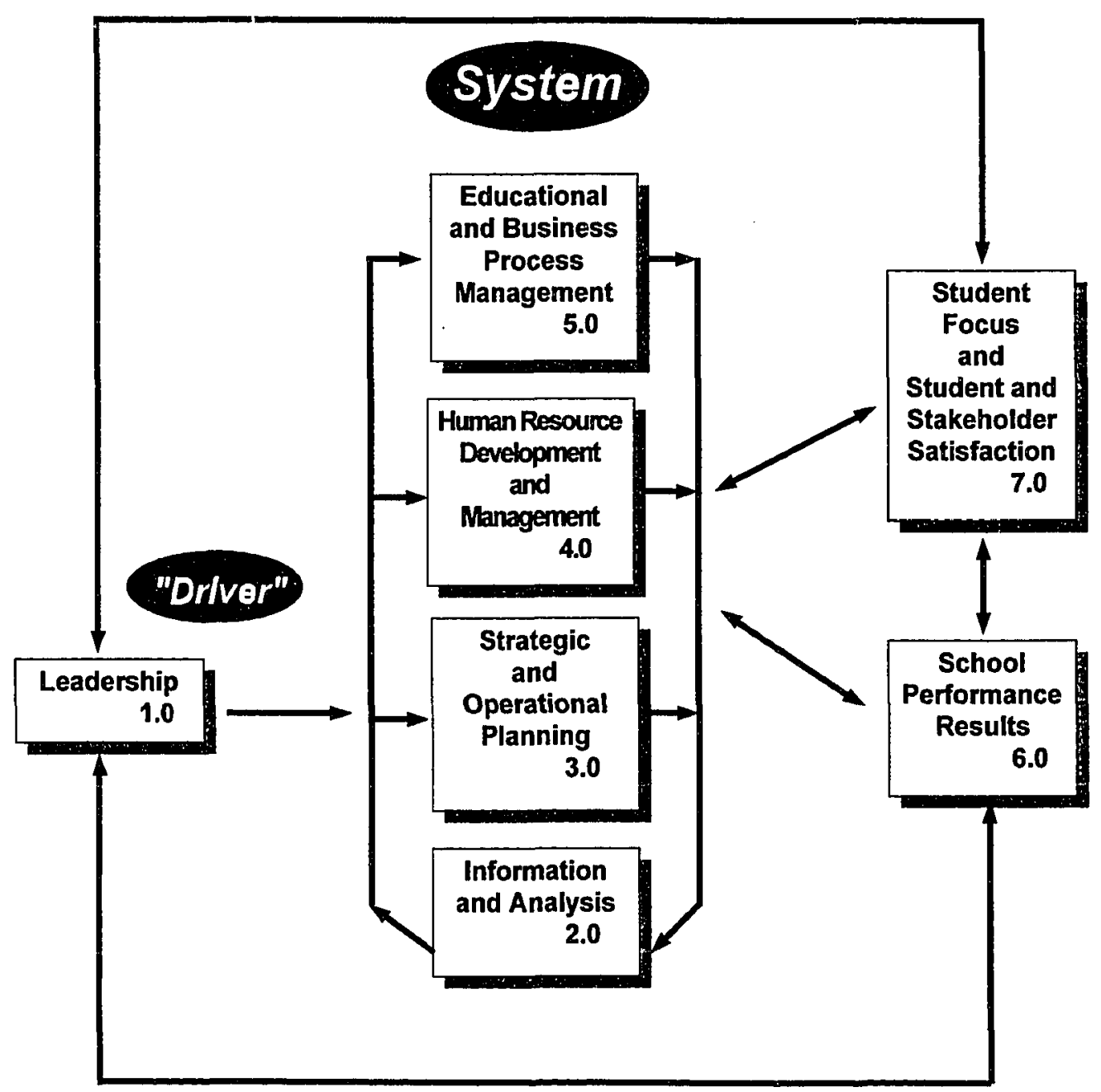

\section{Goal}

\section{Measures of Progress}

- Student Success/ Satisfaction

- Stakeholder Satisfaction

- Student Retention
- Student Performance

- Educational Climate

- Research, Scholarship, and Service

- Efficient Use of Resources 


\section{Appendix C \\ Initial Survey Instrument}

\section{BACKGROUND INFORMATION \\ THE IDENTIFICATION OF BEHAVIORAL INDICATORS OF A SUPERINTENDENT'S LEADERSHIP SUCCESS--A DELPHI STUDY \\ Background Information}

The main objectives of the study are to:

1. identify the key behaviors that demonstrate successful leadership by a superintendent of schools,

2. describe the manner in which the identified behaviors will manifest themselves in a superintendent' performance,

3. rank the identified behaviors in order of importance,

It is hoped that the results of the study will serve as a foundation for:

1. developing a behavior anchored rating scale to assist in surveying the customer's perception of the superintendent's performance

2. developing indicators which enable reporting on the success of the superintendent in the district annual report

3. providing information which could act as a basis for the development of a professional growth plan for the superintendent

Your participation is valuable and greatly appreciated!

Doug Player

Superintendent of Schools
1075 - 21st Street

West Vancouver

British Columbia, Canada V7V 4A9 


\section{University of San Diego}

\section{CONSENT TO ACT AS A RESEARCH INFORMANT}

Douglas George Player, M. ED. is conducting research to examine behavioral indicators of a superintendent's leadership success.

I agree to participate in the study by participating in a Delphi study involving four rounds which survey my perceptions and priorities of behavioral indicators of a superintendent's success.

I understand that I may not benefit personally from the study, but the new knowledge gained will help the investigator examine the differences in the perceptions of behavioral indicators of a superintendent's leadership success. Participation in this study should not involve any added risks or discomfort to me.

Douglas George Player has provided a written explanation of this study to me. If I have other questions I may reach Douglas George Player at either 604-981 1031 or by FAX at $604-981-1001$.

Participation in this research is entirely voluntary. I may refuse to participate or withdraw at any time without jeopardy.

Research records will be kept completely confidential. My identity will not be disclosed without my written consent. I further understand that the anonymity of my district or company affiliation will be preserved. There are no other agreements written or verbal, related to this study beyond that expressed on this consent form.

Signature of informant

Date

Location

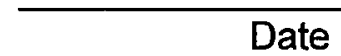

$\overline{\text { Signature of principal researcher }}$

Date 


\section{DEMOGRAPHIC QUESTIONNAIRE}

THE IDENTIFICATION OF BEHAVIORAL INDICATORS OF A SUPERINTENDENT'S LEADERSHIP SUCCESS--A DELPHI STUDY

\section{Demographic Questionnaire}

\section{Personal Background}

Your responses to the following items are requested for the development of an overall profile of the respondents participating in this Delphi study. Your specific responses will be kept anonymous in the development of this general profile.

1. (a) Name:

(b) Organization:

(c) Phone Number: $($ )

(d) Fax Number: $($ )

(e) Your Title:

(f) Number of Years in your Present Position:

2. (a) Your Age (check only one):

$20-30$

$31-40$

$41-50$

(b) Your Gender:

Female Male

3. Number of Employees in your Organization (head count):
(a) 500 or fewer
(e) $2001-2500$
(b) $501-1000$
(f) 2501-3000
(c) 1001-1500
(g) 3001-3500
(d) 1501-2000
(h) more than 3500 
4. Please indicate if your organization has or is currently undertaking a formal Total Quality Management program:

Yes

No

\author{
PLEASE RETURN TO: \\ Doug Player \\ Superintendent of Schools \\ 1075 - 21st Street \\ West Vancouver \\ British Columbia \\ Canada, V7V 4A9
}

If you have any questions, please feel free to call: (604) 981-1031.

THANK YOU FOR YOUR COOPERATION AND ASSISTANCE 


\section{DELPHI INSTRUMENT}

\section{THE IDENTIFICATION OF BEHAVIORAL INDICATORS OF A SUPERINTENDENT'S LEADERSHIP SUCCESS--A DELPHI STUDY}

\section{Delphi Instrument}

Instructions: This instrument provides the space for each respondent to list behaviors that the respondent believes are important to successful leadership by a superintendent of schools. The respondent is asked to list a minimum of five and a maximum of seven key behaviors to a superintendent's successful leadership. The respondent is asked to provide a description of the behavior using 25 words or fewer.

Definition of Behavior: A function of the person and the situation in interaction with one another.

Definition of Leadership: The influence relationship that brings about positive intended change by transforming followers into leaders while bringing out the best in both.

Definition of Success: The ability to consistently meet or exceed customer expectations.

Example of a response:

Behavior: Asking effective questions

Description of the behavior: The superintendent uses his communication skills to seek information from customers by asking effective questions such as: "how do you know?".

\section{QUESTIONNAIRE}

BEHAVIOR:

DESCRIPTION OF BEHAVIOR: 
BEHAVIOR:

DESCRIPTION OF BEHAVIOR:

BEHAVIOR:

DESCRIPTION OF BEHAVIOR:

BEHAVIOR:

DESCRIPTION OF BEHAVIOR: 
BEHAVIOR:

DESCRIPTION OF BEHAVIOR:

BEHAVIOR:

DESCRIPTION OF BEHAVIOR:

BEHAVIOR:

DESCRIPTION OF BEHAVIOR: 


\section{Appendix D \\ Participant Responses to Round One}

Behavior

Description

walking around and

visiting schools and other workplaces to see and

cheerleading

hear how people are feeling and finding positive

achievements to celebrate with them

focus on children and at the board table, staffroom, administrator

their learning

meetings, parent gatherings, always include talk

about children learning to live their lives more

effectively and their need to take charge of their

learning at the earliest age possible (near end of

primary) Taking charge includes being part of the

decision-action cycle on matters such as school

yard behavior, overall learning plan, evaluation of

achievement ... for these goals children need skills

(mediation, negotiation, goal setting, ethics, ...) in

addition to the regular curriculum and adults who

believe and expect children to rise to the occasion. 
focus of the community Establish and keep personal contact with local

leaders of media, government organizations, service clubs, business and unions ... Through words and actions keep the district (admin., board, etc.) thinking about its duality of customers:

children and taxpayers. Also these two customers express apparently differing needs (results and competition / comparison) by taxpayers and children need their strengths celebrated. Satisfying these needs simultaneously is only possible through careful planning.

focus on the business (purpose) of the school district
- ensure the Board develops and publishes values and beliefs that are subscribed to by all

- develop strategic directions that fit values/beliefs

- Foster a working together climate that brings students, trustees, parents, employees, organizations ... into a process that produces priorities and achievements. Formal structures remain in the background when work of district is being done. 
consistent practice of highest ethical

standards
- honest, open relationships of high integrity with individuals, leaders of unions, trustees, etc.

- clear expectations and standards of behavior expected and processes to follow-up fairly complaints or concerns focus on people and participatory leadership
- growth orientation for all people

- encouragement and support for people to use judgment and to be self-reliant in carrying out daily work

- people need to feel challenged, encouraged and developed within a climate where people care about our central purpose "children meaning to live their lives more effectively"

be attentive, concerned, superintendent shall encourage those involved and and flexible but firm affected to be included in decision making process 
be respectful of the

balance between work

and family

responsibilities
- superintendent will, by example, show his responsibilities to duty to work and family

- superintendent shall not be overly demanding of meeting objectives

be decisive

superintendent shall investigate problem situations

expeditiously without too long a delay to arrive at problem solving solutions; favoritism shall not enter into the resolution process

be supportive of staff and take responsibility
- superintendent is the responsible authority in the District

- he/she shall not absolve his/her self from responsibility by laying blame on others be consistent

- superintendent shall interpret policy with set guidelines to show connections

- superintendent shall express all policies and guidelines so all customers do not misinterpret or misunderstand set rules and boundaries 
impacting on leadership

of principals and vice-

principals
- superintendent supports leadership development programs designed by the schoolbased administrators

- superintendent sets high expectations that school-based administrators engage in personal development of leadership skills monitors the system

- superintendent leads (by delegation) in the creation of monitoring systems with a focus on "results" and indicators of quality

- monitoring system is the result of consultation and is one that gathers data of use to all levels of the system for decision making serves as a "midwife" to the systems
- publicly refers to the vision of the system (mission) and ensures that opportunity for all persons (employees) (parents) (community) (trustees) have opportunity to help in creating the vision and in proclaiming the vision

- how: writing, speaking, endorsing, consulting 
hold the system

accountable for its

mandate or vision
- superintendent asks questions (the hard ones)

re: results and challenges others to engage in self and program assessment leading to plans for improvement

- superintendent facilitates others to draw conclusions about effectiveness of their programs, efforts and decisions and does not serve the role of judge building relationships with partner groups superintendent builds personal relationships with heads of unions, parents groups, community leaders, school administrators, district staff and trustees; such is done through visits, meetings, social contact, consultation, correspondence
ensuring adherence to superintendent sets personal example and causes protocols, agreements, all alleged breaches to be properly investigates and due process, and ethical appropriately responded to conduct 


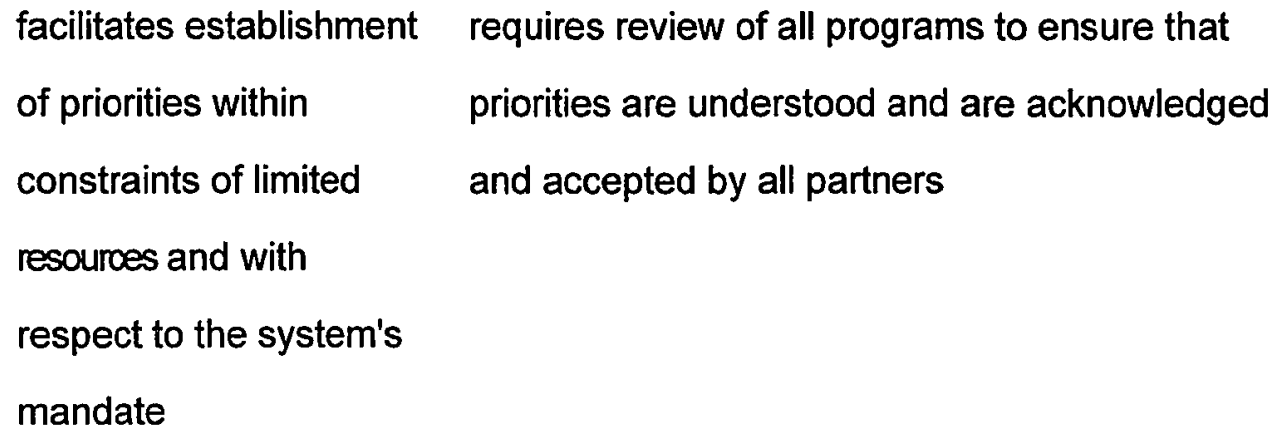


listening attentively

The superintendent listens carefully to parents I public / students to ensure the system is focused on meeting client / customer needs. The superintendent listens to employees carefully to ensure the organizational needs and personal needs of employees are not in direct conflict. The superintendent listens to the solutions brought to him by those responsible for executing the business of the organization.

sharing the vision The superintendent articulates in word and deeds the deep underlying purpose of the school district -to educate all students to the limits of their potential -- with employees, parents, the public. The superintendent is a pastoral shepherd, tending the flock - he oversees the design of a process that ensures all employees understand and share with each other the key purposes for which they all work. (No person is an island, able to survive outside the whole.) 
building trust

focusing on the primary

activity of the

organization (i.e.,

educating children and

adults) establishing a climate where the individual feels free to bring forward concerns and to explore those concerns with both one-to-one and in management group meetings

consistently acting and encouraging others to act in harmony with the primary activity of the district bringing purpose to chaos

communication
Political interference and budget restraint are creating great confusion. The superintencient must constantly help all to cut through this chaos to do the best for education. 
have a values-driven

(principle centered)

leadership style

respect people base complex decisions on a set of values and be

able to articulate those values and justify decisions based on those foster a climate of innovations and risk taking to improve students outcomes demonstrate both in words and actions, a belief in the inherent worth of people and their ability to make a valuable contribution
create a learning
encourage all staff to belong lifelong learners by
organization serving as an example
integrity is recognized as having principles and values that he / she not only expresses but lives by

encourage staff to innovate in program areas and activity promote innovation both in communication and material support

communication concern for dispensing and sharing information -as required -- in varying working relationships (e.g., senior staff $\rightarrow>$ staff $\rightarrow>$ community). Communications are done on a pro-active and in a regular manner using clear and precise language 
knowledge

organizational skills

planning / visionary

interpersonal skills
As a superintendent of schools, the leader must demonstrate a knowledge of educational matters and the ability to "move forward". The leader must also have a knowledge and grasp of financial and human resources issues -- i.e., leadership role is greatly expanded from original training as a classroom teacher.

In the role a superintendent the successful individual demonstrates an ability to manage a number of diverse and complex issues.

Closely related to organizational ability, the successful leader plans for the present needs and identifies future needs. The identification of future needs not only reflects dealing with the unknown but implementing new ventures.

As a leader, an individual works with many individuals and groups. Listening, reasoning, mediation, and conflict resolution skills are among many others, well applied, are required for success. 
risk taking

The ability to know when to take a risk, to expand success and not be daunted with failure. At the same time, the risks should not be foolhardy

planning for the future The superintendent is able to forecast trends and to engage people in taking steps to prepare for change circumstances.

engaging in professional The superintendent models engagement in growth professional development and applies and refines acquired skills

facilitating interchange The superintendent employees effective of ideas communication skills with small and large groups

maintaining political The superintendent is sensitive to the political equilibrium dynamics of the system and is able to take appropriate steps to adjust to system changes and personal agendas.

negotiating with unions and individuals
The superintendent is able to employ conflict resolution and collaborative decision making within the context of strategic changes and personal / organization 


\begin{tabular}{|c|c|}
\hline $\begin{array}{l}\text { engaging personnel in } \\
\text { their field of } \\
\text { specialization }\end{array}$ & $\begin{array}{l}\text { The superintendent is able to delegate wisely and } \\
\text { to develop teamwork (illegible) with shared vision / } \\
\text { mission / quidina principles }\end{array}$ \\
\hline
\end{tabular}

adapting to unforeseen The superintendent is effective in coping with a requirements broad agenda and to prioritize needs with skill and finesse

\begin{tabular}{|c|c|}
\hline interpersonal skills & $\begin{array}{l}\text { The superintendent is able to utilize a broad rang } \\
\text { of interpersonal skills to communicate with divers } \\
\text { groups of people and individuals, thus building a } \\
\text { culture characterized by trusting an open } \\
\text { relationship. }\end{array}$ \\
\hline competence & $\begin{array}{l}\text { The superintendent is knowledgeable of the } \\
\text { organization and of factors which impact on the } \\
\text { organization. Decisions are made based on an } \\
\text { appropriate basis and processes are clearly } \\
\text { established for seeking new knowledge. }\end{array}$ \\
\hline
\end{tabular}


forward looking /

visionary
The superintendent demonstrates a clear sense of direction and is able to build commitment. As a vision for the organization. The vision is well articulated and the employers are confident that there is a clear distinction.

innovative and creative The superintendent demonstrates that she is not content with the status quo and articulates / values continuous improvement, risk taking and new ideas.

caring

The superintendent demonstrates through her actions and others, communicative processes that she cares both about the people she works with and about public education itself.

visible The superintendent is visibly in school and meetings and demonstrates that it is important to spend her time in interaction with people in various facets that impact on the school district.

problem solver and seeker
The superintendent is able to resolve conflicts, solve problems and proactively anticipate potential problems that are often effectively solved before they become problems. 
personal integrity

The superintendent is an excellent role model who

"waiks the talk" and demonstrates a commitment to

a well-articulated set of values.

the superintendent is an The superintendent talks freely about the good and advocate for education positive things that are happening in the schools.

The superintendent is aware that the schools belong to the community. The superintendent directs significant energy in selecting and developing the group who directly deliver services to young people, the teachers.

the superintendent is the The superintendent directs, arranges, implements, catalyst in a growth and/or facilitates growth opportunities for environment employees. The administrator encourages involvement in activities that keep staff members on the growing edge of trends in the field. The superintendent is a people developer. The major purpose of delegation is for the growth of the individual. 
the superintendent has

high performance

expectations
The superintendent has high expectations of self

and others. This person expects to be held accountable and will hold others accountable for their performance. The superintendent strives for perfection and expects others to do the same. The superintendent tends to have an excellent understanding of the balance needed between the performer and the performance. The superintendent is continuously looking for growth opportunities for self and others.
the superintendent is an The superintendent is a highly skilled listener and open and honest speaker. The superintendent has considerable communicator knowledge of classroom presentation and discussion techniques. The opportunity to help others in their communication skills gives this person satisfaction. There is a conscious effort to communicate the positive in situations, always conveying the optimistic point of view. 
the superintendent is Prevention and anticipation are key to the

organized and prepared superintendent's management and leadership style.

The superintendent works from specific goals and

priorities. Highly organized and always prepared

are characteristic of this person. The

superintendent has a well-defined order and

structure in both personal and professional lives.

the superintendent is

The superintendent has well-defined thought

self directed

through goals. The focus is on school

administration at any level. Other careers are not of

interest to this person. A mission of imparting

society in positive ways through future generations

is the primary life ambition of the superintendent.

The superintendent's life direction is to serve

others. 
the superintendent promotes stability and objectivity
The superintendent generates a feeling of confidence among those supervised. The patience and calmness of this person lessen even the most tense situations. The administrator makes decisions based on data and input from those affected. The superintendent does not overreact to situations that require stable and objective behavior. communicates

effectively with

education partners
The superintendent is open to employees, students, parents, and community. Effective, empathetic listening skills followed by appropriate action enhance effective communication skills. sets direction for the district
Through effective involvement of the Board, employees and parents the superintendent identifies district directions and acts in a manner that keeps the direction in focus.

manage competently The superintendent has the credentials, knowledge, and experience to effectively manage the district operations either directly or through delegating authority. 


$$
\begin{aligned}
& \text { Uses a broad base of input before making } \\
& \text { decisions and is comfortable in making the } \\
& \text { decisions. }
\end{aligned}
$$

ethical behavior

The superintendent acts and is perceived to be fair in dealing with others. Has a strong ethical basis from which to operate.

team builder

is able to involve others meaningfully by empowering them to do their jobs and demonstrating confidence in their abilities. Is inclusionary in as a broad a way as is practical and realistic

visibility The superintendent is observed throughout the district and community. Employees see the superintendent as a kite as a demonstration of general interest. 
ability to communicate (fully)
- speaking skills

- writing skills (concise, clear, understandable)

- reading skills (can interpret and carry our written instructions)

- work and communicate in a "team" environment

- can effectively use body language in a positive way

- LISTENING SKILLS: This latter being perhaps the most important communication skill of all -Can he/she hear what was really said -- i.e., get the message?

analytical ability

To read the signs -- identify the problems -determine methods of resolving the "challenge". To see past the surface -- to want to resolve the issues identified. 
flexible and adaptable Can recognize a changed or changing environment and personally adapt. Can be flexible in the face of these changes and be seen to recognize and make the necessary adjustments. To sometimes simply make the best of the new mandate.

productive

To be seen to administer a high quality productive enterprise. One that adjusts, changes, and continues to deliver service under difficult circumstances. Key here is for the chief administrator to be personally productive while working with teams and delegating.

enthusiastic One who personally believes in what he/she does and shows it. Not afraid to be seen to want to be the best one can be. Can build a team of enthusiastic players. "Nothing great has ever been accomplished without enthusiasm."

creative Can analyze the need and come up with new or creative solutions. New or better use of resources or talent. Can catch the imagination of his staff or "audience". 
maturity

Prepared to deal with the unexpected -- with

adversity, with criticism -- with change -- with the broad "public" ... and maintain his/her direction and composure -- To build on defeat (losses) as well as victories in a dignified way.

publicly recognizes, The superintendent is aware of the positive rewards and promotes contributions by individuals (teachers, principals, excellence in individual trustees, etc.) and groups (school, plenary and group achievement committees, etc.) and takes advantage of opportunities to recognize and publicize these accomplishments through public forums, written letters, reports to the Ministry, etc.

an effective public The superintendent uses his/her communication speaker skills effectively to promote the messages of the education system to audiences. The superintendent looks for opportunities to engage with the public, and is well respected to capitalize on these opportunities. 
synthesizes global

changes to determine new directions for education (a conceptual thinker)
The superintendent is a visionary that stays current on global changes and reflects on how these forces will affect the education system. The superintendent takes action from the information to create positive influences of these changes. is involved in the business and community influence circle
The superintendent has professional relationships with business and community leaders. This enables him/her to gain insight and information from others outside the educational system to compliment the services of the organization. manages conflict situations effectively
The superintendent is a skilled conflict manager that leaves the parties feeling that they were offered a fair hearing and the decisions made were for the best of the organization as a whole. visible presence within the organization
The superintendent takes every opportunity to be seen and leads by example. His/her request for change is reinforced by engaging in the similar behavior as well. 


\begin{abstract}
ability to identify, select Can identify and attract dedicated staff with the and keep good staff skills and temperament required to undertake the defined job. This includes promotion from within as well as new employees.
\end{abstract}

educational leader a clear understanding of the (always changing)
educational needs and trends and is able to
articulate these with compelling authority, i.e., is at
the forefront of understanding the need for change,
e.g., to more/less vocational training; career
preparation; co-op; languages; IB; etc.

insures staff growth Ensures that staff at all levels do not get stuck in a rut, but will support and implement the changing needs and trends and also stay "fresh" and motivated.

act with integrity The superintendent has a very important role but has limited ability to mandate the changes, rather he must convince the Board, the Dept. of Ed. and unionized staff as appropriate to support his leadership. Integrity is key to gaining this support. 
innovative

politically competent
Able to think laterally and apply innovation to solve problems, enhance education, and provide effective education in a changing environment and a limited budget. long-term thinking and goal setting
Able to prevent politics from interfering with the operation of the District.

listening

The superintendent institutes systems for regularly receiving comment and criticism from customers and staff.

explaining The superintendent makes sure that all staff (customer service) and customers understand what the school system is doing and why.

representing the customer
The superintendent makes sure that customer concerns are addressed and that customer needs and expectations are met by the system. 
caring

The superintendent takes steps to know if customers or service staff are experiencing personal distress and allocates resources to alleviate it.

rewards performance The superintendent provides incentives to customer services staff who exceed customer service targets.
communicate clearly must be able to speak grammatically, enunciate clearly, remain on topic

giving direction

clearly explains to employees where the organization is going, why key decisions are made. For example: "We will open a new school because we have 300 children moving into the area."

recognition and praise provides positive feedback for contributions "And in particular I would like to mention the excellent work of Mary."

good humored smiles a lot, observes and comments about the humor in a situation (never inappropriately or at someone's expense) 

manages time well Keeps a daybook, is on time for appointments, preparation of reports, etc., meets deadlines on commitments made

Allows speaker to complete their thought.

Acknowledges an understanding of what the speaker said prior to responding: "Jim, what I heard you say is that the staff are exhausted and need some recognition. Let me suggest the following..." ability to reframe problems
Can verbally or diagrammatically restate a problem, and thereby bring clarity to the situation. "I have heard the various concerns presented here tonight and, if I have listened well, believe they break down into three categories $A, B$, and $C$..." speaks and writes with confidence
Stating position clearly with a few qualifying phrases or sentences. States opinions whether popular or not. 
leads by example

The superintendent draws on his/her experience and broader knowledge and understanding of both the "big picture" and specific issues or activities to develop and present to followers a positive model of desired attitudes and behavior/performance that they can, in context, emulate or adopt in, or apply or adapt to, their own professional circumstances.

solicits and welcomes The superintendent creates a mood and stakeholder input and environment that conveys to all adult stakeholder criticism groups and individuals that their direct input and (constructive) criticism is both welcome and critical to the success of his/her mission, and implements appropriate mechanisms, both active and passive, to solicit and respond to same. 
spends time with

children
All District decision-making must be predicated on

"what's best for the kids". Accordingly, the

superintendent should spend a significant portion of

each week in the field engaging in candid

conversation with children/adolescents representing

all student constituencies both within and outside

his/her District, takes their views seriously, and factors them into every aspect of decision-making.

(Also, it is my personal view that it is essential that

the superintendent always retain and display

something of the child within his/her character and

personality.)

is a strong, decisive, and Assuming all input has been solicited and weighed

steadfast leader, even in appropriately, the superintendent must be the

the face of opposition or leader, making and communicating his/her

adversity

decisions clearly, rationally and in a timely manner, and supporting what he/she believes is "right" with strength and integrity. 
"lives" his/her vision

From stakeholder input, experience and training, and personal philosophies, the superintendent develops and actively promotes his/her vision of the future of the people and institutions within his/her sphere of influence, broadening that sphere beyond his/her District as appropriate or necessary to influence others in the educational system to adopt whatever elements of that vision he/she deems beneficial to the system/society at large.
is, him/herself, a lifelong
To keep pace with the ever-expanding fields of multi-disciplinary learner education, management and administration, and in ... the modern equivalent order to better understand the rapidly changing of the "Renaissance world his/her students will have to face, the man" superintendent must be possessed of an unquenchable thirst for knowledge of all kinds, and avail him/herself of every opportunity to learn, both formally and informally, especially those that will benefit his/her District directly. 
ensuring that taxpayers Communication in several directions -- taxpayers, and parents feel that parents, teachers, administrators, students -they are getting value for making sure that all constituencies are heard, that money their views are weighed and balanced -- and that the decision is explained and communicated to the stake holders.

ensuring that students

receive a relevant and

useful all-around

education
Keeping on top of new thinking in relation to curricula -- balancing new ideas with traditional subjects -- all in an effort to produce well-rounded students able to function in a modern economy.

ensuring that taxpayers The key to success for a school superintendent is and parents feel that the to have stakeholders feel that it is their school school system is system. Parents seldom have this feeling. responsive to their views

ensuring that appropriate principals, administrators, and teachers are in place.
Services will be delivered by those in the "front lines". Much of a school superintendent's function is devoted to putting the right people in key locations. 
ensuring that physical

facilities are adequate to

the tasks required

ensuring that students

feel that their views are

known and understood

is flexible, but focused has established direction for district, but listens to everyone to search for ideas that will further enhance the goal or its attainment

emphasizes professional continually demonstrates the improvement ethic by growth for all staff making his learning goals public and demonstrating the outcomes of learning and establishing systems that encourage all to learn

is familiar with educational and noneducational editorial and research literature reads widely in many professional areas including education, psychology, history, sociology and fiction with focus on research and ideas to enhance education 
is actively involved in is heavily involved in the job of superintendent, but

many interests also has a well-rounded life: spends time with family, and in recreation; has interests outside of the job

recognizes the

difference between

unlimited wants and

limited resources

good listener

flexible

self explanatory community

self explanatory

self explanatory

moderates the tendency to "try" to provide children and the community all things. Maintain focus on the basics and defined by the local educational

sense of humor

self evident

honesty / integrity

even handed / fair

self evident 
ability to promote change

building trust and confidence
The superintendent helps create, nurture and develop a vision that is consistent with societal trends and directions and that will lead learning systems to new levels of relevance and accountability: businesses wanting to partner with the schools, innovators developing and delivering curriculum in the area of the "new basics", enthusiasm by students for going to school, positive comments by parents / press, and staff using the language of change.

The superintendent builds trust and confidence with staff, parents, and trustees through consistent behavior, moral integrity, personal commitment, and thoughtful reactions. (Boy he works hard; he really is doing some good things, he listened and changed his mind, he's not prepared to "cave in" to pressure groups.) 
taking advantage of the The superintendent knows staff strengths and is "leadable moment" able to align those strengths with opportunities that contribute to moving the organization towards its mission: linking key teachers with a Ministry initiative to develop a pilot on Information Management.

having the pulse of the organization
The superintendent anticipates and deals with issues before he is forced to react to them: consults and gathers information on a suggested Board policy that is anticipated to upset staff. acting in a decisive manner
The superintendent understands his role and responsibility to the degree that he knows when he must act in a quick and decisive manner for the benefit of staff, students and/or parents: (a perceived threat to students is met by increased security, communication to parents, and awareness programs for students. 
communicating

accurately about the

system's successes and

failures
The superintendent has procedures in place that provide accurate feedback on the performance levels of programs, students, and staff; and that the superintendent reports publicly in written or oral form the strengths and areas requiring attention in the system (through an annual report that details performance in areas of student achievement, program performance, resource allocation, etc.)

ability to read non-verbal The superintendent is able to listen and observe the cues and/or interpret the verbal and non-verbal messages and is able to "real" message in verbal discern what the basic underlying thrust of the communication discussion is about (a parent's concern about drug usage in school is tied to a personal tragedy in the family). 


\section{Appendix E \\ Round One Transition Text Document}

\begin{tabular}{ll}
\hline Behaviour & \multicolumn{1}{c}{ Description / Descriptors } \\
\hline walking around & visiting schools and other workplaces to see and hear how \\
and cheerleading & $\begin{array}{l}\text { people are feeling and finding positive achievements to } \\
\text { celebrate with them }\end{array}$ \\
and theirlearning & $\begin{array}{l}\text { parent gatherings, always include talk about children } \\
\text { learning to live their lives more effectively and their need } \\
\text { to take charge of their learning at the earliest age possible } \\
\text { (near end of primary) Taking charge includes being part } \\
\text { of the decision-action cycle on matters such as school } \\
\text { yard behaviour, overall learning plan, evaluation of } \\
\text { achievement ... for these goals children need skills } \\
\text { (mediation, negotiation, goal setting, ethics, ...) in addition } \\
\text { to the regular curriculum and adults who believe and } \\
\text { expect children to rise to the occasion. }\end{array}$ \\
\hline
\end{tabular}




$\begin{array}{ll}\text { focus of the } & \text { Establish and keep personal contact with local leaders } \\ \text { community } & \text { of media, government organizations, service clubs, } \\ & \text { business and unions ... Through words and actions keep } \\ \text { the district (admin, board, etc.) thinking about its duality } \\ \text { of customers: children and taxpayers. Also these two } \\ \text { customers express apparently differing needs (results and } \\ \text { competition/comparison) by taxpayers and children need } \\ \text { their strengths celebrated. Satisfying these needs } \\ \text { simultaneously is only possible through careful planning. }\end{array}$

focus on the

business

(purposefof the

schooldistrict
- ensure the Board develops and publishes values

and beliefs that are subscribed to by all

- develop strategic directions that fit values/beliefs

- Foster a working together climate that brings students, trustees, parents, employees, organizations ... into a process that produces priorities and achievements. Formal structures remain in the background when work of district is being done. 
consistent

practice of

highest ethical

standards
- honest, open relationships of high integrity with individuals, leaders of unions, trustees, etc.

- clear expectations and standards of behaviour expected and processes to follow-up fairly complaints or concerns

\begin{abstract}
focus on people and-participative leadership

- growth orientation for all people

- encouragement and support for people to use judgment and to be self-reliant in carrying out daily work
\end{abstract}

- people need to feel challenged, encouraged and developed within a climate where people care about our central purpose "children meaning to live their lives more effectively"

be-attentive, superintendent shall encourage those involved and concerned, and affected to be included in decision making process flexible-but firm 


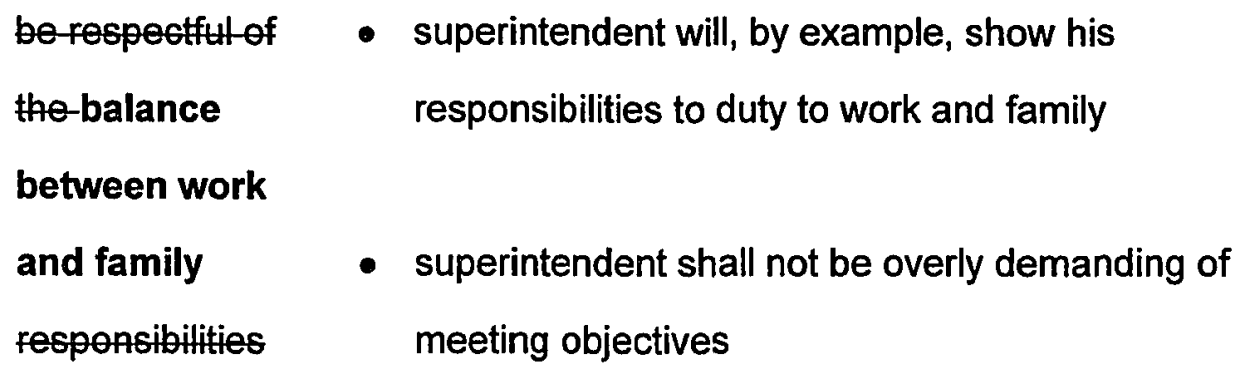
be decisive superintendent shall investigate problem situations expeditiously without too long a delay to arrive at problem solving solutions; favoritism shall not enter into the resolution process
- superintendent is the responsible authority in the staffand-take District responsibility
- he/she shall not absolve his/her self from responsibility by laying blame on others

be consistent - superintendent shall interpret policy with set guidelines to show connections

- superintendent shall express all policies and guidelines so all customers do not misinterpret or misunderstand set rules and boundaries 


\begin{abstract}
impacting-on
- superintendent supports leadership development

leadership of

programs designed by the school-based administrators

principats and

vice-principals

- superintendent sets high expectations that schoolbased administrators engage in personal development of leadership skills
\end{abstract}

monitors the

- superintendent leads (by delegation) in the creation of

system monitoring systems with a focus on "results" and indicators of quality

- monitoring system is the result of consultation and is one that gathers data of use to all levels of the system for decision making

servesasa "midurfe" to the systems
- publicly refers to the vision of the system (mission) and ensures that opportunity for all persons (employees) (parents) (community) (trustees) have opportunity to help in creating the vision and in proclaiming the vision

- how: writing, speaking, endorsing, consulting 


$\begin{aligned} & \text { hold the system } \\ & \text { accountable-for }\end{aligned}$
$\begin{aligned} & \text { results and challenges others to engage in self and } \\ & \text { program assessment leading to plans for improvement }\end{aligned}$
$\begin{aligned} & \text { - } \\ & \text { superintendent facilitates others to draw conclusions } \\ & \text { about effectiveness of their programs, efforts and } \\ & \text { decisions and does not serve the role of judge }\end{aligned}$

$\begin{array}{ll}\begin{array}{l}\text { building } \\ \text { relationships }\end{array} & \text { heaperintendent builds personal relationships with } \\ \text { with partner } & \text { school administrators, district staff and trustees; such is } \\ \text { groups } & \text { done through visits, meetings, social contact, consultation, } \\ & \text { correspondence }\end{array}$

ensuring superintendent sets personal example and causes all adherence to alleged breaches to be properly investigates and protocols, appropriately responded to agreements, due process, and ethical conduct 
facilitates requires review of all programs to ensure that priorities are establishment of understood and are acknowledged and accepted by all prioritieswithin partners

constraints-of

limited resoufces

and with respect

to the-system's

mandate

focusing on The superintendent constantly asks: What do we want to

what really achieve? Where do we want to go? and then says:

counts What do we have to do to get there?

modeling the The superintendent doesn't just ask others to change. He behaviour he changes himself. He hands over responsibility to experse tho who are best able to accomplish tasks and lets those people determine best action, etc. He empowers others. 


\begin{abstract}
listening The superintendent listens carefully to parents / public / attentively students to ensure the system is focused on meeting client / customer needs. The superintendent listens to employees carefully to ensure the organizational needs and personal needs of employees are not in direct conflict. The superintendent listens to the solutions brought to him by those responsible for executing the business of the organization.
\end{abstract}

sharing the The superintendent articulates in word and deed the deep vision underlying purpose of the school district -- to educate all students to the limits of their potential -- with employees, parents, the public. The superintendent is a pastoral shepherd, tending the flock -- he oversees the design of a process which ensures all employers understand and share with each other the key purposes for which they all work. (No person is an island, able to survive outside the whole.)

building trust establishing a climate where the individual feels free to bring forward concerns and to explore those concerns with both one-to-one and in management group meetings 
focusing on the consistently acting and encouraging others to act in primary activity harmony with the primary activity of the district of the organization (i.e., educating Ghildren and adults)

$\begin{array}{ll}\text { bringing } & \text { political interference and budget restraint are creating } \\ \text { purpose to } & \text { great confusion. The superintendent must constantly help } \\ \text { chaos } & \text { all to cut through this chaos to do the best for education. }\end{array}$

communication believe that a well-informed board, management, staff, students, and public will eventually lead to the best education system and set up those systems and practice the necessary openness to see that communications are effective

$\begin{array}{ll}\text { have a values- } & \text { base complex decisions on a set of values and be able } \\ \text { driven (principle } & \text { to articulate those values and justify decisions based on } \\ \text { centred) } & \text { those } \\ \text { leadership style } & \end{array}$




\begin{abstract}
respect people demonstrate both in words and actions, a belief in the inherent worth of people and their ability to make a valuable contribution
\end{abstract}
foster a climate encourage staff to innovate in program areas and activity
of innovations promote innovation both in communication and material
and risk taking to support
improve-students
outcomes
Greate-a learning encourage all staff to become lifelong learners by organization serving as an example
integrity is recognized as having principles and values that he I she not only expresses but lives by

communication concern for dispensing and sharing information -- as required -- in varying working relationships (e.g., senior staff $\rightarrow$ staff $\rightarrow$ community). Communications are done on a pro-active and in a regular manner using clear and precise language 
knowledge As a superintendent of schools, the leader must

demonstrate a knowledge of educational matters and the ability to "move forward". The leader must also have a knowledge and grasp of financial and human resources issues -- i.e., leadership role is greatly expanded from original training as a classroom teacher.

organizational In the role a superintendent the successful individual skills demonstrates an ability to manage a number of diverse and complex issues.

\begin{tabular}{|c|c|}
\hline $\begin{array}{l}\text { planningt } \\
\text { visionary }\end{array}$ & $\begin{array}{l}\text { Closely related to orcanizational ability, the successful } \\
\text { leader plans for the present needs and identifies future }\end{array}$ \\
\hline & $\begin{array}{l}\text { needs. The identification of future needs not only reflects } \\
\text { dealing with the unknown but implementing new ventures. }\end{array}$ \\
\hline
\end{tabular}

interpersonal As a leader, an individual works with many individuals and skills groups. Listening, reasoning, mediation, and conflict resolution skills are among many others, well applied, are required for success.

risk taking The ability to know when to take a risk, to expand success and not be daunted with failure. At the same time, the risks should not be foolhardy 
planning for the The superintendent is able to forecast trends and to future engage people in taking steps to prepare for change circumstances.

engaging in The superintendent models engagement in professional professional development and applies and refines acquired skills growth

facilitating The superintendent employees effective communication interchange of skills with small and large groups ideas

$\begin{array}{ll}\text { maintaining } & \text { The superintendent is sensitive to the political } \\ \text { political } & \text { dynamics of the system and is able to take appropriate } \\ \text { equilibrium } & \text { steps to adjust to system changes and personal agendas. }\end{array}$

negotiating The superintendent is able to employ conflict resolution and collaborative decision making within the context of individuals strategic changes and personal / organization

engaging The superintendent is able to delegate wisely and to develop teamwork (illegible) with shared vision I field of mission/guiding principles specialization 
The superintendent is effective in coping with a broad

thforeseen agenda and to prioritize needs with skill and finesse requirements

interpersonal

skills

The superintendent is able to utilize a broad range of interpersonal skills to communicate with diverse groups of people and individuals, thus building a culture characterized by trusting an open relationships.

sompetence

The superintendent is knowledgeable of the organization and of factors which impact on the organization.

Decisions are made based on an appropriate basis and processes are clearly established for seeking new knowledge.

\section{forward tookingt The superintendent demonstrates a clear sense of visionary direction and is able to build commitment. As a vision for the organization. The vision is well articulated and the employers are confident that there is a clear distinction.}

innovative and The superintendent demonstrates that she is not content creative with the status quo and articulates / values continuous improvement, risk taking and new ideas. 
caring

The superintendent demonstrates through her actions and

others communicative processes that she cares both

about the people she works with and about public

education itself.

visible

The superintendent is visibly in school and meetings and

demonstrates that it is important to spend her time in

interaction with people in various facets that impact on

the school district.

problem solver The superintendent is able to resolve conflicts, solve

and seeker

problems and proactively anticipate potential problems

which are often effectively solved before they become problems.

personal The superintendent is an excellent role model who "walks
integrity
the talk" and demonstrates a commitment to a well-
articulated set of values.


The superintendent talks freely about the good and superintendentis positive things that are happening in the schools. The anadvocate for superintendent is aware that the schools belong to the education community. The superintendent directs significant energy in selecting and developing the group who directly deliver services to young people, the teachers.

the superintendentis the-catalyst in a growth environment

the superintendent has-high performance expectations
The superintendent directs, arranges, implements, and/or facilitates growth opportunities for employees. The administrator encourages involvement in activities that keep staff members on the growing edge of trends in the field. The superintendent is a people developer. The major purpose of delegation is for the growth of the individual. 
the

superintendent is

antopen and

honest

communicator communication skills gives this person satisfaction. There

is a conscious effort to communicate the positive in situations, always conveying the optimistic point of view.

The superintendent is a highly skilled listener and

speaker. The superintendent has considerable

knowledge of classroom presentation and discussion

techniques. The opportunity to help others in their$$
\text { shuations, always conveying the optimistic point of view. }
$$

\begin{abstract}
the
superintendent is

organized and

prepared

Prevention and anticipation are key to the

superintendent's management and leadership style. The

superintendent works from specific goals and priorities.

Highly organized and always prepared are characteristic of

this person. The superintendent has a well defined order

and structure in both personal and professional life.
\end{abstract}

the

The superintendent has well defined thought through

superintendentis

goals. The focus is on school administration at any

self directed

level. Other careers are not of interest to this person. A

mission of imparting society in positive ways through

future generations is the primary life ambition of the

superintendent. The superintendent's life direction is to

serve others. 
the

superintendent

promotes

stability and

objectivity
The superintendent generates a feeling of confidence among those supervised. The patience and calmness of this person lessens even the most tense situations. The administrator makes decisions based on data and input from those affected. The superintendent does not overreact to situations which require stable and objective behaviour.

communicates The superintendent is open to employees, students, parents, and community. Effective, empathetic listening education skills followed by appropriate action enhance effective partners communication skills.

sets direction-for Through effective involvement of the Board, employees the district and parents the superintendent identifies district directions and acts in a manner that keeps the direction in focus.

manage The superintendent has the credentials, knowledge, and competently experience to effectively manage the district operations either directly or through delegating authority.

decision making Uses a broad base of input before making decisions and is comfortable in making the decisions. 
ethical

behaviour

team builder

visibility
The superintendent acts and is perceived to be fair in dealing with others. Has a strong ethical basis from which to operate.

is able to involve others meaningfully by empowering them to do their jobs and demonstrating confidence in their abilities. Is inclusionary in as a broad a way as is practical and realistic

The superintendent is observed throughout the district and community. Employees see the superintendent as a kite as a demonstration of general interest. 
ability to

communicate

(fully)

- writing skills (concise, clear, understandable)

- reading skills (can interpret and carry our written instructions)

- work and communicate in a "team" environment

- can effectively use body language in a positive way

- LISTENING SKILLS: This latter being perhaps the most important communication skill of all -- Can he/she hear what was really said -- i.e. get the message?

analytical ability To read the signs -- identify the problems -- determine methods of resolving the "challenge". To see past the surface -- to want to resolve the issues identified. 


\begin{abstract}
flexible and Can recognize a changed or changing environment and adaptable personally adapt. Can be flexible in the face of these changes and be seen to recognize and make the necessary adjustments. To sometimes simply make the best of the new mandate.
\end{abstract}

productive To be seen to administer a high quality productive enterprise. One that adjusts, changes, and continues to deliver service under difficult circumstances. Key here is for the chief administrator to be personally productive while working with teams and delegating.

\begin{tabular}{|c|c|}
\hline enthusiastic & $\begin{array}{l}\text { One who personally believes in what he/she does and } \\
\text { shows it. Not afraid to be seen to want to be the best } \\
\text { one can be. Can build a team of enthusiastic players. } \\
\text { "Nothing great has ever been accomplished without } \\
\text { enthusiasm." }\end{array}$ \\
\hline creative & $\begin{array}{l}\text { Can analyze the need and come up with new or creative } \\
\text { solutions. New or better use of resources or talent. Can } \\
\text { catch the imagination of his staff or "audience". }\end{array}$ \\
\hline
\end{tabular}


maturity

Prepared to deal with the unexpected -- with adversity, with criticism -- with change -- with the broad "public" ... and maintain his/her direction and composure -- To build on defeat (losses) as well as victories in a dignified way.

publicly The superintendent is aware of the positive contributions

recognizes, by individuals (teachers, principals, trustees, etc.) and rewards and groups (school, plenary committees, etc.) and takes promotes advantage of opportunities to recognize and publicize excellence-in these accomplishments through public forums, written individuatand letters, reports to the Ministry, etc.

group achievement

an effective The superintendent uses his/her communication skills public speaker effectively to promote the messages of the education system to audiences. The superintendent looks for opportunities to engage with the public, and is well respected to capitalize on these opportunities. 
synthesizes The superintendent is a visionary that stays current on global changes global changes and reflects on how these forces will affect to the education system. The superintendent takes action directions for from the information to create positive influences of these education fa changes.

conceptual thinker)

is involved in the The superintendent has professional relationships with business and business and community leaders. This enables him/her community to gain insight and information from others outside of the educational system to compliment the services of the organization.

$\begin{array}{ll}\text { manages } & \text { The superintendent is a skilled conflict manager that } \\ \text { conflict } & \text { leaves the parties feeling that they were offered a fair } \\ \text { situations } & \text { hearing and the decisions made were for the best of the } \\ \text { effectively } & \text { organization as a whole. }\end{array}$

visible presence The superintendent takes every opportunity to be seen within the and leads by example. His/her request for change is organization reinforced by engaging in the similar behaviour as well. 


\begin{tabular}{ll}
$\begin{array}{l}\text { ability to } \\
\text { identify, select }\end{array}$ & $\begin{array}{l}\text { Can identify and attract dedicated staff with the skills } \\
\text { and keep good }\end{array}$ \\
staff & This includes promotion from within as well as new \\
employees. & \\
\hline educational & Has a clear understanding of the (always changing) \\
leader & educational needs and trends and is able to articulate \\
these with compelling authority, i.e. is at the forefront of \\
understanding the need for change, e.g. to more/less \\
vocational training; career preparation; co-op; languages; \\
IB; etc. etc. \\
insures staff \\
Insures that staff at all levels do not get stuck in a rut, but \\
will support and implement the changing needs and trends \\
and also stay "fresh" and motivated.
\end{tabular}

act with integrity The superintendent has a very important role but has limited ability to mandate the changes, rather he must convince the Board, the Dept. of Ed. and unionized staff as appropriate to support his leadership. Integrity is key to gaining this support. 


$$
\begin{aligned}
& \text { innovative Able to think laterally and apply innovation to solve } \\
& \text { problems, enhance education, and provide effective } \\
& \text { education in a changing environment and a limited budget. }
\end{aligned}
$$

$$
\begin{array}{ll}
\text { politically } & \text { Able to prevent politics from interfering with the } \\
\text { competent } & \text { operation of the District. }
\end{array}
$$

long-term The superintendent carries out or uses research to

thinking goal develop improvements in the school system that will be setting needed in the future by future customers.

listening The superintendent institutes systems for regularly receiving comment and criticism from customers and staff.

explaining The superintendent makes sure that all staff (customer service) and customers understand what the school system is doing and why.

representing the The superintendent makes sure that customer concerns customer are addressed and that customer needs and expectations are met by the system. 
caring

rewards

performance

communicate

clearly

giving direction
The superintendent takes steps to know if customers or service staff are experiencing personal distress and allocates resources to alleviate it.
The superintendent provides incentives to customer services staff who exceed customer service targets.

must be able to speak grammatically, enunciate clearly, remain on topic

clearly explains to employees where the organization is going, why key decisions are made. For example: "We will open a new school because we have 300 children moving into the area.

recognition and provides positive feedback for contributions "And in praise particular I would like to mention the excellent work of Mary."

good humored smiles a lot, observes and comments about the humor in a situation (never inappropriately or at someone's expense) 

manages time Keeps a daybook, is on time for appointments, well preparation of reports, etc., meets deadlines on commitments made

listens well Allows speaker to complete their thought. Acknowledges an understanding of what the speaker said prior to responding: "Jim, what I heard you say is that the staff are exhausted and need some recognition. Let me suggest the following..."

\begin{abstract}
ability to reframe Can verbally or diagrammatically restate a problem, and problems thereby bring clarity to the situation. "I have heard the various concerns presented here tonight and, if I have listened well, believe they break down into three categories A, B, and C ..."
\end{abstract}

speaks and Stating position clearly with a few qualifying phrases or writes with sentences. States opinions whether popular or not. confidence 


\begin{abstract}
leads by The superintendent draws on his/her experience and example broader knowledge and understanding of both the "big picture" and specific issues or activities to develop and present to followers a positive model of desired attitudes and behavior/performance that they can, in context, emulate or adopt in, or apply or adapt to, their own professional circumstances.
\end{abstract}

solicits and The superintendent creates a mood and environment that welcomes conveys to all adult stakeholder groups and individuals stakeholder that their direct input and (constructive) criticism is both input and welcome and critical to the success of his/her mission, and griticism implements appropriate mechanisms, both active and passive, to solicit and respond to same. 
spends time All District decision-making must be predicated on "what's

with children best for the kids". Accordingly, the superintendent should spend a significant portion of each week in the

field engaging in candid conversation with children/adolescents representing all student constituencies both within and outside his/her District, takes their views seriously, and factors them into every aspect of decision-making. (Also, it is my personal view that it is essential that the superintendent always retain and display something of the child within his/her character and personality.)
is a strong,
Assuming all input has been solicited and weighed
decisive, and appropriately, the superintendent must be the leader, steadfast leader, making and communicating his/her decisions clearly, even in the face rationally and in a timely manner, and supporting what ofoppesition of he/she believes is "right" with strength and integrity. adversity 


\begin{abstract}
"lives" his/her From stakeholder input, experience and training, and vision personal philosophies, the superintendent develops and actively promotes his/her vision of the future of the people and institutions within his/her sphere of influence, broadening that sphere beyond his/her District as appropriate or necessary to influence others in the educational system to adopt whatever elements of that vision he/she deems beneficial to the system/society at large.
\end{abstract}
is, him/herself, a To keep pace with the ever-expanding fields of education, lifelong multi- management and administration, and in order to better disciplinary understand the rapidly changing world his/her students will learner the have to face, the superintendent must be possessed of an unquenchable thirst for knowledge of all kinds, and equivalent the avail him/herself of every opportunity to learn, both "Renaissance formally and informally, especially those that will benefit man" his/her District directly.

ensuring that Communication in several directions -- taxpayers,
paxpayers and the teachers, administrators, students -- making sure
parents feet that that all constituencies are heard, that their views are
whey
value for money explained and communicated to the stake holders.


ensuring that Keeping on top of new thinking in relation to curricula -students receive balancing new ideas with traditional subjects -- all in an a relevant-and effort to produce well-rounded students able to function in usefulallaround a modern economy. education

ensuring that The key to success for a school superintendent is to have taxpayers stakeholders feel that it is their school system.

parents feel that Parents seldom have this feeling.

the school-system

is-responsive to

their views

ensuring that Services will be delivered by those in the "front lines". appropriate Much of a school superintendent's function is devoted to principals, putting the right people in key locations. administrators, and teachers are in place. 
ensuring that

physical

facilities are

adequate to the

tasks-required

ensuring that

students feel that

theirviews are

knownand

understood

is flexible, has established direction for district, but listens to

focused everyone to search for ideas that will further enhance the

goal or its attainment

emphasizes

continually demonstrates the improvement ethic by

professional making his learning goals public and demonstrating the

growth for all outcomes of learning and establishing systems that

staff

encourage all to learn 
is familiar with reads widely in many professional areas including

educational and education, psychology, history, sociology and fiction with

non-educational focus on research and ideas to enhance education

editoriatand

research

literature

\begin{abstract}
is actively is heavily involved in the job of superintendent, but also
involved in has a well-rounded life: spends time with family, and in

many interests recreation; has interests outside of the job
\end{abstract}

recognizes the moderates the tendency to "try" to provide children and

difference the community all things. Maintain focus on the

between basics and defined by the local educational

unlimited wants community

and limited

resources

good listener self explanatory

flexible self explanatory

sense of humor self explanatory 


honesty $1 \quad$ self evident
integrity

even handed $I$ self evident

fair

ability to The superintendent helps create, nurture and develop a

promote change vision that is consistent with societal trends and directions

and that will lead learning systems to new levels of

relevance and accountability: businesses wanting to

partner with the schools, innovators developing and

delivering curriculum in the area of the "new basics",

enthusiasm by students for going to school, positive

comments by parents/ press, and staff using the language

of change.

building trust The superintendent builds trust and confidence with staff, andents, and trustees through consistent behavior, moral integrity, personal commitment, and thoughtful reactions. (Boy he works hard; he really is doing some good things, he listened and changed his mind, he's not prepared to "cave in" to pressure groups.) 
taking advantage The superintendent knows staff strengths and is able to of the-leadable align those strengths with opportunities that contribute moment" to moving the organization towards its mission: linking key teachers with a Ministry initiative to develop a pilot on Information Management.

having the pulse The superintendent anticipates and deals with issues of the before he is forced to react to them: consults and organization gathers information on a suggested Board policy that is anticipated to upset staff.

actingina The superintendent understands his role and responsibility

decisive manner to the degree that he knows when he must act in a quick and decisive manner for the benefit of staff, students and/or parents: (a perceived threat to students is met by increased security, communication to parents, and awareness programs for students. 
communicating The superintendent has procedures in place that provide accurately about accurate feedback on the performance levels of programs, thesystem's students, and staff; and that the superintendent reports suceseses and publicly in written or oral form the strengths and areas failures requiring attention in the system (through an annual report that details performance in areas of student achievement, program performance, resource allocation, etc.)

ability to read The superintendent is able to listen and observe the verbal non-verbal cues and non-verbal messages and is able to discern what the and/orinterpret basic underlying thrust of the discussion is about (a the "real" parent's concern about drug usage in school is tied to a message in personal tragedy in the family).

verbal sommunisation

\section{Key to text formats:}

$\begin{array}{lll}\text { bold text } & = & \text { suggested behavior } \\ \text { strikethrough text } & = & \text { text to be deleted } \\ \text { bold and underlined text } & = & \text { suggested descriptor }\end{array}$




\section{Appendix F}

\section{Synthesized Behavior and Description Document}

\begin{tabular}{|c|c|c|}
\hline Grouping & Behaviour & Description / Descriptors \\
\hline $\mathbf{x x}$ & - flexible & \\
\hline $\mathbf{x x}$ & - even handed / fair & \\
\hline 01 & - walking around & \\
\hline & - visible & $\begin{array}{l}\text { interaction with people in various } \\
\text { facets }\end{array}$ \\
\hline & - visibility & $\begin{array}{l}\text { observed throughout the district } \\
\text { and community }\end{array}$ \\
\hline & - visible presence & to be seen and leads by example \\
\hline
\end{tabular}


- leads by example a positive model of desired attitudes

02 focus on learning

always include talk about children learning

adults who believe and expect children to rise to the occasion.

- focusing on what

What do we want to achieve? really counts

What do we have to do to get there?

- focusing on the

prioritize needs with skill primary activity

- spends time with

"what's best for the kids" children

each week in the field 
- recognizes the difference between

unlimited wants and limited resources children and the community all things

Maintain focus on the basics and defined by the local educational community
03

- focus of the community contact with local leaders

duality of customers: children and taxpayers.
- building relationships

superintendent builds personal relationships

- maintaining political sensitive to the political dynamics equilibrium

- involved in business and community professional relationships with business and community

- politically competent

prevent politics from interfering with the operation 
- representing the customer concerns are addressed customer

- solicits and all adult stakeholder welcomes stakeholder input

- ensuring value for

Communication in several money directions

- responsive to views

stakeholders feel that it is their school system

04 focus on purpose

develops and publishes values and beliefs

develop strategic directions

working together climate

- facilitates establishment of priorities opportunity to help in creating the vision 
- sharing the vision

deep underlying purpose

pastoral shepherd

- bringing purpose to

teamwork with shared vision / chaos mission / guiding principles

- have a values-driven

base complex decisions on a set leadership style of values

- planning for the

forecast trends future

- visionary

a clear sense of direction and is able to build commitment

- sets direction

- analytical ability

read the signs

- synthesizes global visionary changes 
- long-term thinking uses research to develop improvements

- giving direction

explains to employees where the organization is going

- ability to reframe

restate a problem

problems

- "lives" his/her vision

From stakeholder input, develops and actively promotes his/her vision

- flexible, focused

- ability to promote change

- "leadable moment"

able to align those strengths with opportunities

its mission 
05 ethical standards

- honesty / integrity honest, open relationships

clear expectations and standards of behaviour

- ensuring adherence sets personal example to protocols, ethical conduct

- integrity

values

lives by
- personal integrity
"walks the talk"

- ethical behaviour

strong ethical basis

\begin{tabular}{lll}
\hline $06 \quad$ act with integrity & Integrity \\
\hline & leadership & growth orientation \\
& people need to feel challenged, \\
& encouraged and developed \\
\hline
\end{tabular}


- concern

- modeling the behaviour included in decision making

supports leadership development

sets high expectations

hands over responsibility

empowers others.

- learning organization all staff to become lifelong learners

- catalyst in a growth environment

- decision making

broad base of input

- team builder facilitates growth opportunities for employees

- insures staff growth 
- lifelong multidisciplinary learner

- professional growth possessed of an unquenchable thirst for knowledge of all kinds demonstrates the improvement ethic

learning goals

07

- balance between work and family

- is actively involved in well-rounded life many interests

08

- be decisive

favoritism shall not enter

- take responsibility

- maturity

Prepared to deal with the unexpected

- decisive

build on defeat

a dignified way. 
- a strong, decisive, must be the leader and steadfast leader

rationally

timely manner

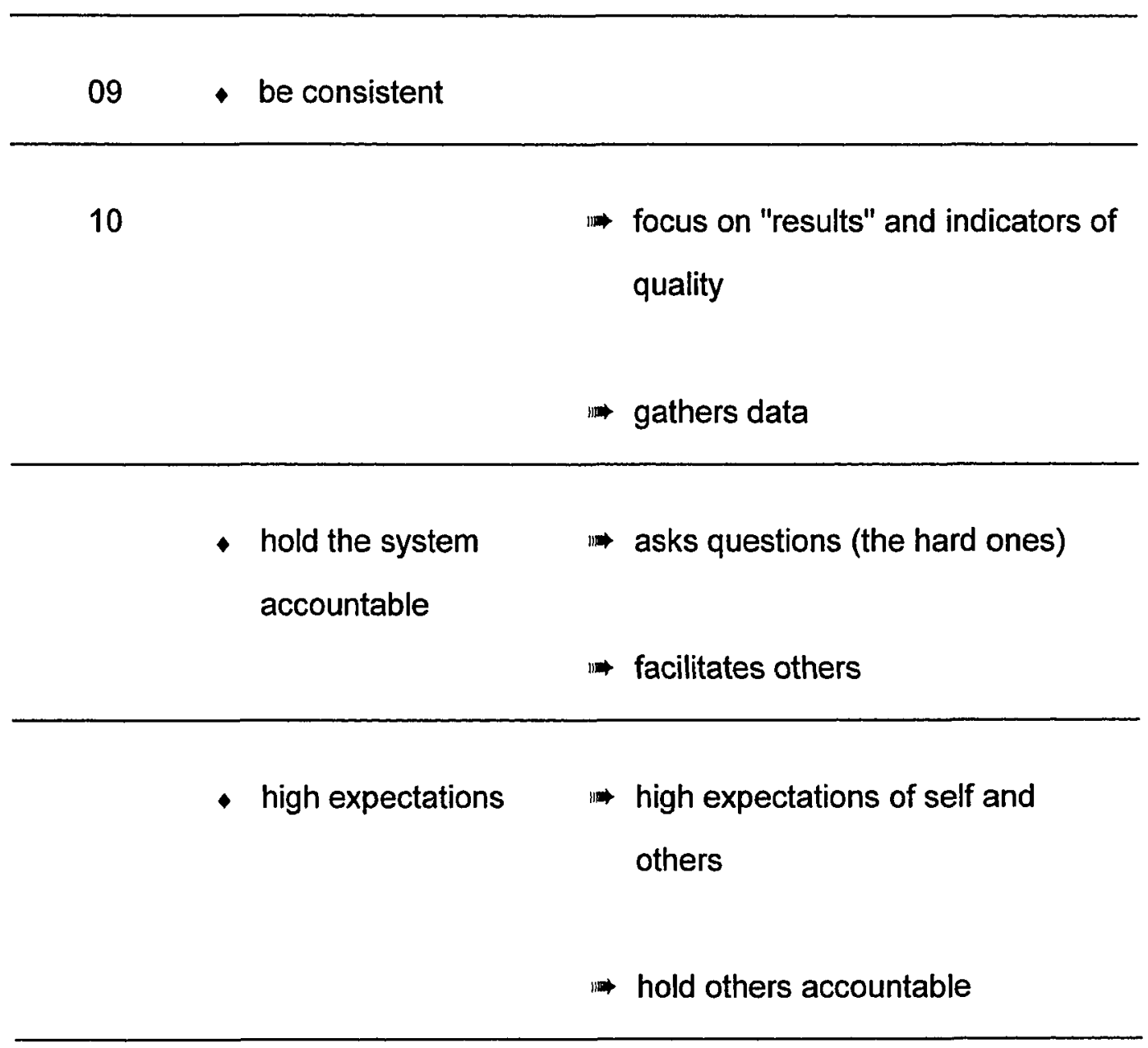


- promotes stability and objectivity generates a feeling of confidence among those supervised

\section{decisions based on data}

11 listening attentively

listens carefully

listens to employees

- communication

practice the necessary openness

\begin{tabular}{ll}
\hline communication & pro-active \\
\hline+ interpersonal skills & Listening, reasoning, mediation, \\
& and conflict resolution skills \\
\hline interchange & effective communication skills \\
\hline & communicate with diverse groups \\
\hline
\end{tabular}


- problem solver and seeker

- open and honest

highly skilled listener and speaker communicator

- communicates

- ability to

"team"

communicate

LISTENING SKILLS: most important

- an effective public communication skills speaker

- manages conflict

skilled conflict manager situations effectively

- listening

institutes systems for regularly receiving comment 
- explaining

understand what the school

system is doing

- communicate clearly

- listens well

- speaks and writes with confidence
States opinions whether popular or not.

- good listener

- pulse of the organization react to them: consults and gathers information

- communicating

- read non-verbal cues

12

- building trust

individual feels free to bring forward concerns

- building trust 
13

- respect people

a belief in the inherent worth of people

- caring

- caring

14 foster a climate; risk encourage staff taking

- risk taking not be daunted with failure

- innovative and

creative

- creative new or creative solutions

- innovative

15 knowledge

demonstrate a knowledge of educational matters

- engaging in

models engagement in

professional growth professional development 
knowledgeable; seeking new knowledge.

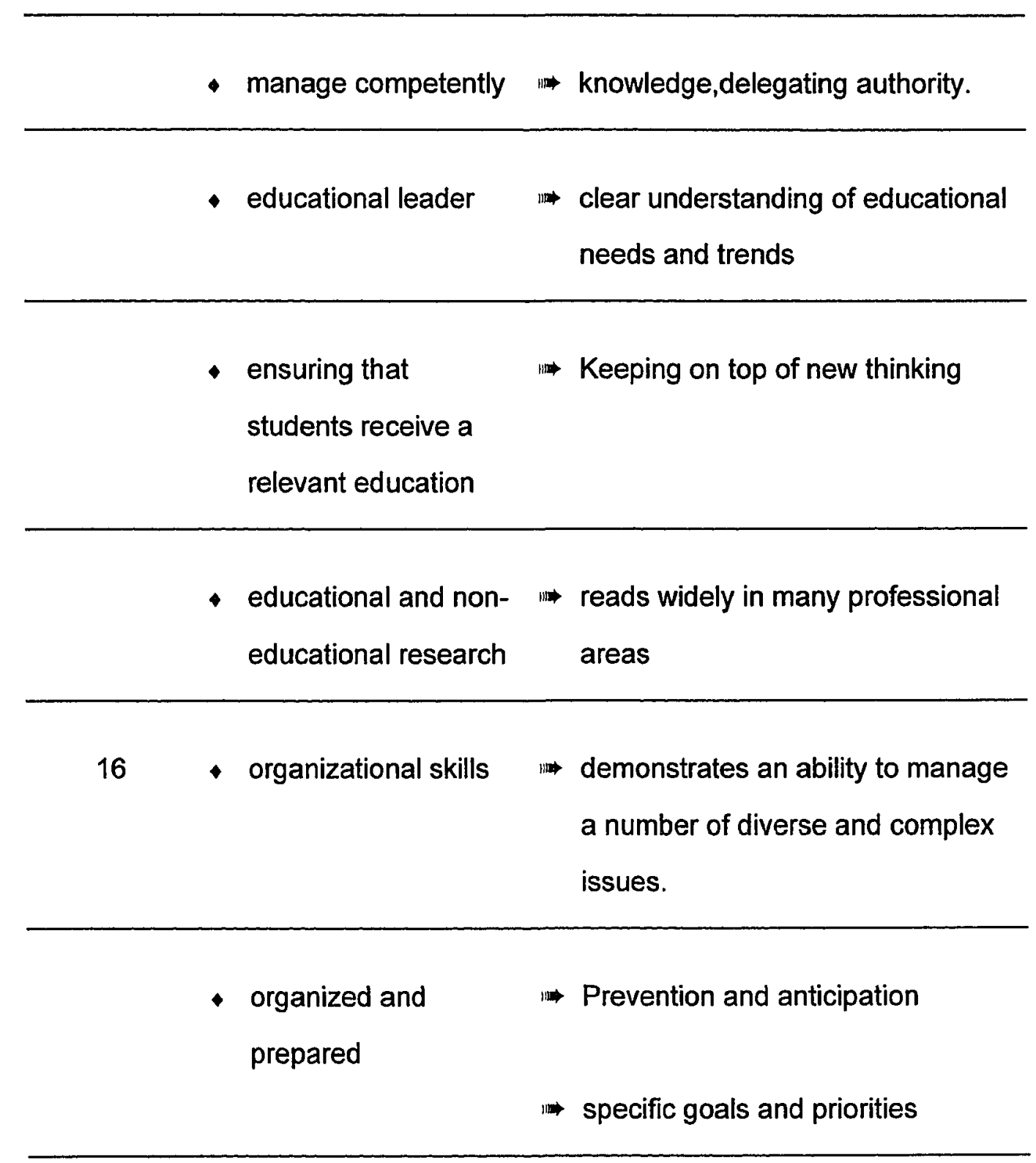


- productive

personally productive while working with teams and delegating.

- manages time well

Keeps a daybook

\begin{tabular}{lll}
\hline $17 \quad$ visionary & identifies future needs \\
\hline $18-$ negotiating & conflict resolution \\
& \\
\hline
\end{tabular}

19

- advocate for

education

$20 \quad$ self directed

focus is on school administration

to serve others.

21 flexible and

flexible in the face of these adaptable changes and be seen to recognize

$22+$ enthusiastic

Not afraid to be seen to want to be the best one can be. 
- recognizes, rewards

and promotes

excellence

- rewards performance

- recognition and

positive feedback for contributions

praise

23 ability to identify,

identify and attract dedicated staff

select and keep good

staff

- good humored

- ensuring that

putting the right people in key

appropriate locations.

principals,

administrators, and

teachers are in place.

- sense of humor 
$24+$ ensuring that

physical facilities are

adequate

Reproduced with permission of the copyright owner. Further reproduction prohibited without permission. 
Appendix G

Round Three Survey Instrument

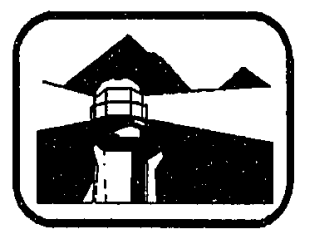

WEST VANCOUVER

SCHOOL DISTRICT \#45

June 20, 1995

Dear Delphi Study Participant:

Thank you very much for your speedy responses to Round 2 . This is the last time I will call upon your time for the survey project.

Please give a rank order for the top seven behaviours that you believe will contribute to a superintendent's success as a leader. The behaviour ranked as \#1 will be the most important and items will progress in descending order.

Due to the urgent need for this data, please send your completed response by FAX to (604) $981-1001$ by Tuesday, June 27, 1995.

Most sincerely yours,

Douglas G. Player

$\mathrm{T}:(604) 981-1000$

1075 - 21 Street

West Vancouver, B.C.

F: (604) 981-1001 V7V 4A9 


\section{Leadership Behaviours Delphi Study}

The study document has been revised based on your input.

PART III:
PLEASE RANK BEHAVIORS IN ORDER OF
IMPORTANCE
(USE (1) TO REPRESENT THE MOST IMPORTANT BEHAVIOUR,
(2) TO IDENTIFY THE SECOND MOST IMPORTANT BEHAVIOUR, ETC.)

\section{What are the behaviors that are essential to successful \\ leadership by a superintendent of schools?}

\begin{tabular}{||c||l|l|}
\hline $\begin{array}{c}\text { Your } \\
\text { Rank }\end{array}$ & \multicolumn{1}{|c|}{ Behavior } & \multicolumn{1}{c|}{ How demonstrated } \\
\hline \hline & $\begin{array}{l}\text { Exhibits a visible } \\
\text { presence by } \\
\text { employing } \\
\text { Management By } \\
\text { Walking Around } \\
\text { (MBWA) } \\
\text { electronically and } \\
\text { physically }\end{array}$ & $\begin{array}{l}\text { Spends time in the field } \\
\text { interacting with } \\
\text { instructional and support } \\
\text { personnel at all levels of } \\
\text { the organization and within } \\
\text { the community }\end{array}$ \\
\hline
\end{tabular}




\begin{tabular}{||l|l|l|}
\hline 2. & $\begin{array}{l}\text { Focuses on the } \\
\text { primary activity of the } \\
\text { organization -- } \\
\text { learning }\end{array}$ & $\begin{array}{l}\text { Manages attention by } \\
\text { directing the focus of } \\
\text { employees to what is best } \\
\text { for student learning }\end{array}$ \\
\hline \hline $\begin{array}{l}\text { Builds, maintains, } \\
\text { and fosters } \\
\text { relationships within } \\
\text { and without the } \\
\text { organization }\end{array}$ & $\begin{array}{l}\text { Cultivates relationships } \\
\text { with all "customers" and } \\
\text { partners of the system } \\
\text { through regular contact } \\
\text { and communication, e.g., } \\
\text { using business } \\
\text { partnerships as a way of } \\
\text { creating change and } \\
\text { developing resources }\end{array}$ \\
\hline $\begin{array}{l}\text { Develops, shares, } \\
\text { and focuses on a } \\
\text { vision of the } \\
\text { organization that } \\
\text { leads to the future }\end{array}$ & $\begin{array}{l}\text { Collaboratively develops a } \\
\text { vision which the } \\
\text { Superintendent then } \\
\text { employs as an underlying } \\
\text { purpose for all strategic } \\
\text { goal-setting and decisions }\end{array}$ \\
\hline \hline $\begin{array}{l}\text { Maintains ethical } \\
\text { standards and } \\
\text { integrity }\end{array}$ & $\begin{array}{l}\text { Establishes and operates } \\
\text { on a set of clear } \\
\text { expectations and } \\
\text { standards of behavior }\end{array}$ \\
\hline
\end{tabular}




\begin{tabular}{||l|l|l|}
\hline 6. & $\begin{array}{l}\text { Creates and nurtures } \\
\text { a Learning } \\
\text { Community culture }\end{array}$ & $\begin{array}{l}\text { Actively fosters a learning } \\
\text { community by } \\
\text { demonstrating a personal, } \\
\text { unquenchable thirst for } \\
\text { knowledge while providing } \\
\text { and supporting } \\
\text { opportunities for employee } \\
\text { growth and leadership }\end{array}$ \\
\hline \hline $\begin{array}{l}\text { Ensures that } \\
\text { leadership is } \\
\text { participatory in } \\
\text { nature and / or } \\
\text { encourages decisive } \\
\text { decision making by } \\
\text { teams at the "action } \\
\text { level" }\end{array}$ & $\begin{array}{l}\text { Uses and supports shared } \\
\text { decision making models } \\
\text { throughout the system } \\
\text { while being prepared to } \\
\text { make decisions when } \\
\text { convinced they are } \\
\text { required. }\end{array}$ \\
\hline \hline $\begin{array}{l}\text { Balances work and } \\
\text { family life }\end{array}$ & $\begin{array}{l}\text { Actively pursues many } \\
\text { interests, including fitness }\end{array}$ \\
\hline \hline $\begin{array}{l}\text { Is decisive } \\
\text { 8. }\end{array}$ & $\begin{array}{l}\text { Makes rational decisions in } \\
\text { a timely manner and } \\
\text { assumes responsibility for } \\
\text { same }\end{array}$ \\
\hline \hline
\end{tabular}




\begin{tabular}{|c|c|c|}
\hline & Is consistent & $\begin{array}{l}\text { Applies consistent } \\
\text { principles to actions } \\
\text { undertaken, insuring } \\
\text { favoritism does not enter } \\
\text { into decision making }\end{array}$ \\
\hline & $\begin{array}{l}\text { Holds system } \\
\text { accountable }\end{array}$ & $\begin{array}{l}\text { Maintains a data rich } \\
\text { environment which } \\
\text { focuses on results and } \\
\text { indicators of quality so that } \\
\text { determination of the } \\
\text { system's accountability is } \\
\text { always present. }\end{array}$ \\
\hline 12. & $\begin{array}{l}\text { Communicates } \\
\text { continuously and } \\
\text { effectively }\end{array}$ & $\begin{array}{l}\text { Actively and } \\
\text { empathetically listens to all } \\
\text { constituents, speaks and } \\
\text { writes well, gathers and } \\
\text { provides information in a } \\
\text { proactive manner. } \\
\text { Handles public relations } \\
\text { duties well. }\end{array}$ \\
\hline & Builds trust & $\begin{array}{l}\text { Supports a culture in which } \\
\text { individuals feel free to } \\
\text { bring forth concerns and or } \\
\text { make decisions about } \\
\text { concerns }\end{array}$ \\
\hline
\end{tabular}




\begin{tabular}{|c|c|c|}
\hline 14 & $\begin{array}{l}\text { Respects and cares } \\
\text { for people and } \\
\text { encourages the } \\
\text { same in others }\end{array}$ & $\begin{array}{l}\text { Actions demonstrate a } \\
\text { belief in the inherent worth } \\
\text { of each individual }\end{array}$ \\
\hline 15 & $\begin{array}{l}\text { Fosters a climate of } \\
\text { risk-taking }\end{array}$ & $\begin{array}{l}\text { Encourages innovation } \\
\text { and creativity while } \\
\text { viewing honest failure as a } \\
\text { positive learning } \\
\text { opportunity }\end{array}$ \\
\hline 16 & $\begin{array}{l}\text { Continues to } \\
\text { enhance personal } \\
\text { knowledge related to } \\
\text { the development / } \\
\text { delivery of relevant } \\
\text { learning systems }\end{array}$ & $\begin{array}{l}\text { Keeps abreast of new } \\
\text { thinking by reading } \\
\text { (business, professional, } \\
\text { technical, social, } \\
\text { psychological journals) } \\
\text { and participating in a } \\
\text { variety of pro-D activities } \\
\text { (workshops, conferences) }\end{array}$ \\
\hline 17 & $\begin{array}{l}\text { Organizes and } \\
\text { prepares well }\end{array}$ & $\begin{array}{l}\text { Sets short- and long-term } \\
\text { goals, delegates tasks, } \\
\text { and accepts ambiguity in } \\
\text { complex issues }\end{array}$ \\
\hline & Negotiates & $\begin{array}{l}\text { Mediates conflict as it } \\
\text { arises }\end{array}$ \\
\hline
\end{tabular}




\begin{tabular}{||l|l|l|}
\hline \hline 19. $\begin{array}{l}\text { Advocate for } \\
\text { education }\end{array}$ & $\begin{array}{l}\text { Seeks opportunities to } \\
\text { advocate for the benefits } \\
\text { of education }\end{array}$ \\
\hline \hline 20. & Self-directing & $\begin{array}{l}\text { Anticipates issues and } \\
\text { concerns, and acts in a self- } \\
\text { directed manner to deal with } \\
\text { them }\end{array}$ \\
\hline $\begin{array}{l}\text { Adaptable and } \\
\text { flexible }\end{array}$ & $\begin{array}{l}\text { Demonstrates a } \\
\text { willingness to adjust } \\
\text { actions to the situation at } \\
\text { hand }\end{array}$ \\
\hline $\begin{array}{l}\text { Recognizes and } \\
\text { rewards excellence }\end{array}$ & $\begin{array}{l}\text { Actively praises behaviors } \\
\text { that lead to and } \\
\text { demonstrate excellence }\end{array}$ \\
\hline $\begin{array}{l}\text { Identifies, selects } \\
\text { and keeps strong } \\
\text { staff in appropriate } \\
\text { placements }\end{array}$ & $\begin{array}{l}\text { Gives the required attention } \\
\text { to recruiting and hiring staff } \\
\text { as well as to placements that } \\
\text { are challenging and growth } \\
\text { enhancing while correctly } \\
\text { identifying staffs strengths } \\
\text { and weaknesses }\end{array}$ \\
\hline \hline
\end{tabular}




\begin{tabular}{|c|c|c|}
\hline & $\begin{array}{l}\text { Ensures that } \\
\text { physical facilities and } \\
\text { equipment are } \\
\text { adequate }\end{array}$ & $\begin{array}{l}\text { Demonstrates through } \\
\text { planning and budgeting a } \\
\text { desire to provide adequate } \\
\text { facilities and equipment }\end{array}$ \\
\hline 25. & $\begin{array}{l}\text { Displays a positive } \\
\text { attitude }\end{array}$ & $\begin{array}{l}\text { Reacts well in difficult } \\
\text { times. Is a coach and role } \\
\text { model. }\end{array}$ \\
\hline 26. & Good work ethic & $\begin{array}{l}\text { Meets commitments and } \\
\text { time lines can be relied } \\
\text { upon. }\end{array}$ \\
\hline 27. & $\begin{array}{l}\text { Maintains budget } \\
\text { control }\end{array}$ & $\begin{array}{l}\text { Oversees and operates } \\
\text { within budget. } \\
\text { Is innovative in seeking } \\
\text { legitimate financial } \\
\text { solutions. }\end{array}$ \\
\hline 28. & $\begin{array}{l}\text { Provides adequate } \\
\text { preparation for board } \\
\text { members }\end{array}$ & $\begin{array}{l}\text { Provides a good induction } \\
\text { for new Board members, } \\
\text { allowing them to be } \\
\text { effective as quickly as } \\
\text { possible. }\end{array}$ \\
\hline
\end{tabular}




\begin{tabular}{||l||l|l|}
\hline 29. & $\begin{array}{l}\text { Demonstrates I } \\
\text { cultivates } \\
\text { Superintendent- } \\
\text { Board relationships } \\
\text { by facilitating } \\
\text { effective, informed } \\
\text { Board decision- } \\
\text { making }\end{array}$ & $\begin{array}{l}\text { Provides and interprets } \\
\text { data to elected officials to } \\
\text { facilitate policy-making for } \\
\text { the district }\end{array}$ \\
\hline \hline 30. & $\begin{array}{l}\text { Technically } \\
\text { competent }\end{array}$ & $\begin{array}{l}\text { Uses current technology to } \\
\text { assist in performance of } \\
\text { duties }\end{array}$ \\
\hline \hline $31 . \quad$ Is charismatic & $\begin{array}{l}\text { Displays enthusiasm which } \\
\text { captures the constituents' } \\
\text { attention }\end{array}$ \\
\hline
\end{tabular}

\section{Detail of Survey Administration:}

In Round Two, participants were given the opportunity to review their personal responses against the total survey response and verify the interpretation made of demonstrated behaviors. This verification (or "echo check") lead to requests for the inclusion of two indicators seen as distinctly separate from the interpretation made. In addition, this round also generated five new indicators for the final survey instrument. 


\begin{abstract}
Appendix $\mathrm{H}$
Triangulation of Top Seven Behavioral Indicators

with the Literature Review and Deming's 14 Points
\end{abstract}

\begin{tabular}{|c|c|c|}
\hline $\begin{array}{c}\text { Demonstrated } \\
\text { Behavior } \\
\end{array}$ & $\begin{array}{c}\text { Literature Review } \\
\text { Reference } \\
\end{array}$ & $\begin{array}{c}\text { Deming's } 14 \text { Points } \\
\text { (1986) }\end{array}$ \\
\hline $\begin{array}{l}\text { Develops, shares, } \\
\text { and focuses on a } \\
\text { vision of the } \\
\text { organization that } \\
\text { leads to the future }\end{array}$ & $\begin{array}{l}\text { Steiner (1983) } \\
\text { Kouzes \& Posner (1987) } \\
\text { Shaskin \& Burke (1990) } \\
\text { Truskie (1990) } \\
\text { Lee (1991) } \\
\text { Newton (1991) } \\
\text { Kirby (1992) } \\
\text { Eggers \& Leahy (1994) } \\
\text { Collins \& Parras (1994) } \\
\text { Toney (1994) }\end{array}$ & $\begin{array}{l}\text { Point 1: Create a } \\
\text { constancy of purpose } \\
\text { for improvement of } \\
\text { product and service. }\end{array}$ \\
\hline
\end{tabular}




\begin{tabular}{|c|c|c|}
\hline $\begin{array}{l}\text { Focuses on the } \\
\text { primary activity of the } \\
\text { organization -- } \\
\text { learning }\end{array}$ & as above & $\begin{array}{l}\text { Point 7: Adopt and } \\
\text { institute leadership. }\end{array}$ \\
\hline $\begin{array}{l}\text { Maintains ethical } \\
\text { standards and } \\
\text { integrity }\end{array}$ & $\begin{array}{l}\text { Kouzes \& Posner (1987) } \\
\text { Kirby (1992) } \\
\text { Tomey (1994) }\end{array}$ & $\begin{array}{l}\text { Point 12: Removes } \\
\text { barriers that rob } \\
\text { people of pride of } \\
\text { workmanship. }\end{array}$ \\
\hline $\begin{array}{l}\text { Builds, maintains, } \\
\text { and fosters } \\
\text { relationships within } \\
\text { and without }\end{array}$ & $\begin{array}{l}\text { Hersey \& Blanchard (1969) } \\
\text { House (1971) } \\
\text { Burns (1978) } \\
\text { Sales (1989) }\end{array}$ & $\begin{array}{l}\text { Point 9: Breakdown } \\
\text { barriers between } \\
\text { staff areas. }\end{array}$ \\
\hline organization & $\begin{array}{l}\text { Tjosvold (1991) } \\
\text { Kearns (1992) } \\
\text { Maxwell (1993) } \\
\text { Toney (1994) }\end{array}$ & $\begin{array}{l}\text { Point 5: Improve } \\
\text { constantly and } \\
\text { forever the system of } \\
\text { production and } \\
\text { service. }\end{array}$ \\
\hline
\end{tabular}




\begin{tabular}{lll}
$\begin{array}{l}\text { Ensures that } \\
\text { leadership is }\end{array}$ & Walton (1986) & Point 9: Breakdown \\
participatory in & Lee (1991) & barriers between \\
nature and/or & Newton (1991) & staff areas. \\
encourages decisive & Tjosvold (1991) & \\
decision making by & Glass (1992) & \\
teams at the "action & Eggers \& Leahy (1994) & \\
level" & Toney (1994) & \\
\hline & & \\
Communicates & Steiner (1983) & Point 8: Drive out \\
continuously and & Truskie (1990) & fear \\
effectively & Lee (1991) & Point 14: Take \\
& Newton (1991) & action to accomplish \\
& Eggers \& Leahy (1994) & the transformation. \\
\hline & Thomas (1994) &
\end{tabular}


Creates and nurtures Deming (1986)

a Learning

Community culture

Point 6: Institute

training and

retraining.

Point 13: Initiate a

rigorous program of

education and

training. 


\section{Appendix I \\ Statistical Report on Participant Responses}

\section{What are the behaviors that are essential to successful leadership by a superintendent of schools?}

\begin{tabular}{|c|c|c|c|c|c|}
\hline & Behavior & $\begin{array}{c}\text { How } \\
\text { demonstrated }\end{array}$ & CEOs & Supts & Total \\
\hline 1. & $\begin{array}{l}\text { Exhibits a } \\
\text { visible } \\
\text { presence by } \\
\text { employing } \\
\text { Management } \\
\text { By Walking } \\
\text { Around } \\
\text { (MBWA) } \\
\text { electronically } \\
\text { and physically }\end{array}$ & $\begin{array}{l}\text { Spends time in the } \\
\text { field interacting with } \\
\text { instructional and } \\
\text { support personnel } \\
\text { at all levels of the } \\
\text { organization and } \\
\text { within the } \\
\text { community }\end{array}$ & $\begin{array}{l}n=2 \\
t=11 \\
m=5.50 \\
\text { Rank } 14\end{array}$ & $\begin{array}{l}n=3 \\
t=15 \\
m=5.00 \\
\text { Rank } 12\end{array}$ & $\begin{array}{l}n=5 \\
t=26 \\
m=5.20 \\
\text { Rank } 13\end{array}$ \\
\hline 2. & $\begin{array}{l}\text { Focuses on the } \\
\text { primary activity } \\
\text { of the } \\
\text { organization -- } \\
\text { learning }\end{array}$ & $\begin{array}{l}\text { Manages attention } \\
\text { by directing the } \\
\text { focus of employees } \\
\text { to what is best for } \\
\text { student learning }\end{array}$ & $\begin{array}{l}n=7 \\
t=32.5 \\
m=4.64 \\
\text { Rank } 7\end{array}$ & $\begin{array}{l}n=12 \\
t=70 \\
m=5.83 \\
\text { Rank } 1\end{array}$ & $\begin{array}{l}n=19 \\
t=102.5 \\
m=5.40 \\
\text { Rank 2 }\end{array}$ \\
\hline
\end{tabular}




\begin{tabular}{|c|c|c|c|c|c|}
\hline & Behavior & $\begin{array}{c}\text { How } \\
\text { demonstrated }\end{array}$ & CEOs & Supts & Total \\
\hline 3. & $\begin{array}{l}\text { Builds, } \\
\text { maintains, and } \\
\text { fosters } \\
\text { relationships } \\
\text { within and } \\
\text { without the } \\
\text { organization }\end{array}$ & $\begin{array}{l}\text { Cultivates } \\
\text { relationships with all } \\
\text { "customers" and } \\
\text { partners of the } \\
\text { system through } \\
\text { regular contact and } \\
\text { communication, } \\
\text { e.g., using business } \\
\text { partnerships as a } \\
\text { way of creating } \\
\text { change and } \\
\text { developing } \\
\text { resources }\end{array}$ & $\begin{array}{l}n=10 \\
t=38 \\
m=3.80 \\
\text { Rank } 3\end{array}$ & $\begin{array}{l}n=9 \\
t=42 \\
m=4.67 \\
\text { Rank } 4\end{array}$ & $\begin{array}{l}\mathrm{n}=19 \\
\mathrm{t}=80 \\
\mathrm{~m}=4.21 \\
\text { Rank } 4\end{array}$ \\
\hline 4. & $\begin{array}{l}\text { Develops, } \\
\text { shares, and } \\
\text { focuses on a } \\
\text { vision of the } \\
\text { organization } \\
\text { that leads to } \\
\text { the future }\end{array}$ & $\begin{array}{l}\text { Collaboratively } \\
\text { develops a vision } \\
\text { which the } \\
\text { Superintendent } \\
\text { then employs as an } \\
\text { underlying purpose } \\
\text { for all strategic } \\
\text { goal-setting and } \\
\text { decisions }\end{array}$ & $\begin{array}{l}n=12 \\
t=67 \\
m=5.58 \\
\operatorname{Rank} 1\end{array}$ & $\begin{array}{l}n=12 \\
t=68 \\
m=5.67 \\
\text { Rank } 2\end{array}$ & $\begin{array}{l}n=24 \\
t=135 \\
m=5.63 \\
\text { Rank } 1\end{array}$ \\
\hline 5. & $\begin{array}{l}\text { Maintains } \\
\text { ethical } \\
\text { standards and } \\
\text { integrity }\end{array}$ & $\begin{array}{l}\text { Establishes and } \\
\text { operates on a set of } \\
\text { clear expectations } \\
\text { and standards of } \\
\text { behavior }\end{array}$ & $\begin{array}{l}n=7 \\
t=37 \\
m=5.29 \\
\text { Rank } 4\end{array}$ & $\begin{array}{l}n=10 \\
t=53 \\
m=5.30 \\
\text { Rank } 3\end{array}$ & $\begin{array}{l}\mathrm{n}=17 \\
\mathrm{t}=90 \\
\mathrm{~m}=5.29 \\
\text { Rank } 3\end{array}$ \\
\hline
\end{tabular}




\begin{tabular}{|c|c|c|c|c|c|}
\hline & Behavior & $\begin{array}{c}\text { How } \\
\text { demonstrated }\end{array}$ & CEOs & Supts & Total \\
\hline 6. & $\begin{array}{l}\text { Creates and } \\
\text { nurtures a } \\
\text { Learning } \\
\text { Community } \\
\text { culture }\end{array}$ & $\begin{array}{l}\text { Actively fosters a } \\
\text { learning community } \\
\text { by demonstrating a } \\
\text { personal, } \\
\text { unquenchable thirst } \\
\text { for knowledge while } \\
\text { providing and } \\
\text { supporting } \\
\text { opportunities for } \\
\text { employee growth } \\
\text { and leadership }\end{array}$ & $\begin{array}{l}n=7 \\
t=37 \\
m=5.29 \\
\text { Rank } 5\end{array}$ & $\begin{array}{l}n=5 \\
t=23 \\
m=4.60 \\
\text { Rank } 7\end{array}$ & $\begin{array}{l}n=12 \\
t=60 \\
m=5.00 \\
\text { Rank } 7\end{array}$ \\
\hline 7. & $\begin{array}{l}\text { Ensures that } \\
\text { leadership is } \\
\text { participatory in } \\
\text { nature and / or } \\
\text { encourages } \\
\text { decisive } \\
\text { decision } \\
\text { making by } \\
\text { teams at the } \\
\text { "action level" }\end{array}$ & $\begin{array}{l}\text { Uses and supports } \\
\text { shared decision } \\
\text { making models } \\
\text { throughout the } \\
\text { system while being } \\
\text { prepared to make } \\
\text { decisions when } \\
\text { convinced they are } \\
\text { required. }\end{array}$ & $\begin{array}{l}n=10 \\
t=30.5 \\
m=3.05 \\
\text { Rank } 8\end{array}$ & $\begin{array}{l}n=12 \\
t=37 \\
m=3.08 \\
\text { Rank } 5\end{array}$ & $\begin{array}{l}n=22 \\
t=67.5 \\
m=3.07 \\
\text { Rank } 5\end{array}$ \\
\hline 8. & $\begin{array}{l}\text { Balances work } \\
\text { and family life }\end{array}$ & $\begin{array}{l}\text { Actively pursues } \\
\text { many interests, } \\
\text { including fitness }\end{array}$ & $\begin{array}{l}n=2 \\
t=6 \\
m=3.00 \\
\text { Rank } 18\end{array}$ & $\begin{array}{l}n=2 \\
t=4 \\
m=2.00 \\
\text { Rank } 16\end{array}$ & $\begin{array}{l}n=4 \\
t=10 \\
m=2.50 \\
\text { Rank } 17\end{array}$ \\
\hline 9. & Is decisive & $\begin{array}{l}\text { Makes rational } \\
\text { decisions in a timely } \\
\text { manner and } \\
\text { assumes } \\
\text { responsibility for } \\
\text { same }\end{array}$ & $\begin{array}{l}n=4 \\
t=16.5 \\
m=4.13 \\
\text { Rank } 12\end{array}$ & $\begin{array}{l}n=1 \\
t=5 \\
m=5.00 \\
\text { Rank } 14\end{array}$ & $\begin{array}{l}n=5 \\
t=21.5 \\
m=4.30 \\
\text { Rank } 15\end{array}$ \\
\hline
\end{tabular}




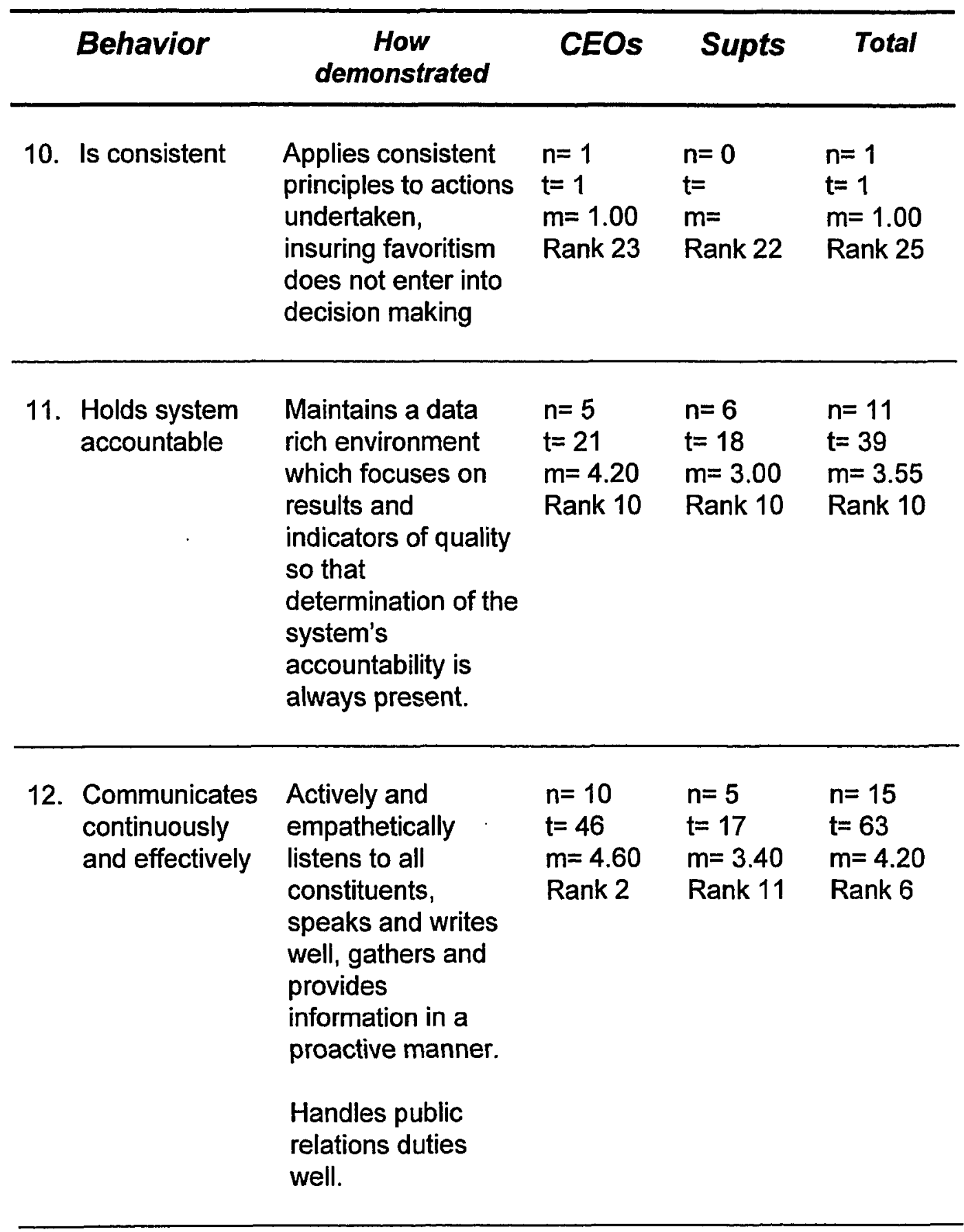




\begin{tabular}{|c|c|c|c|c|c|}
\hline & Behavior & $\begin{array}{c}\text { How } \\
\text { demonstrated }\end{array}$ & CEOs & Supts & Total \\
\hline 13. & Builds trust & $\begin{array}{l}\text { Supports a culture } \\
\text { in which individuals } \\
\text { feel free to bring } \\
\text { forth concerns and } \\
\text { or make decisions } \\
\text { about concerns }\end{array}$ & $\begin{array}{l}n=6 \\
t=18 \\
m=3.00 \\
\text { Rank } 11\end{array}$ & $\begin{array}{l}n=6 \\
t=34 \\
m=5.67 \\
\text { Rank } 6\end{array}$ & $\begin{array}{l}n=12 \\
t=52 \\
m=4.33 \\
\text { Rank } 8\end{array}$ \\
\hline 14. & $\begin{array}{l}\text { Respects and } \\
\text { cares for } \\
\text { people and } \\
\text { encourages } \\
\text { the same in } \\
\text { others }\end{array}$ & $\begin{array}{l}\text { Actions } \\
\text { demonstrate a } \\
\text { belief in the } \\
\text { inherent worth of } \\
\text { each individual }\end{array}$ & $\begin{array}{l}n=6 \\
t=21 \\
m=3.50 \\
\text { Rank } 9\end{array}$ & $\begin{array}{l}\mathrm{n}=8 \\
\mathrm{t}=22 \\
\mathrm{~m}=2.75 \\
\text { Rank } 8\end{array}$ & $\begin{array}{l}n=14 \\
t=43 \\
m=3.07 \\
\text { Rank } 9\end{array}$ \\
\hline 15. & $\begin{array}{l}\text { Fosters a } \\
\text { climate of risk- } \\
\text { taking }\end{array}$ & $\begin{array}{l}\text { Encourages } \\
\text { innovation and } \\
\text { creativity while } \\
\text { viewing honest } \\
\text { failure as a positive } \\
\text { learning opportunity }\end{array}$ & $\begin{array}{l}n=5 \\
t=12.5 \\
m=2.50 \\
\text { Rank } 13\end{array}$ & $\begin{array}{l}n=4 \\
\mathrm{t}=12 \\
\mathrm{~m}=3.00 \\
\text { Rank } 13\end{array}$ & $\begin{array}{l}n=9 \\
t=24.5 \\
m=2.72 \\
\text { Rank } 14\end{array}$ \\
\hline 16. & $\begin{array}{l}\text { Continues to } \\
\text { enhance } \\
\text { personal } \\
\text { knowledge } \\
\text { related to the } \\
\text { development / } \\
\text { delivery of } \\
\text { relevant } \\
\text { learning } \\
\text { systems }\end{array}$ & $\begin{array}{l}\text { Keeps abreast of } \\
\text { new thinking by } \\
\text { reading (business, } \\
\text { professional, } \\
\text { technical, social, } \\
\text { psychological } \\
\text { journals) and } \\
\text { participating in a } \\
\text { variety of pro-D } \\
\text { activities } \\
\text { (workshops, } \\
\text { conferences) }\end{array}$ & $\begin{array}{l}n=3 \\
t=9 \\
m=3.00 \\
\text { Ranik } 22\end{array}$ & $\begin{array}{l}n=0 \\
t= \\
m= \\
\text { Rank } 22\end{array}$ & $\begin{array}{l}n=3 \\
t=9 \\
m=3.00 \\
\text { Rank } 22\end{array}$ \\
\hline
\end{tabular}




\begin{tabular}{|c|c|c|c|c|c|}
\hline & Behavior & $\begin{array}{c}\text { How } \\
\text { demonstrated }\end{array}$ & CEOs & Supts & Total \\
\hline 17. & $\begin{array}{l}\text { Organizes and } \\
\text { prepares well }\end{array}$ & $\begin{array}{l}\text { Sets short- and } \\
\text { long-term goals, } \\
\text { delegates tasks, } \\
\text { and accepts } \\
\text { ambiguity in } \\
\text { complex issues }\end{array}$ & $\begin{array}{l}n=0 \\
t= \\
m= \\
\text { Rank } 24\end{array}$ & $\begin{array}{l}n=2 \\
t=3 \\
m=1.50 \\
\text { Rank } 18\end{array}$ & $\begin{array}{l}n=2 \\
t=3 \\
m=1.50 \\
\text { Rank } 23\end{array}$ \\
\hline 18. & Negotiates & $\begin{array}{l}\text { Mediates conflict as } \\
\text { it arises }\end{array}$ & $\begin{array}{l}n=0 \\
t= \\
m= \\
\text { Rank } 24\end{array}$ & $\begin{array}{l}n=0 \\
t= \\
m= \\
\text { Rank } 22\end{array}$ & $\begin{array}{l}n=0 \\
t= \\
m= \\
\text { Rank } 26\end{array}$ \\
\hline 19. & $\begin{array}{l}\text { Advocate for } \\
\text { education }\end{array}$ & $\begin{array}{l}\text { Seeks opportunities } \\
\text { to advocate for the } \\
\text { benefits of } \\
\text { education }\end{array}$ & $\begin{array}{l}n=3 \\
t=5.5 \\
m=1.83 \\
\text { Rank } 19\end{array}$ & $\begin{array}{l}n=1 \\
t=2 \\
m=2.00 \\
\text { Rank } 20\end{array}$ & $\begin{array}{l}\mathrm{n}=4 \\
\mathrm{t}=7.5 \\
\mathrm{~m}=1.88 \\
\text { Rank } 20\end{array}$ \\
\hline 20. & Self-directing & $\begin{array}{l}\text { Anticipates issues } \\
\text { and concerns, and } \\
\text { acts in a self- } \\
\text { directed manner to } \\
\text { deal with them }\end{array}$ & $\begin{array}{l}n=0 \\
t= \\
m= \\
\text { Rank } 24\end{array}$ & $\begin{array}{l}n=0 \\
t= \\
m= \\
\text { Rank } 22\end{array}$ & $\begin{array}{l}n=0 \\
t= \\
m= \\
\text { Rank } 26\end{array}$ \\
\hline 21. & $\begin{array}{l}\text { Adaptable and } \\
\text { flexible }\end{array}$ & $\begin{array}{l}\text { Demonstrates a } \\
\text { willingness to adjust } \\
\text { actions to the } \\
\text { situation at hand }\end{array}$ & $\begin{array}{l}n=1 \\
t=5 \\
m=5.00 \\
\text { Rank } 21\end{array}$ & $\begin{array}{l}n=0 \\
t= \\
m= \\
\text { Rank } 22\end{array}$ & $\begin{array}{l}n=1 \\
t=5 \\
m=5.00 \\
\text { Rank } 21\end{array}$ \\
\hline 22. & $\begin{array}{l}\text { Recognizes } \\
\text { and rewards } \\
\text { excellence }\end{array}$ & $\begin{array}{l}\text { Actively praises } \\
\text { behaviors that lead } \\
\text { to and demonstrate } \\
\text { excellence }\end{array}$ & $\begin{array}{l}\mathrm{n}=6 \\
\mathrm{t}=5.5 \\
\mathrm{~m}=0.92 \\
\text { Rank } 20\end{array}$ & $\begin{array}{l}n=2 \\
t=5 \\
m=2.50 \\
\text { Rank } 15\end{array}$ & $\begin{array}{l}n=8 \\
t=10.5 \\
m=1.31 \\
\text { Rank } 16\end{array}$ \\
\hline
\end{tabular}




\begin{tabular}{|c|c|c|c|c|c|}
\hline & Behavior & $\begin{array}{c}\text { How } \\
\text { demonstrated }\end{array}$ & CEOs & Supts & Total \\
\hline 23. & $\begin{array}{l}\text { Identifies, } \\
\text { selects and } \\
\text { keeps strong } \\
\text { staff in } \\
\text { appropriate } \\
\text { placements }\end{array}$ & $\begin{array}{l}\text { Gives the required } \\
\text { attention to } \\
\text { recruiting and hiring } \\
\text { staff as well as to } \\
\text { placements that are } \\
\text { challenging and } \\
\text { growth enhancing } \\
\text { while correctly } \\
\text { identifying staff's } \\
\text { strengths and } \\
\text { weaknesses }\end{array}$ & $\begin{array}{l}n=6 \\
t=33 \\
m=5.50 \\
\text { Rank } 6\end{array}$ & $\begin{array}{l}\mathrm{n}=3 \\
\mathrm{t}=4 \\
\mathrm{~m}=1.33 \\
\text { Rank } 17\end{array}$ & $\begin{array}{l}n=9 \\
t=37 \\
m=4.11 \\
\text { Rank } 11\end{array}$ \\
\hline 24. & $\begin{array}{l}\text { Ensures that } \\
\text { physical } \\
\text { facilities and } \\
\text { equipment are } \\
\text { adequate }\end{array}$ & $\begin{array}{l}\text { Demonstrates } \\
\text { through planning } \\
\text { and budgeting a } \\
\text { desire to provide } \\
\text { adequate facilities } \\
\text { and equipment }\end{array}$ & $\begin{array}{l}\mathrm{n}=0 \\
\mathrm{t}= \\
\mathrm{m}= \\
\text { Rank } 24\end{array}$ & $\begin{array}{l}\mathrm{n}=0 \\
\mathrm{t}= \\
\mathrm{m}= \\
\text { Rank } 22\end{array}$ & $\begin{array}{l}n=0 \\
t= \\
m= \\
\text { Rank 26 }\end{array}$ \\
\hline 25. & $\begin{array}{l}\text { Displays a } \\
\text { positive } \\
\text { attitude }\end{array}$ & $\begin{array}{l}\text { Reacts well in } \\
\text { difficult times. Is a } \\
\text { coach and role } \\
\text { model. }\end{array}$ & $\begin{array}{l}n=2 \\
t=8 \\
m=4.00 \\
\text { Rank } 15\end{array}$ & $\begin{array}{l}n=1 \\
t=2 \\
m=2.00 \\
\text { Rank } 21\end{array}$ & $\begin{array}{l}n=3 \\
t=10 \\
m=3.33 \\
\text { Rank } 18\end{array}$ \\
\hline 26. & $\begin{array}{l}\text { Good work } \\
\text { ethic }\end{array}$ & $\begin{array}{l}\text { Meets commitments } \\
\text { and time lines can } \\
\text { be relied upon. }\end{array}$ & $\begin{array}{l}n=3 \\
t=8 \\
m=2.67 \\
\text { Rank } 16\end{array}$ & $\begin{array}{l}n=0 \\
\mathrm{t}= \\
\mathrm{m}= \\
\operatorname{Rank} 22\end{array}$ & $\begin{array}{l}n=3 \\
t=8 \\
m=2.67 \\
\text { Rank } 19\end{array}$ \\
\hline
\end{tabular}




\begin{tabular}{|c|c|c|c|c|c|}
\hline & Behavior & $\begin{array}{c}\text { How } \\
\text { demonstrated }\end{array}$ & CEOs & Supts & Total \\
\hline 27. & $\begin{array}{l}\text { Maintains } \\
\text { budget control }\end{array}$ & $\begin{array}{l}\text { Oversees and } \\
\text { operates within } \\
\text { budget. } \\
\text { Is innovative in } \\
\text { seeking legitimate } \\
\text { financial solutions. }\end{array}$ & $\begin{array}{l}\mathrm{n}=0 \\
\mathrm{t}= \\
\mathrm{m}= \\
\text { Rank } 24\end{array}$ & $\begin{array}{l}n=0 \\
t= \\
m= \\
\text { Rank } 22\end{array}$ & $\begin{array}{l}\mathrm{n}=0 \\
\mathrm{t}= \\
\mathrm{m}= \\
\text { Rank } 26\end{array}$ \\
\hline 28. & $\begin{array}{l}\text { Provides } \\
\text { adequate } \\
\text { preparation for } \\
\text { board } \\
\text { members }\end{array}$ & $\begin{array}{l}\text { Provides a good } \\
\text { induction for new } \\
\text { Board members, } \\
\text { allowing them to be } \\
\text { effective as quickly } \\
\text { as possible. }\end{array}$ & $\begin{array}{l}n=0 \\
t= \\
m= \\
\text { Rank } 24\end{array}$ & $\begin{array}{l}\mathrm{n}=1 \\
\mathrm{t}=3 \\
\mathrm{~m}=3.00 \\
\text { Rank } 19\end{array}$ & $\begin{array}{l}n=1 \\
t=3 \\
m=3.00 \\
\text { Rank } 24\end{array}$ \\
\hline 29. & $\begin{array}{l}\text { Demonstrates / } \\
\text { cultivates } \\
\text { Superintendent } \\
\text {-Board } \\
\text { relationships } \\
\text { by facilitating } \\
\text { effective, } \\
\text { informed Board } \\
\text { decision- } \\
\text { making }\end{array}$ & $\begin{array}{l}\text { Provides and } \\
\text { interprets data to } \\
\text { elected officials to } \\
\text { facilitate policy- } \\
\text { making for the } \\
\text { district }\end{array}$ & $\begin{array}{l}n=2 \\
t=8 \\
m=4.00 \\
\text { Rank } 17\end{array}$ & $\begin{array}{l}\mathrm{n}=8 \\
\mathrm{t}=20 \\
\mathrm{~m}=2.50 \\
\text { Rank } 9\end{array}$ & $\begin{array}{l}n=10 \\
t=28 \\
m=2.80 \\
\text { Rank } 12\end{array}$ \\
\hline 30. & $\begin{array}{l}\text { Technically } \\
\text { competent }\end{array}$ & $\begin{array}{l}\text { Uses current } \\
\text { technology to assist } \\
\text { in performance of } \\
\text { duties }\end{array}$ & $\begin{array}{l}n=0 \\
t= \\
m= \\
\text { Rank } 24\end{array}$ & $\begin{array}{l}n=0 \\
t= \\
m= \\
\text { Rank } 22\end{array}$ & $\begin{array}{l}n=0 \\
t= \\
m= \\
\text { Rank 26 }\end{array}$ \\
\hline
\end{tabular}




\begin{tabular}{|c|c|c|c|c|}
\hline Behavior & $\begin{array}{c}\text { How } \\
\text { demonstrated }\end{array}$ & CEOs & Supts & Total \\
\hline 31. Is charismatic & $\begin{array}{l}\text { Displays } \\
\text { enthusiasm which } \\
\text { captures the } \\
\text { constituents' } \\
\text { attention }\end{array}$ & $\begin{array}{l}n=0 \\
t= \\
m= \\
\text { Rank } 24\end{array}$ & $\begin{array}{l}n=0 \\
t= \\
m= \\
\text { Rank } 22\end{array}$ & $\begin{array}{l}n=0 \\
t= \\
m= \\
\text { Rank 26 }\end{array}$ \\
\hline
\end{tabular}

KEY:

$\mathrm{n}=\quad$ number of times item scored in top seven behaviours

$\mathbf{t}=\quad$ total number of points ascribed to this behaviour determined as:

Rank $1=7$ points; Rank $2=6$ points; Rank $3=5$ points; Rank $4=4$ points;

Rank $5=3$ points; Rank $6=2$ points; Rank $7=1$ point

$\mathbf{m}=\quad$ mean or average score

Rank relative ranking of this behaviour to all (31) behaviors within this group 


\section{Appendix $\mathbf{J}$}

\section{Behaviorally Anchored Rating Scale Model}

\begin{tabular}{|c|c|c|c|c|}
\hline \multicolumn{5}{|c|}{$\begin{array}{r}\text { Develops, shares, and focuses on a vision } \\
\text { that leads to the future }\end{array}$} \\
\hline $\begin{array}{l}\text { does not } \\
\text { express or } \\
\text { promote a } \\
\text { vision for the } \\
\text { organization }\end{array}$ & $\begin{array}{l}\text { publishes and } \\
\text { promotes } \\
\text { his/her } \\
\text { personal } \\
\text { vision for the } \\
\text { organization }\end{array}$ & $\begin{array}{l}\text { expresses } \\
\text { his/her vision } \\
\text { and employs } \\
\text { it as an } \\
\text { underlying } \\
\text { purpose for }\end{array}$ & $\begin{array}{l}\text { collaboratively } \\
\text { develops a } \\
\text { vision with } \\
\text { internal } \\
\text { customers } \\
\text { which he/she } \\
\text { then employs } \\
\text { as an } \\
\text { underlying } \\
\text { purpose for } \\
\text { some } \\
\text { strategic goal } \\
\text { setting }\end{array}$ & $\begin{array}{l}\text { collaboratively } \\
\text { develops a } \\
\text { vision with } \\
\text { all customers } \\
\text { which he/she } \\
\text { then employs } \\
\text { as an } \\
\text { underlying } \\
\text { purpose for } \\
\text { some } \\
\text { strategic goal } \\
\text { setting }\end{array}$ \\
\hline
\end{tabular}




\begin{tabular}{|c|c|c|c|c|}
\hline \multicolumn{5}{|c|}{ Focuses on the primary activity of the organization -- learning } \\
\hline $\begin{array}{l}\text { does not } \\
\text { manage the } \\
\text { attention by } \\
\text { directing the } \\
\text { focus of } \\
\text { employees to } \\
\text { what is best } \\
\text { for student } \\
\text { learning }\end{array}$ & $\begin{array}{l}\text { comments on } \\
\text { the purpose } \\
\text { of the } \\
\text { organization - } \\
\text { - learning } \\
\text { when } \\
\text { prodded }\end{array}$ & $\begin{array}{l}\text { occasionally } \\
\text { attempts to } \\
\text { direct the } \\
\text { attention of } \\
\text { employees to } \\
\text { the focus of } \\
\text { the } \\
\text { organization }\end{array}$ & $\begin{array}{l}\text { often } \\
\text { promotes the } \\
\text { focus of the } \\
\text { organization } \\
\text { by directing } \\
\text { employees' } \\
\text { attention to } \\
\text { student } \\
\text { learning }\end{array}$ & $\begin{array}{l}\text { manages } \\
\text { attention by } \\
\text { continuously } \\
\text { directing the } \\
\text { focus of the } \\
\text { employees to } \\
\text { what is best } \\
\text { for student } \\
\text { learning }\end{array}$ \\
\hline \multicolumn{5}{|c|}{ Maintains ethical standards and integrity } \\
\hline $\begin{array}{l}\text { has no } \\
\text { expectations } \\
\text { or standards } \\
\text { of behavior }\end{array}$ & $\begin{array}{l}\text { expectations } \\
\text { and } \\
\text { standards of } \\
\text { behavior are } \\
\text { varied or } \\
\text { unclear }\end{array}$ & $\begin{array}{l}\text { establishes } \\
\text { but does not } \\
\text { model } \\
\text { expectations } \\
\text { or standards } \\
\text { of behavior }\end{array}$ & $\begin{array}{l}\text { establishes } \\
\text { and usually } \\
\text { operates on a } \\
\text { clear set of } \\
\text { expectations } \\
\text { and } \\
\text { standards of } \\
\text { behavior }\end{array}$ & $\begin{array}{l}\text { establishes } \\
\text { and operates } \\
\text { on a clear set } \\
\text { of } \\
\text { expectations } \\
\text { and } \\
\text { standards of } \\
\text { behavior }\end{array}$ \\
\hline
\end{tabular}




\begin{tabular}{|c|c|c|c|c|}
\hline \multicolumn{5}{|c|}{$\begin{array}{r}\text { Builds, maintains, and fosters relationsh } \\
\text { the organization }\end{array}$} \\
\hline $\begin{array}{l}\text { no apparent } \\
\text { for concern } \\
\text { for } \\
\text { relationship } \\
\text { building }\end{array}$ & $\begin{array}{l}\text { minimal } \\
\text { relationship } \\
\text { building } \\
\text { when invited } \\
\text { to various } \\
\text { functions and } \\
\text { events }\end{array}$ & $\begin{array}{l}\text { visits schools } \\
\text { and fosters } \\
\text { relationships } \\
\text { with } \\
\text { employees }\end{array}$ & $\begin{array}{l}\text { cultivates } \\
\text { relationships } \\
\text { with some } \\
\text { 'customers' } \\
\text { and partners } \\
\text { through } \\
\text { occasional } \\
\text { contact and } \\
\text { communicatio } \\
\mathrm{n}\end{array}$ & $\begin{array}{l}\text { cultivates } \\
\text { relationships } \\
\text { with all } \\
\text { 'customers' } \\
\text { and partners } \\
\text { through } \\
\text { regular } \\
\text { contact and } \\
\text { communicatio } \\
\mathrm{n}\end{array}$ \\
\hline
\end{tabular}




\begin{tabular}{|c|c|c|c|c|}
\hline \multicolumn{5}{|c|}{$\begin{array}{c}\text { Ensures that leadership is participatory in nature } \\
\text { and/or encourages decisive decision making } \\
\text { by teams at the "action level" }\end{array}$} \\
\hline $\begin{array}{l}\text { makes all } \\
\text { decisions in } \\
\text { an autocratic } \\
\text { manner }\end{array}$ & $\begin{array}{l}\text { consults but } \\
\text { retains } \\
\text { responsibility } \\
\text { for all } \\
\text { decision } \\
\text { making } \\
\text { authority }\end{array}$ & $\begin{array}{l}\text { uses shared } \\
\text { decision } \\
\text { making in } \\
\text { some parts } \\
\text { of system } \\
\text { and } \\
\text { periodically } \\
\text { delegates } \\
\text { responsibility } \\
\text { for decision } \\
\text { making }\end{array}$ & $\begin{array}{l}\text { occasionally } \\
\text { uses and } \\
\text { supports } \\
\text { shared } \\
\text { decision } \\
\text { making } \\
\text { models } \\
\text { throughout } \\
\text { the system } \\
\text { while usually } \\
\text { being } \\
\text { prepared to } \\
\text { make } \\
\text { decisions } \\
\text { when } \\
\text { convinced } \\
\text { they are } \\
\text { required }\end{array}$ & $\begin{array}{l}\text { uses and } \\
\text { supports } \\
\text { shared } \\
\text { decision } \\
\text { making } \\
\text { models } \\
\text { throughout } \\
\text { the system } \\
\text { while being } \\
\text { prepared to } \\
\text { make } \\
\text { decisions } \\
\text { when } \\
\text { convinced } \\
\text { they are } \\
\text { required }\end{array}$ \\
\hline
\end{tabular}




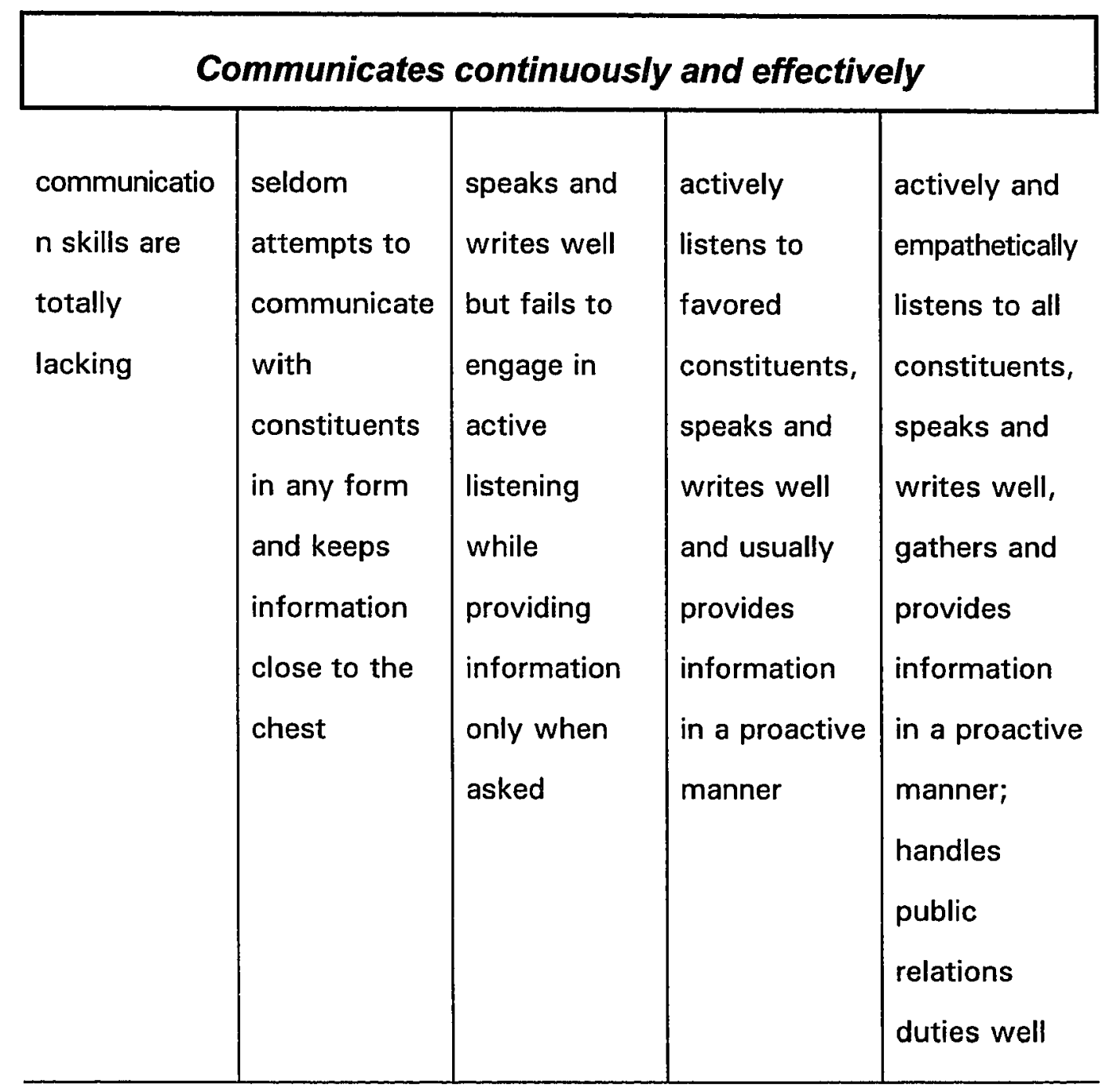




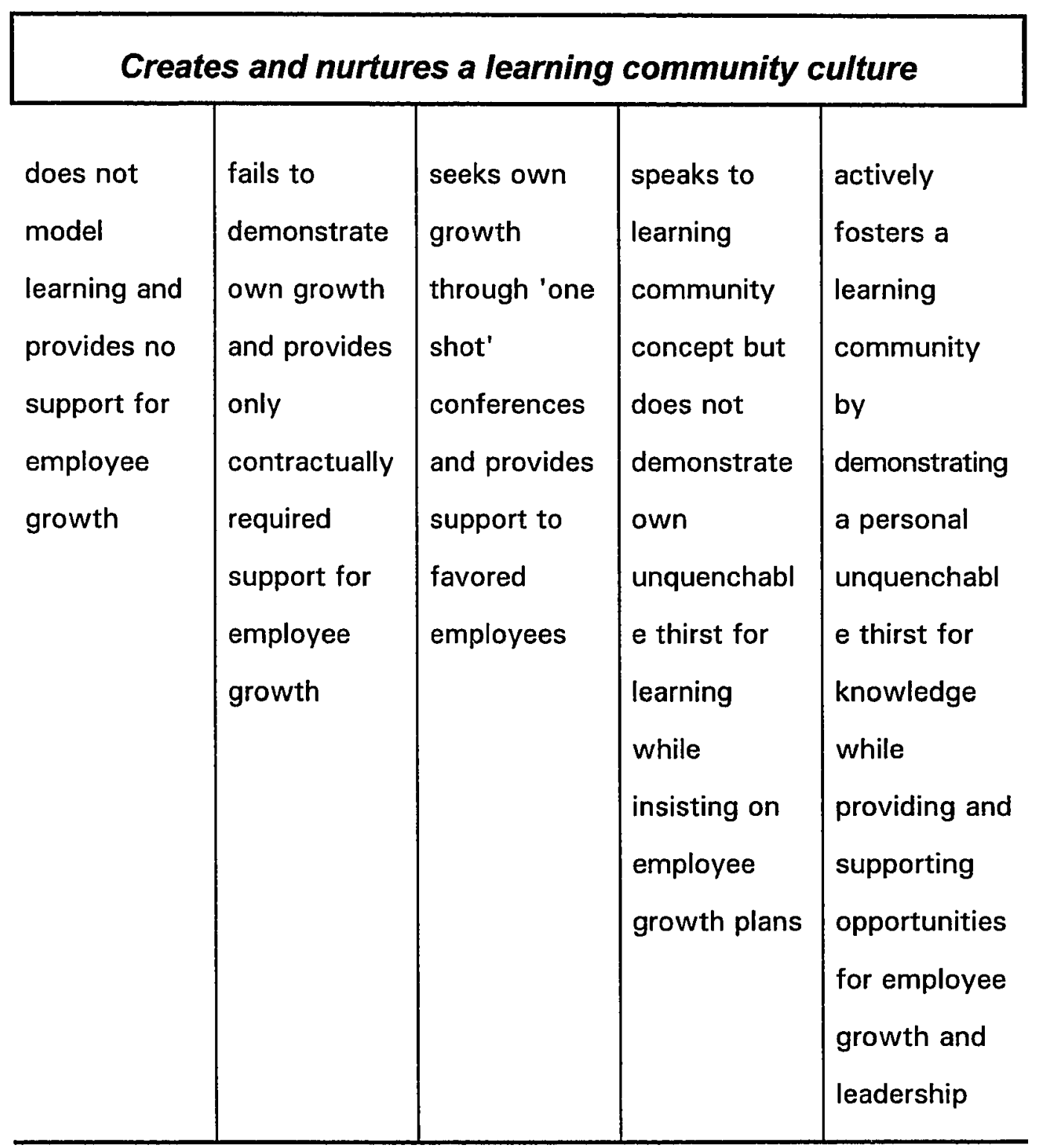


Appendix K

\section{START}

Design \& Secure Approva of Methods \& Processes

Select Panelists

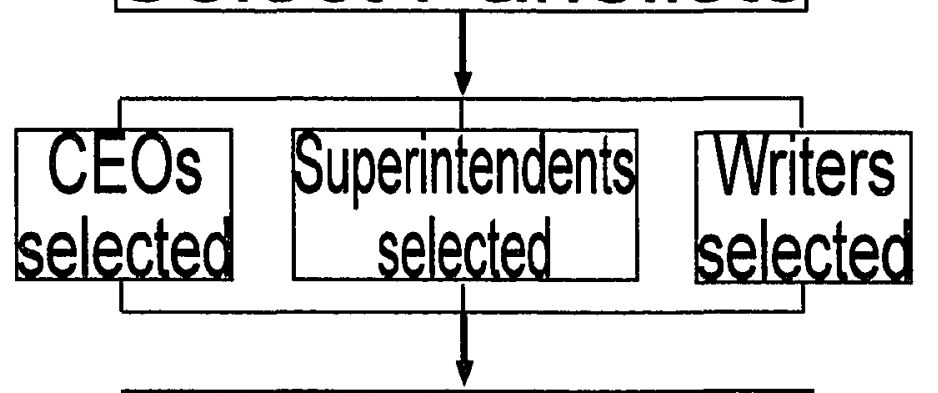

Complete materials for Round 1 \& distribute

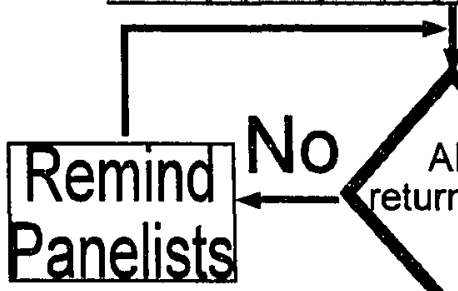

\section{Writers Dropped}

Projected Timelines

July 1994

Nov. 1994

Nov. 1994

\section{Yes}

Analyze returns and prepare materials for Round 2 \& distribute

Feb. 1995 


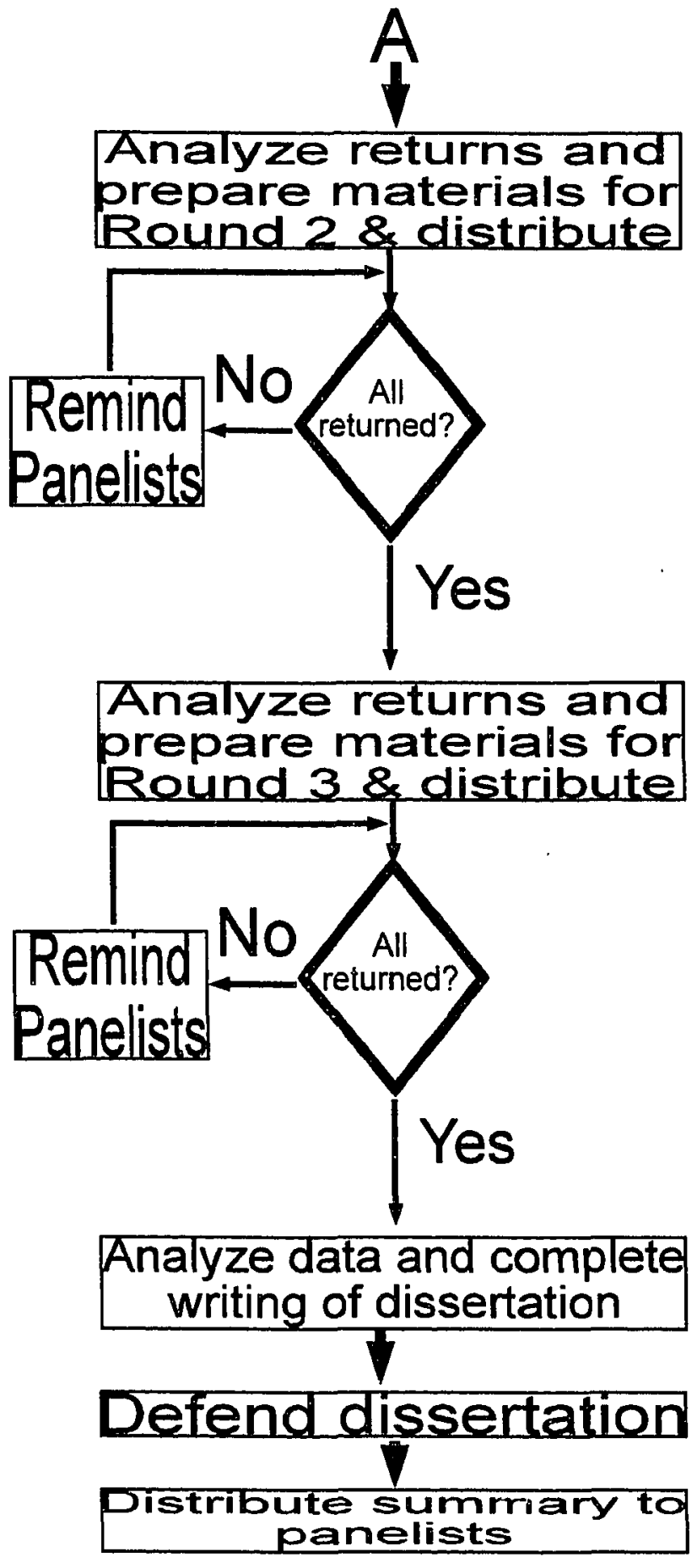

Feb. 1995

\section{May 1995}

\author{
June-July \\ 1995 \\ Aug. 1995 \\ Sept. 1995
}

